\title{
Implications of prefeeding for the development of
}

\author{
bait aversions in brushtail possums
}

(Trichosurus vulpecula)

\author{
A thesis \\ submitted in partial fulfilment \\ of the requirements for the Degree of \\ Master of Science \\ at \\ Lincoln University \\ by \\ Zane N. Moss \\ Lincoln University \\ 1997
}




\section{Abstract of a thesis submitted in partial fulfilment of the requirements for the Degree of Master of Science}

\section{Implications of prefeeding for the development of bait aversions in brushtail possums (Trichosurus vulpecula)}

\section{by Zane N. Moss}

Cost effective control of brushtail possums (Trichosurus vulpecula) in New Zealand is currently reliant on the use of toxins, particularly aerial application of sodium monofluoroacetate (1080). However, possums' development of bait aversions threatens the continued efficacy of such control operations. Bait aversions (or shyness) have been well studied in rats (Rattus spp.), but only recently documented in possums. The aim of this study was to examine the influence of novelty, familiarity, and bait 'cues' on possums' development of aversions, in both cage and field environments. The motivation of this work was to provide better understanding of the problem and provide advice for managers undertaking possum control.

The first cage trial determined the effects of prefeeding on aversion development. Three treatment groups received for 7 days either $i$ ) no prefeed $i$ ) plain prefeed, or $i i i$ ) dyed and lured prefeed baits. Each possum then ingested a sub-lethal 1080 bait. Seven days later, the possums were tested for development of an aversion towards a 1080 bait, a prefeed bait, and a prefeed bait containing brodifacoum. Most (96\%) non-prefed possums became averse to the 1080 bait, compared with only $55 \%$ and $9 \%$ of the two prefed groups. Similarly, over $90 \%$ of the non-prefed possums were averse to prefeed and brodifacoum baits, compared to $<15 \%$ of the prefed possums. The trial also showed that novelty has an influence on possums' aversion development; as prefeed and toxic baits became more similar (i.e. the more cues shared), fewer prefed possums were able to distinguish between the two after sub-lethal poisoning and so few developed aversions.

The second cage trial examined the influence of bait cues and prefeeding duration on possums' development of aversion. Three main treatment groups received either $i$ ) dyed, ii) cinnamon lured, or $i i i)$ dyed and lured prefeed baits, for either 1 or 7 days. 
After sub-lethal poisoning possums were tested for aversion towards a 1080 bait and a prefeed bait. Once again the influence of familiarity was apparent, with only $34 \%$ averse to the toxic bait, significantly less than for non-prefed possums (cf. trial one). Dye seemed to provide relatively weak cues linking prefeed and toxic bait, with 7 days prefeeding required to inhibit aversion development. In contrast, cinnamon appeared to provide relatively strong olfactory and/or taste cues linking prefeed and toxic baits, with one exposure to cinnamon lured prefeed sufficient to inhibit aversion development. As in the first trial, most of the possums that developed aversion to the toxic bait did not generalise this aversion to the prefeed bait. Some possums were seemingly able to detect $0.08 \% 1080$, despite it being 'masked' with cinnamon oil.

The field trial aimed to validate results of the cage trials and to examine whether possums preferentially associate certain cues with poisoning. Two treatment groups received either cinnamon lured baits, or apples, for 3 weeks. After sub-lethal poisoning possums were tested for aversion towards a non-toxic prefeed bait, a dyed non-toxic bait, a toxic bait, and a dyed toxic bait, all of which contained cinnamon. Once again most non-prefed possums developed generalised aversions, avoiding all cereal baits. In contrast, prefed possums consumed familiar prefeed baits, but avoided all other baits. This demonstrated that possums could detect both dye and 1080 in a cinnamon-lured bait. This result also suggests that extended prefeeding may enable possums to distinguish between prefeed and toxic baits and therefore develop aversions.

These trials demonstrate that possums develop aversions that are similar in character to those described in rats. Novelty of a bait has a strong influence on possums' potential to develop aversion to that bait and to other baits perceived as similar. Ways that prefeeding offers potential for future management of bait aversion in pest populations are discussed.

Keywords: brushtail possum; Trichosurus vulpecula; 1080; sodium monofluoroacetate; conditioned food aversion; prefeeding; preexposure; shyness; bait stations; 


\section{Acknowledgements}

I would like to thank Dr Cheryl O'Connor, for providing me the opportunity to conduct my research at the Animal Behaviour and Welfare Research Centre, AgResearch, Ruakura, for her guidance and expertise during planning and completion of this study, for her role as external co-supervisor and for her cheerful advise on preparation of this manuscript. I am equally indebted to Dr Graham Hickling, my university co-supervisor, for his knowledge and enthusiasm for all things possum, for his advise and assistance during planning of trials, his assistance during the field trial and his guidance during preparation of this manuscript. I am also grateful for the assistance of Dr Chris Frampton, who made statistical analysis a pleasure!

I would also like to thank Rob Miller and Allen Olgle of Groome Poyroy Ltd for access to Waiake Forest, and for use of their hut during long night vigils!

Finally, I would like to thank my parents for their support, for fostering my interest in New Zealand's unique outdoors, and for developing my desire to understand. 


\section{Contents}

Acknowledgements

Contents

$\mathbf{v}$

$\begin{array}{ll}\text { List of Tables } & \text { vii }\end{array}$

$\begin{array}{lc}\text { List of Plates } & \text { vii }\end{array}$

$\begin{array}{ll}\text { List of Figures } & \text { viii }\end{array}$

\section{Chapter 1}

General Introduction

1.1 Possum Ecology and Impacts

1.1.1 Possums in New Zealand: Introduction and Colonisation 1

1.1.2 Possums' evolution with the Australian vegetation 2

1.1.3 Possum impact on New Zealand conservation values 3

1.1.4 Transmission of bovine tuberculosis $\quad 4$

$\begin{array}{ll}1.2 \text { Possum control } & 5\end{array}$

$\begin{array}{ll}\text { 1.2.1 Historical versus current control } & 5\end{array}$

$\begin{array}{ll}\text { 1.2.2 Operational success } & 7\end{array}$

1.3 Animal resistance to poisoning $\quad 7$

$\begin{array}{ll}\text { 1.3.1 Physiological resistance } & 7\end{array}$

$\begin{array}{ll}\text { 1.3.2 Behavioural resistance } & 9\end{array}$

$\begin{array}{ll}\text { 1.3.2.1 Non-learned behavioural resistance } & 9\end{array}$

$\begin{array}{ll}\text { Neophobia } & 9\end{array}$

$\begin{array}{ll}\text { Innate poison avoidance } & 10\end{array}$

$\begin{array}{ll}\text { 1.3.2.2 Learned behavioural resistance } & 11\end{array}$

1.4 Conditioned Food Aversions (CFAs). $\quad 12$

1.4.1 Evolution of conditioned food aversions 12

1.4.2 Formation of conditioned food aversions 13

1.4.3 Characteristics of conditioned food aversions $\quad 14$

$\begin{array}{ll}\text { 1.4.4 Prefeeding and pre-exposure in pest control } & 17\end{array}$

$\begin{array}{ll}\text { 1.4.5 Conditioned food aversions in possums } & 18\end{array}$

$\begin{array}{lr}1.5 \text { Justification and objectives of thesis } & 19\end{array}$ 


\section{Chapter 2}

Implications of prefeeding for the development of

bait aversions in brushtail possum

2.0 Introduction

2.1 Methodology

2.2 Results

2.3 Discussion

\section{Chapter 3}

Influence of bait components and prefeeding duration on

bait aversion in brushtail possums

$\begin{array}{ll}3.0 \text { Introduction } & 36\end{array}$

3.1 Methods

3.2 Results $\quad 41$

$\begin{array}{ll}3.3 \text { Discussion } & 45\end{array}$

\section{Chapter 4}

Influence of prefeeding at bait stations on the development of

bait aversions in free-ranging brushtail possums

4.0 Introduction

4.1 Methodology

4.2 Results

4.3 Discussion

\section{Chapter 5}

General Discussion

5.1 Possums' resistance to poisoning

5.1.1 Physiological resistance

5,1.2 Non-learned behavioural resistance

Neophobia

Innate poison avoidance

Innate bait avoidance

5.1.3 Learned behavioural resistance

The salient influence of novelty

Strength of 'cues'

Future research; utilising behavioural characteristics

5.2 Management implications

Approaches to prefeeding; 


\section{List of Tables}

Table (some captions have been abbreviated)

Page

2.1. Consumption of prefeed over the seven days that it was provided.

3.1. Consumption of prefeed by possums that subsequently avoided ingestion of a sub-lethal bait.

\section{List of Plates}

Plate

Page

2.1 Possum in its nest box; situated on shelf $400 \mathrm{~mm}$ above cage floor.

2.2 Presentation of mash and prefeed; the possum is shown consuming prefeed baits.

2.3. Presentation of prefeed, in mash tray, and a test bait.

4.1 Location of bait station and presentation of test baits.

4.2 Baited cage-trap showing presentation of 'sub-lethal' bait.

4.3 Possum displaying tag that enables individual identification. 


\section{List of Figures}

Figure (some captions have been abbreviated)

Page

2.1. Prefeeding and testing protocol for the first cage trial.

2.2. Mean consumption of the two types of prefeed offered in first cage trial

2.3. The effect of prefeeding on the percentage of possums developing aversions towards toxic cereal bait

2.4. The effect of prefeeding on the percentage of possums developing a generalized aversion towards non-toxic cereal bait.

2.5. The effect of prefeeding on the percentage of possums developing a generalized aversion towards plain cereal bait, containing $0.002 \%$ brodifacoum.

3.1. Prefeeding and testing protocol for the second cage trial.

3.2. Mean consumption of prefeed over the seven days that it was provided.

3.3. The effect of prefeed treatment on the percentage of possums developing aversions towards toxic cereal bait.

3.4. The effect of one versus seven days prefeeding on the development of aversion towards toxic cereal bait. 


\section{Chapter 1}

\section{General Introduction}

This chapter provides a brief background to the introduction, colonisation, and ecological significance as a pest species of the common brushtail possum (Trichosurus vulpecula) in New Zealand. After highlighting the necessity of possum control, the concept of 'bait-shyness' is introduced, its significance outlined and the research on which this thesis is based justified.

\subsection{Possum Ecology and Impacts}

To constitute a pest species an animal must have a negative impact on one or more resources that are of anthropocentric value. The relative 'pestiness' of a species arises from characteristics of its ecology that allow it to impact on the resources concerned and that make limiting the animals' impact difficult or expensive (Parkes, 1994). The following section outlines why the brushtail possum is currently considered New Zealand's most serious vertebrate pest species.

\subsubsection{Possums in New Zealand: Introduction and Colonisation}

The common brushtail possum Trichosurus vulpecula (Kerr) belongs to the Phalangeridae (five-fingered) family of marsupials that is indigenous to Australia. The common brushtail possum (henceforth referred to as 'possum') was first introduced to New Zealand around 1840 to establish the basis of a fur trade, with subsequent introductions occurring as late as 1924 (Pracy, 1974). Resurgence in their skin value caused additional liberations of New Zealand born possums as late as the 1980s (pers. obs.). The majority of the New Zealand possum population are thought to have been derived from Eastern Australian and Tasmanian stock (Pracy, 1974).

In Australia possum populations are indirectly regulated by the availability of den sites and food resources. When these resources are limited both males and females defend exclusive areas, particularly den sites, forcing the dispersal of adults and 
newly independent young which then suffer heavy mortality (Green, 1984). In New Zealand resources are comparatively abundant, and resident possums seem less able to defend exclusive areas. As a consequence New Zealand possum populations are thought to be food rather than behaviorally limited, allowing densities as high as 25 $\mathrm{ha}^{-1}$ on forest/pasture margins (Coleman et al. 1980) with an average of around 10-12 $\mathrm{ha}^{-1}$ in podocarp-broadleaf forest (Coleman et al. 1980; Brockie, 1982) and lower densities in beech (Nothofagus) forest, pine plantations and scrubby farmland (Cowan, 1990). The abundance of food and den sites has allowed possums to reach densities over ten times those of their natural habitats of Australia (Green, 1984), with New Zealand's total possum population estimated at between 60-70 million (Batchelor \& Cowan, 1988). Possums' extreme adaptability has enabled them to occupy more than $90 \%$ of the country, with only the high rainfall, mountainous terrain of Fiordland and the remote tip of Northland as yet uncolonised (Cowan, 1990).

\subsubsection{Possums' evolution with the Australian vegetation}

The possum has the widest distribution of any Australian marsupial, occurring from the temperate forests of Tasmania to the tropical forests in Northern Australia (Kerle, 1984b). The possum differs regionally across Australia, varying from 1 to $4 \mathrm{~kg}$ in body size and fur colour from pale grey through reddish brown to black (Kerle, 1984b).

There is great variation in possum food preference between habitats in Australia, with diet including leaves, flowers, fruits, grasses and insects (Kerle, 1984a). Plant toxins are thought to influence possums' food selection (Freeland and Janzen, 1974) as is seasonal variation in nutritive value (Kerle, 1984b), fibre content and relative digestibility (Lintermans, 1979). Possums are also thought to be able to distinguish and choose between conspecific trees on the basis of favourable chemical composition (MacLennan, 1984).

Evolving with the selective pressures of arboreal browsing, the vegetation of Australia developed defensive chemicals to deter herbivores (e.g. Twigg and King, 
1991). Some species of Eucalyptus produce hydrogen cyanide gas through cyanogenesis (Pass et al. 1993), while Eucalyptus species generally produce foliage that contains a high level of toxins and secondary compounds that make digestion difficult and thereby restricts the amount that herbivores consume (Freeland and Winter, 1975; MaCaughley and Fox, 1980). However, some possum populations have evolved the ability to detoxify some species of Eucalyptus foliage (MacLennan et al. 1983), enabling them to become heavily reliant on such foliage in their diet.

In Western Australia, 41 legumes of the genera Gastrolobium and Oxylobium produce fluoroacetate (Twigg, 1994), which is metabolised to toxic fluorocitrate (Mcllroy, 1982). Fluoroacetate is also formed by hydrolysis of sodium monofluoroacetate (1080). Many Australian animal species exposed to such vegetation have evolved increased tolerance to fluoroacetate, enabling them to consume foliage, or prey that have consumed foliage, containing high levels of the compound (Twigg, 1994). Considered the most adaptable of the Australian marsupials (Kerle, 1984b), the possums of Western Australia have the highest recorded mammalian tolerance of fluoroacetate (King et al. 1978; Oliver et al. 1979; McIlroy, 1982) allowing them to utilise these nutritious legumes in amounts that would constitute a toxic meal for possums from other areas.

\subsubsection{Possum impact on New Zealand conservation values}

The native flora and fauna of New Zealand is unique as it evolved in the absence of terrestrial mammals (excluding three species of bat). Niche filled by herbivorous mammals in other countries were instead occupied by large flightless birds, the most famous of which were the moa (Worthy, 1990). In contrast to Australia, vegetation of the forest sub-canopy and canopy had never been subjected to the selection pressures of browsing prior to the introduction of the possum. As a consequence the chemical plant defenses that evolved in Australian vegetation are largely absent and many species have proven extremely vulnerable to possum browsing (e.g. DoC, 1994). 
Possums display marked preferences in their diet selection (e.g. Green, 1984), consequently they selectively remove some species from plant communities over time, resulting in compositional shifts in forest diversity (e.g. Campbell, 1990). When preferred species are major stand components, such as in the rata-kamahi (Metrosideros umbellata- Weinmannia racemosa) forests of Westland, possums have caused catastrophic forest dieback (Rose et al. 1992). When species are relatively minor stand components but highly preferred, possums may rapidly reduce or even eliminate local populations (e.g. mistletoe species, particularly Peraxilla colensoi; R. Nichol, pers. comm. 1997).

Possums are generally perceived as a herbivorous pest destroying our flora. However, the significance of possums' impact on our fauna is becoming evident. Possums are now known to have consumed eggs and killed chicks or adults, of at least six native bird species (Brown et al. 1993; Innes, 1994) and such direct predation, as well as competition for food and nest sites, contributes to a previously unconsidered significant possum impact.

In addition to their predation of avifauna, possums may threaten localised populations of invertebrates. Cowan and Moeed (1987) found that over half of the possum faeces examined in a 5-year study contained invertebrate remains, concluding that invertebrate consumption was opportunistic. Studies conducted on the large native Powelliphanta snails indicate that possums are capable of severe localised predation (K. Walker, pers. comm. 1997).

\subsubsection{Transmission of bovine tuberculosis}

Bovine tuberculosis (Mycobacterium bovis) was introduced to New Zealand with the first cattle shipments of European settlers. Although cattle are its natural host, the disease infects most mammal species, including humans (Tortora \& Grabowski, 1993). When the disease was identified in possums in 1967 it became apparent that possums acted as a reservoir of infection that was inhibiting attempts to eradicate the disease from stock (Animal Health Board, 1996). 
Possums are now regarded as the principal wildlife vector of Tb to domesticated stock (Julian, 1981). Possums are particularly effective vectors for $\mathrm{Tb}$ because they are highly susceptible to the disease, become highly infectious and have relatively frequent contact with stock on pasture/forest margins (Hickling, 1991).

\subsection{Possum control}

Funding for possum control has increased in the last decade to over 30 million/year (Animal Health Board, 1996). This increase has resulted from concern at both the possums' role in the spread and maintenance of $\mathrm{Tb}$ and possums' impact on conservation values. The following section outlines historical control, the basis of current control, and the potential significance of 'bait shyness'.

\subsubsection{Historical versus current control}

The first possums killed in New Zealand were trapped for their skins and by the 1890s unauthorized trapping had become quite extensive (Pracy, 1974). Varying degrees of protection were afforded the possum until 1946-47 when all protective legislation was removed, and limited poisoning was legalised (Pracy, 1974). From 1951-1962 a bounty was paid per unskinned possum in an effort to control increasing and expanding possum populations; despite 8.2 million being paid in bounties, effective control was not achieved (Cowan, 1990).

Fluoroacetate (fluoroacetic acid) was first synthesized in 1896, however, its potential as a rodenticide was not appreciated until the 1940s (Kalmbach, 1945). Fluoroacetate is converted within the animal to fluorocitrate which inhibits the tricarboxylic acid (TCA) cycle enzyme, aconitate hydratase, and blocks the TCA cycle at the citrate stage (Morrison \& Peters, 1954: Stryer, 1988). This results in accumulation of citrate in the tissues and plasma, energy deprivation and subsequent death (Morrison \& Peters, 1954). 
Fluoroacetate's sodium salt 'Compound 1080' (sodium monofluoroacetate), was first used as a rodenticide in the USA in 1945 (Kalmbach, 1945). In New Zealand, aerial sowing of sodium monofluoroacetate (1080) baits was evaluated as a control technique in 1956 (Batchelor, 1978). During the 1970s carrot bait was sown at rates of up to $40 \mathrm{~kg} \mathrm{ha}^{-1}$ and cereal pellet baits at up to $20 \mathrm{~kg} \mathrm{ha}^{-1}$ (Morgan, 1994a, 1994b). More recently sowing rates have been reduced to $5 \mathrm{~kg} \mathrm{ha}^{-1}$, use of cereal pollard baits has become common and carrot baits are screened to remove 'chaff' (Morgan, 1994a).

Public concern at the increase in use of 1080 prompted an investigation by the Parliamentary Commissioner for the Environment (Hughes, 1994). The report concluded that over areas of difficult terrain and poor access aerial sowing of 1080 bait remains the most cost-effective method of control. However, the report also concluded that ground hunters operating under performance contract may provide cost-effective control when terrain is accessible. Nevertheless, aerial-1080 remains the predominant possum control technique for large tracts of land (Hughes, 1994).

From the 1960 s to late 1980 s, most 1080 operations were large scale and generally aimed at a one-off 'knockdown' of the possum population. Operations were often not repeated until the possum population had recovered close to its pre-control density. In contrast, control in the 1990s has aimed at sustaining the population at low levels consistent with the operational objectives (i.e. conservation and/or Tb control).

This change in the strategy from 'one off' to 'sustained' control has affected possum control in most areas of New Zealand. The Animal Health Board's goal to eradicate Tb from cattle and farmed deer by the year 2000 (Animal Health Board, 1996), and the Department of Conservation's more strategic approach to conservation objectives (DoC, 1994), has resulted in an increase in both the frequency and intensity of possum control operations, so that by 1996 more than 2 million hectares of New Zealand came within the bounderies of sustained possum control (Animal Health Board, 1996). 


\subsubsection{Operational success}

An increase in the frequency of aerial poisoning operations has been associated with a marked decrease in the efficacy of some subsequent operations. One striking example is the control undertaken at the Mapara Wildlife Reserve in the central North Island, which contains a population of North Island kokako (Callaeas cinerea wilsoni). Possum control in the reserve aimed to reduce and maintain the possum population at as low a density as possible. Whilst initial control achieved an acceptable kill (>70\%; Hughes, 1994) successive operations failed to do so, killing $30 \%$ and $0 \%$ (Warburton and Cullen, 1993).

Speculation soon arose that such reductions in success of 'follow up' control was due to the residual possum population developing 'bait-shyness'. Indeed, 15 months after the last poisoning operation at Mapara over $60 \%$ of possums were found to avoid 1080 baits (O'Connor and Matthews, 1996).

\subsection{Animal resistance to poisoning}

'Bait-shyness' is a generic term used to describe an animal's behavioural avoidance of toxic bait. However, there are two general mechanisms through which an animal can avoid succumbing to a lethal dose of a poison; physiological and behavioural. The following section introduces these broad mechanisms and defines individual behaviours.

\subsubsection{Physiological resistance}

Physiological resistance refers to poisoning-induced metabolic strategies that enable animals to tolerate or detoxify toxins that they have consumed (Kandel and Chenoweth, 1952). Short-term tolerance of a toxin may be acquired through repeated ingestion of sub-lethal quantities. For example Howard et al. (1968) described a dramatic increase in tolerance of strychnine by rodents after multiple exposures. Kandel and Chenoweth (1952) reported an increased short-term tolerance of 1080 in rats and mice after repeated sub-lethal doses. 
The ability to tolerate or detoxify a toxin may increase over generations in populations of animals that are repeatedly poisoned as animals carrying resistant genes are genetically favoured. Such selection and resistance is well documented in populations of rats and mice (e.g. Greaves and Rennison, 1973; Pelz et al. 1995) many of which have for decades been frequently poisoned with anticoagulant toxins (Greaves et al. 1976). Howard et al. (1973) determined that only a few generations of selective breeding was required to significantly increase rats' tolerance of 1080 .

A parallel is provided in the natural evolution of increased tolerance of possums to fluoroacetate (Twigg and King, 1991). Over 40 species of legume in Western Australia produce fluoroacetate (Twigg, 1994; section 1.1.2). Possums with a tolerance of fluoroacetate that allowed them to utilise these highly nutritive plants were genetically advantaged (King et al. 1978). Consequently, possums from Western Australia have evolved a tolerance of fluoroacetate nearly 150 times that of possums from other parts of Australia that were devoid of fluoroacetate producing vegetation (Mead et al. 1979). Fortunately possums introduced to New Zealand were not of Western Australian origin and currently have a relatively low tolerance to 1080 .

Estimates of New Zealand possum populations' tolerance have been quite variable (e.g. McIlroy, 1983), although intrinsic variability may have been overstated through comparison of tolerance estimates obtained using different experimental procedures (McIlroy, 1994). Other factors, such as an animal's age, breeding condition, metabolic rate, and ambient temperature, can also affect tolerance (McIlroy, 1994).

Wheeler and Hart (1979) found no significant increase in tolerance of 1080 in three different populations of wild rabbits regularly poisoned for more than 20 years. At present there are no data that indicate an increase in 1080 tolerance in repeatedly poisoned possum populations (G. Hickling, pers. comm. 1997). 


\subsubsection{Behavioural resistance}

Behavioural resistance describes the range of behavioural traits that can reduce an animal's tendency to consume a lethal dose of toxic bait (Brunton et al. 1993). Behavioural resistance can be both learned (enhanced neophobia and learned aversions) or genetically determined (non-learned innate rejection of poison and neophobia expressed towards baits; O'Connor and Matthews, 1996). In contrast with physiological resistance, there is evidence that behavioural resistance has a significant impact on possum poisoning operations in New Zealand (Hickling, 1994, 1995; Warburton and Drew, 1994; O'Connor and Matthews, 1995, 1996; Morgan et al. 1996).

\subsubsection{Non-learned behavioural resistance}

\section{Neophobia}

Neophobia is the avoidance of unfamiliar objects or foods in a familiar environment (e.g. Cowan, 1977) and may be associated with a 'cautious feeding' strategy. Neophobic animals may be highly cautious when they encounter a novel food, consuming small amounts during initial encounters (Cowan, 1977; Hickling, 1994). If the animal experiences positive post-ingestive consequences; i.e. nutritional benefit and no adverse stimuli, during subsequent encounters the animal may 'recognise' the food, exhibit less caution and consume a greater amount.

Neophobia is most pronounced in commensal rodents, which may actively avoid novel objects on first encounter (Mitchell, 1985). Such behaviour is not pronounced in non-commensal species (Cowan, 1977) and so is thought to have evolved as a cautious feeding strategy, which has been extended to avoidance of humans' traps and poisoned baits.

The decline in efficacy of rabbit poisoning operations over a 10 year period in Australia was attributed to repeated selection for neophobic behaviour (Oliver et al. 1982). Similarly, low kills (30-40\%) in a repeatedly poisoned Central Otago rabbit population was attributed to rabbits' continued cautious behaviour towards toxic and non-toxic baits (Fraser, 1985), although this has been questioned by Ross et al.(1993). 
O'Connor and Matthews (1996) have demonstrated neophobic behaviour among possums. They found that in a choice test, possums consumed $97 \%$ of their daily food intake from a familiar flavoured food. However, on first exposure they consumed only $76 \%$ of this food. Further study of two possum populations revealed that $16 \%$ and $20 \%$ of naive possums avoided toxic bait when first encountered (O'Connor and Matthews, 1996). Based on this research it appears that neophobia in possum populations may have an underestimated influence on the efficacy of non-prefed poisoning operations (C. O'Connor, pers. comm. 1997).

\section{Innate poison avoidance}

The other non-learned behavioural mechanism that may contribute to possums' behavioural resistance is innate poison avoidance. As with neophobia, innate poison avoidance may result from selection pressure over many generations of poisoning.

A probable example of such selection is provided by the level of innate cyanide avoidance of some possum populations in New Zealand. In research conducted on possum populations with varying history of exposure to cyanide Warburton and Drew (1994) found that more than half of a population may avoid cyanide. In one population that had not been subjected to cyanide for at least seven years they found $60 \%$ avoided the poison. This suggests that avoidance was not due to previous sublethal exposure but rather was a result of innate cyanide aversion. Some species of Eucalyptus produce hydrogen cyanide gas (Pass et al. 1993; section 1.1.1) so possums may have evolved the ability to detect and reject cyanide through innate aversion. Warburton and Drew (1994) suggest that this may be the partial cause for the high level of innate aversion and that the frequent exposure to cyanide that some possum populations received during the high skin price era of the 1970s and early 1980s may have provided a strong additional selection pressure for those possums that innately avoided cyanide. 
Morgan's (1990) research gives further evidence of innate poison aversion. Whilst only 5-7\% of naive possums rejected non-toxic carrot and cereal baits, addition of 1080 increased rejection to $28 \%$ and $34 \%$ respectively. However, inclusion of either orange or cinnamon in a bait effectively 'masked' the averse taste and smell of 1080, so that consumption became equal to that of non-toxic bait. This is clear indication of both possums' ability to detect 1080 when unmasked, and of their innate avoidance of it.

\subsubsection{Learned behavioural resistance}

There are two behavioural mechanisms that result from experience and are therefore classed as 'learned'; enhanced neophobia and conditioned food aversion.

If an animal samples a novel food and subsequently experiences an aversive stimuli, such as the malaise resulting from sub-lethal ingestion of a toxin, the animal may associate the adverse stimuli with some aspect of the food or bait and develop a learned food aversion, or 'conditioned food aversion' (Revusky and Bedarf, 1967). If an animal develops a conditioned food aversion, it will either avoid or drastically reduce its consumption of foods that it perceives as the same, or possessing the same characteristics as the aversive food (Gustavson, 1977).

In addition to developing a conditioned food aversion the animal may become increasingly cautious of other novel foods; this is termed 'enhanced neophobia' (Robbins, 1980). For example, rats poisoned with a novel food subsequently show increased avoidance of other novel foods (Brunton et al. 1993). O'Connor and Matthews (1995) found that when cyanide was paired with a novel food in possums, subsequent consumption of a different novel food in a choice test decreased from $76 \%$ to $38 \%$; evidence of enhanced neophobia. 


\subsection{Conditioned Food Aversions (CFAs).}

Of the different mechanisms of animal resistance to poisoning conditioned food aversions seem to have the greatest short-term potential to decrease the efficacy of possum poisoning operations (Hickling, 1994a). Whilst the significance of physiological and non-learned avoidance mechanisms should not be overlooked (C. O'Connor, pers. comm. 1997) and is likely to increase in future through generations of selective breeding (Hickling, 1995) the speed at which CFAs can form means that they are a more immediate threat to the sustainability of possum control in New Zealand. The following section introduces conditioned food aversions and outlines their evolution, characteristics, research in other species, and current knowledge of aversions in possums.

\subsubsection{Evolution of conditioned food aversions}

Evolutionary pressures have favoured (and still favour) individuals able to recognise and associate both nutritionally beneficial and detrimental consequences of a food. Subsequent alteration of their diet to exclude toxic foods (Gustavson, 1977) would enable them to prevent the accumulation of a possibly debilitating or fatal dose of a toxin (Riley and Tuck, 1985). There is much evidence supporting the theory that food-aversion learning is an adaptative behaviour that evolved in response to toxins in potential food sources; animals learn this avoidance response primarily to foods (the likely source of toxins) with only a single pairing of taste and toxicosis, which limits the need for repeated and possibly deleterious sampling. Animals can even learn when a long delay is imposed between consumption and the onset of toxicosis (Kalat and Rozin, 1973). Such a delay is likely to occur in natural circumstances as a result of the temporal characteristics of digestion.

A striking aspect of conditioned food aversions is the consistency and similarity in behaviour observed across such a variety of species. It might be expected that since a large proportion of plant species contain toxic substances, compared to the proportion of toxic animal prey species, carnivores might not demonstrate learned food aversions as readily as either omnivores or herbivores (Gustavson, 1977). However, this is not 
the case and conditioned food aversions have been described in primates, bears, canids, felids, mustelids, ungulates, rodents, reptiles, birds, fish, molluscs, coelenterates and invertebrates (Gustavson, 1977; Du Toit et al. 1991; Berenbaum and Miliczy, 1983).

\subsubsection{Formation of conditioned food aversions}

More than 40 years ago an applied ecologist noted, in what amounts to the first recorded evidence of 'bait-shyness', that when he used a single bait or poison for several months to control Norway rats (Rattus norvegicus), he had initial success but later acceptance of bait was negligible (Steiniger, 1950, in Galef, 1990). The first experimental report of conditioned food aversion was that of Garcia et al. (1955), who demonstrated that rats receiving a dose of radiation and given a novel taste in food or drink subsequently avoided that taste. Since then, well over a thousand studies have examined the phenomenon (Smith et al. 1994). A review in 1985 listed over 50 toxins and over 150 compounds with which conditioned food aversions had been induced (Riley and Tuck, 1985); further toxins and compounds have continued to be added to the list in the subsequent 12 years.

In a pest control context, conditioned food aversions result from a sub-lethal ingestion of poison from a toxic bait. The animal associates the malaise induced by the poison with one or more characteristics of the recently consumed novel bait, such as the baitbase, lure or poison, and subconsciously classifies that characteristic as potentially lethal. When the animal next encounters a food that it perceives to possess one or more of these now aversive characteristics (termed 'cues'), it will either completely avoid the food, or drastically reduce its consumption.

There are several circumstances in possum control operations when an animal may only ingest a sub-lethal quantity of toxic bait. As noted previously neophobic or enhanced neophobic possums may only sample a small portion of a bait (section 1.3.2.2). Heavy rain following an operation can reduce pest feeding activity, leach 1080 from baits, and reduce bait palatability, particularly of cereal based pellets (Henderson and Morriss, 1996). Poor kills have been reported after such operations, 
with many survivors presumably receiving sub-lethal doses (Hickling, 1994). Possums may consume partial baits containing a sub-lethal dose (Morgan, 1994a) and the toxin may influence behaviour before other baits are encountered and consumed (Morgan, 1990). Agonistic interactions among pests aggregating at baits may result in some individuals being displaced before they consume a lethal dose (Henderson \& Hickling, 1997); such behaviour is more likely to occur at bait stations rather than during aerial poisoning operations where baits are spread widely. Controlling a species susceptible to a toxin can lead to sub-lethal poisoning of a sympatric species with a larger bodyweight and/or higher physiologically tolerance (e.g. controlling rabbits and sub-lethally poisoning possums; Hickling, 1994; Thomas, 1997).

\subsubsection{Characteristics of conditioned food aversions}

Many psychologists site the surprising parallels between food learning behaviours in different species as evidence that the behaviour is based upon relatively primitive associative learning mechanisms (e.g. Garcia et al. 1974). However, whether primative or not, many remarkable characteristics of this form of learning are exhibited by a vast range of species. The following section outlines some of these characteristics that may prove to be important components of possums' aversions.

1) Perhaps the most salient characteristic of food-aversion learning is the speed at which an aversion to a novel food or flavour is acquired, with a single flavour/toxicosis pairing sufficient (e.g. Robbins, 1978, 1980a, 1980b; O'Connor and Matthews, 1995).

2) Aversions can form despite long delays between ingestion and the onset of malaise, even with only a single flavour/toxicosis pairing (e.g. Revusky, 1968). Aversions in rats have formed with delays of 13 hours between ingestion and malaise (Andrews and Braveman, 1975), and weak aversions can develop with delays in the onset of symptoms as long as 24 and 36 hours after ingestion (Tuck et al. 1984, cited in Riley and Tuck, 1985). Such delays contrast with results from many other types of learning experiments where learning apparently does not occur with delays longer than a few seconds (Kalat and Rozin, 1973). 
Kalat and Rozin's (1973) theory of 'learned-safety' is the most robust that has been advanced to explain this apparent anomaly. They contend that in contrast with tracedecay theory (Rozin \& Kalat, 1971), learned-safety theory regards the delay between ingestion of food and onset of malaise as representing a learning process rather than a forgetting process. They reason that with long taste-poison delays, the animal gradually reclassifies a taste from 'possibly dangerous' (therefore associable with poison) to 'probably safe' (therefore relatively unassociable with poison). Eventually the delay is such that the animal finds it difficult to associate the malaise with a food it perceives as safe and therefore fails to develop a CFA. In such circumstances several taste/poison pairings may be necessary before the animals reclassifies the food as aversive (Klein et al. 1978).

3) The most influential factor regarding the ease to which an aversion can be developed towards a foodstuff is the relative novelty of that foodstuff (e.g. Kalat 1974; Fenwick et al. 1975). For example, if ruminants ingest a novel food during a meal, and the food contains a toxin (or is paired with a toxin) they will reduce their intake of the novel food, rather than familiar foods, in subsequent meals and can remember and distinguish individual novel foods from a meal of several items (Burritt and Provenza, 1991).

If an animal has prior experience of a food/flavour not linked with aversive stimuli (and therefore classifies the food as safe; Kalat and Rozin, 1973) such experience inhibits the subsequent development of an aversion. For example, a solution to which a rat has been pre-exposed becomes 'safe' and resistant to aversion for a period of time proportional to the solutions familiarity (e.g. Klein et al. 1976). Similarly, Elkins (1973) showed that the strength of saccharin-based aversions in rats was inversely proportional to the duration of their pre-conditioning exposure to saccharin.

4) CFAs can be very resistant to extinction. For example, O'Connor and Matthews (1997) found that possums may exhibit aversions to a novel flavoured food, paired with cyanide induced malaise, for more than 24 months. They also found that 
it required 5 subsequent exposures to 'safe' food before levels of aversion were reduced. Burritt and Provenza (1990) found that ruminants have the ability to remember for at least 1-3 years foods that produce aversive postingestive consequences. In a study of a possum population subjected to an aerial poisoning operation, over $80 \%$ of mature possums avoided 1080 bait 30 months after the population had been poisoned (O'Connor and Matthews, 1996).

5) Many studies report a dose dependent effect, with levels of aversion acquired proportional to the dose of toxin/agent administered (Nachman and Ashe, 1973; O'Connor and Matthews, 1995; Morgan et al. 1996). However, not every toxin induces CFAs; it appears the agent must affect the emetic system of the brainstem (Garcia, 1989). Failure to induce aversions in rats with sodium cyanide (Nachman and Hartley, 1975; Ionescu and Buresova, 1977) has been attributed to cyanide's action on the nervous system and metabolism rather than emetic system (Garcia, 1989). However, O'Connor and Matthews (1996) successfully induced aversions with cyanide in possums, an anomaly they attributed to physiological differences between rats and possums, in conjunction with dose and route of administration.

The severity of emetic and nauseous symptoms induced with different agents does not necessarily correspond to the level of aversion developed. For example, lithium chloride ( $\mathrm{LiCl})$ is particularly effective at inducing CFAs, and is the agent most commonly used for this purpose, (O'Connor and Matthews, 1996) yet it produces only minor symptoms of illness. In contrast, both strychnine and sodium cyanide are extremely toxic and produce profound symptoms of illness but are ineffective at inducing aversion in rats (Nachman and Hartley, 1975).

The presence or absence of nausea is difficult to infer from behaviour. However, study of human subjects offers an opportunity to examine the role of nausea in the development of an aversion. Schwartz et al. (1996) paired a distinctive beverage with a single chemotherapy administration and found that patients that experienced nausea expressed a significant decrease in their preference for the beverage, whereas those not experiencing nausea did not. However, both nauseous and non-nauseous patients significantly reduced their consumption of the beverage, consequently Schwartz et al. 
concluded that nausea predicted changes in perception but not changes in consumption. This supports the theory of Pelchat and Rozin (1982) and Rozin and Fallon (1987) that nausea plays a special role in changes of impression of foods, whereas changes in overall food consumption can be induced by a wider range of postingestinal events (e.g. respiratory distress).

6) Taste has the greatest influence in decisions of what is fit to eat (Garcia et al. 1989). Consequently the strongest CFAs are acquired to taste cues of a food/flavour. Lesser aversions may be acquired to other food stimuli, with odour next strongest (Garcia and Koelling, 1967) followed by cues that impinge on the mouth, such as moisture or tactile cues that may also stimulate taste receptors (Garcia et al. 1972). However, when weak cues for inducing CFA (e.g. odour, tactile, visual, place and noise) are paired with taste prior to nausea, the 'weak' cues become strongly aversive when subsequently tested alone; an affect termed 'taste potentiation' (Garcia et al. 1989).

The strength of an aversion is related to the intensity or concentration of the taste or flavour of the conditioning foodstuff (Kalat and Rozin, 1973; Gustavson, 1977). However, Kalat (1974) proposed that the strength or intensity of a flavour is a function of its novelty; i.e. if an animal has no experience with a solute then the more concentrated of two solutions will be more novel.

\subsubsection{Prefeeding and pre-exposure in pest control}

In poisoning operations, whether targeting rooks, rodents, rabbits or possums, pest populations are frequently 'prefed' before exposure to toxic bait (e.g. rats; Sugihara et al. 1995). 'Prefeeding' is the colloquial term used to describe any prior exposure of a targeted pest animal to a non-toxic bait compound. A toxin is subsequently added to the bait compound and the population re-exposed to the bait.

The rationale behind prefeeding is that any neophobic animal that may be tentative in its consumption when encountering the novel bait will experience 'positive feedback' from consumption (i.e. ' learned safety' section 1.4.3). When subsequently exposed to a toxic version of the prefed bait the animal either fails to distinguish between the 
two, or associates the toxic bait with the prefed bait, is less cautious and thereby consumes a lethal amount.

'Prefeeding' can be accepted as synonymous with 'pre-exposure', the term more frequently used in applied studies of conditioned food aversions; both are functionally equivalent in their reduction of flavour/bait base novelty.

\subsubsection{Conditioned food aversions in possums}

In New Zealand, possums' preferences for plant species varies widely between areas. For example, Fuchsia excorticata is highly preferred over most of the country and frequently browsed until death (C. Pekelharing, pers. comm. 1994; pers. obs.) but is apparenly relatively unpalatable in the eastern South Island (Batchelor, 1983). The less palatable forms have lower nutrient concentrations (P. Sweetapple, unpubl. data in Nugent 1994 and pers. comm. 1994). Such diet selection can be thought of as reciprocal behaviour to that of a CFA, with possums associating the positive postingestive consequences with a species (or individual tree), thereby developing a preference and increasing subsequent consumption. This behaviour may have a fundamental role in the diet selection of many herbivores (Provenza et al. 1995).

Because possums evolved with seasonably variable, toxin bearing vegetation, the ability to form CFAs would have been advantageous. However, despite anecdotal reports of 'bait-shyness' in possum populations, especially to cyanide baits, work confirming possums' ability to develop CFAs following sub-lethal ingestion of a pest bait was not reported prior to Hickling (1994).

Hickling showed that a high proportion (57\%) of possums from an area recently poisoned with low strength $(0.02 \%) 1080$ carrot baits for rabbit control subsequently exhibited aversion to $(0.08 \%) 1080$ cereal baits, and that differences in the proportion of possums averse in two areas was related to the recency of such poisoning.

Warburton and Drew (1994) found that more than half of a possum population may avoid cyanide. However, they found it hard to induce aversion following sub-lethal ingestion of cyanide and concluded that avoidance was a result of innate cyanide 
aversion. Additional work by O'Connor and Matthews (1995) showed that possums are able to develop CFAs induced by cyanide, although the effect was very dose dependent.

Morgan et al. (1996) reported that following sub-lethal ingestion of a cereal bait equivalent to a mean dose of $0.4 \mathrm{mg} \mathrm{kg}^{-1} 43 \%$ of possums refused the same bait two days later. Significantly more possums (82\%) became shy following sub-lethal ingestion of $1.0 \mathrm{mg} \mathrm{kg}^{-1}$, indication that as with cyanide (O'Connor and Matthews, 1995), the proportion of possums developing a CFA induced by 1080 is dose dependent.

Similarly, O'Connor and Matthews (1996) showed that up to $65 \%$ of non-prefed possums exhibit aversions seven days after sub-lethal exposure to a 1080 cereal bait. Both O'Connor and Matthews (1996) and Morgan et al (1996) found that changing either lure or toxin was not sufficient to overcome aversion. However, changing both lure and bait base resulted in most averse possums consuming the altered bait.

\subsection{Justification and objectives of thesis}

As Gustavson (1977) noted, the most striking aspect of conditioned food aversions is the consistency and similarity in behaviour observed across such a variety of species. Therefore, we should expect 'bait shy' possums to exhibit similar behavioural characteristics to those described in species that have been more rigorously studied.

That the relative novelty of a foodstuff has a primary influence on the ease with which an animal can develop a CFA to that foodstuff, has been well documented in other species, particularly rodents (e.g. Revusky and Bedarf, 1967; Fenwick et al. 1975; Robbins, 1978). I proposed that as Hickling's (1994) trial suggests, novelty may have as greater influence on the ability of possums to develop aversions as it does in other species. Elucidation of the influence of pre-exposure may therefore expose characteristics of possums' CFAs that could be utilised. If possums' aversions 
prove similar to those of other species prefeeding may limit the formation and generality of aversions and therefore increase efficacy of current and future control operations.

In a series of experiments I examined the influence of;

1. Novelty versus familiarity on possums' development of aversions.

2. Bait ' cues' and prefeeding duration on possums' development of aversions.

3. Prefeeding on possums' generality of aversions in a field situation.

The motivation of this work was to provide better understanding and advice to assist managers when undertaking possum control. The structure of the following sections reflects their preperation as independent scientific papers intended for submission to various journals. As a result of their independent preparation, there is some degree of repetition, particularly in introduction and methodology. 


\section{Chapter 2}

\section{Implications of prefeeding for the development of}

\section{bait aversions in brushtail possum*}

\subsection{Introduction}

As discussed in Chapter 1, an increase in the frequency of 1080 use has been associated with a marked decrease in the success of some successive operations (eg., Hickling, 1994). It has been postulated that this decline in success is due to some surviving possums developing an aversion (i.e. a learned avoidance behaviour; e.g., O'Connor and Matthews, 1995) to 1080 and/or associated baits through ingestion of a sublethal dose during earlier control operations (Hickling, 1994). This hypothesis is supported by several studies (section 1.4.6); for example O'Connor and Matthews (1996) found that $63 \%$ of possums from an area that had been poisoned for three consecutive years avoided 1080 baits on re-exposure.

There has been relatively little study of 'bait shyness' and 'poison shyness' in possums, whereas in rodents the behaviours have long been apparent and have been studied extensively (sections 1.3 \& 1.4). Rodents can learn to avoid ingesting distinctive flavours following a single flavour/toxicosis experience, with the formation of these aversions being strongly influenced by the novelty of the flavour (e.g. Kalat, 1974) and the strength of the illness (Nachman and Hartley, 1975). However, if rodents have been exposed to the flavour and/or bait prior to poisoning this familiarization inhibits the formation of a taste aversion, decreases its persistence, and decreases its generalisation to other baits and flavours (e.g. Klein et al. 1976; Bhardwaj and Prakash, 1982).

I speculated that, as Hickling's (1994) trial suggests, the behavioural mechanisms of aversion development previously described in rats are likely to be similar in possums, in that sublethal doses of 1080 will induce aversion primarily to the novel

\footnotetext{
* Subsequently published in Wildlife Research
} 
components of the toxic bait. Prefeeding may therefore inhibit the formation of aversion to bait ingredients that are common to both the prefeed and the toxic bait.

Prefeeding with a non-toxic bait is a common strategy in vertebrate pest control, intended to increase the consumption of toxic bait when it is subsequently laid, and in possum control is generally used in 'bait station' operations (e.g. Thomas, 1994). If prefeeding has the potential to inhibit the formation of an aversion following a sublethal poisoning (as in rats) it may have an additional benefit not previously considered in possum control.

In the following experiment I aimed to show that by prefeeding baits with different components (thereby making some components of a toxic bait familiar, whilst some remained novel) and then sub-lethally poisoning, when subsequently tested possums would exhibit discriminative aversions. I predicted that the baits they found aversive would contain components common to the toxic bait that were novel at the time of sub-lethal poisoning (i.e. not contained in prefeed).

\subsection{Methods}

In October 1995 wild possums were captured using cage traps baited with apple. Trapping was conducted in a forest near Taupo that had no previous history of 1080 poisoning. In total, 96 possums of mixed age and sex were caught and transported to Ruakura, Hamilton, where they were quarantined in cages for six weeks to allow acclimatization to captivity, during which time health checks were conducted. The experiment was approved by an Independent Animal Ethics Committee, which regulates the use of animals in experiments under New Zealand legislation.

After acclimatization possums were individually housed in $600 \times 500 \times 700 \mathrm{~mm}$ galvanised steel cages and provided with a metal nest box $400 \times 250 \times 250 \mathrm{~mm}$ on a shelf $400 \mathrm{~mm}$ above the floor of the cage (Plate 2.1). The possums were maintained on reverse 12:12 hour light/dark cycle and trained to a 30 minute feeding period at the start of the dark period (1000 hours). A wet mash diet consisting of lucerne based possum pellets 
(NRM New Zealand Ltd) mixed with water at a ratio of 1:1.5 (wt/wt) was fed daily. The mash was presented in $85 \times 115 \times 30 \mathrm{~mm}$ plastic containers which fitted inside galvanised steel trays attached to the front wall of each cage (Plate 2.2). Possums were offered $200 \mathrm{~g}$ of mash and a fresh apple daily throughout the trial. All individuals had continuous access to water via nipple dispensers.

Possums were divided into three treatment groups, balanced for age, sex and weight. Treatment group A received no prefeed pellets, group B received plain RS5 cereal pellets (non-dyed, non-lured; Animal Control Products, Waimate) and group $\mathrm{C}$ received greendyed (0.01\% Special Green V200A, Bayer NZ Ltd, Auckland) and cinnamon-lured (0.1\% cinnamon oil) RS5 pellets (Fig. 2.1). The individuals that were prefed received $30 \mathrm{~g} /$ day $( \pm 1 \mathrm{~g}$ ) of the appropriate pellets for 7 consecutive days, in addition to their apple and mash which was reduced to $180 \mathrm{~g} /$ day. Pellets were presented in the front half of the mash trays (Plates 2.2 and 2.3a). Individual consumption of both the prefeed and mash was recorded daily $( \pm 0.1 \mathrm{~g})$.

On completion of prefeeding, testing was initiated (Fig. 2.1). On test days possums were given $200 \mathrm{~g}$ of mash on which the test bait was placed, centred $2 \mathrm{~cm}$ from the front of the tray (Plate 2.3b). Initially all possums were presented with a standard commercial RS5 toxic bait which contained $0.08 \% 1080,0.1 \%$ cinnamon lure, and $0.01 \%$ Special Green V200A dye. Baits were cut to size to provide individual possums with $0.4 \mathrm{mg} 1080 / \mathrm{kg}$ bodyweight, half the $\mathrm{LD}_{50}$ estimated by Bell (1972). Following a 7 day recovery period each possum was presented with a standard $\sim 1.7 \mathrm{~g}$ toxic bait $(0.08 \% 1080)$, such as they had been poisoned with. Those eating less than $0.5 \mathrm{~g}$ were classed as averse. Animals that were not initially averse were re-tested after another 7 days.

Behavioural observations were conducted every hour for the first six hours after possums' sub-lethal ingestion and again the following morning. Symptoms of illness were recorded, such as salivation, lethargy, and vomiting. 

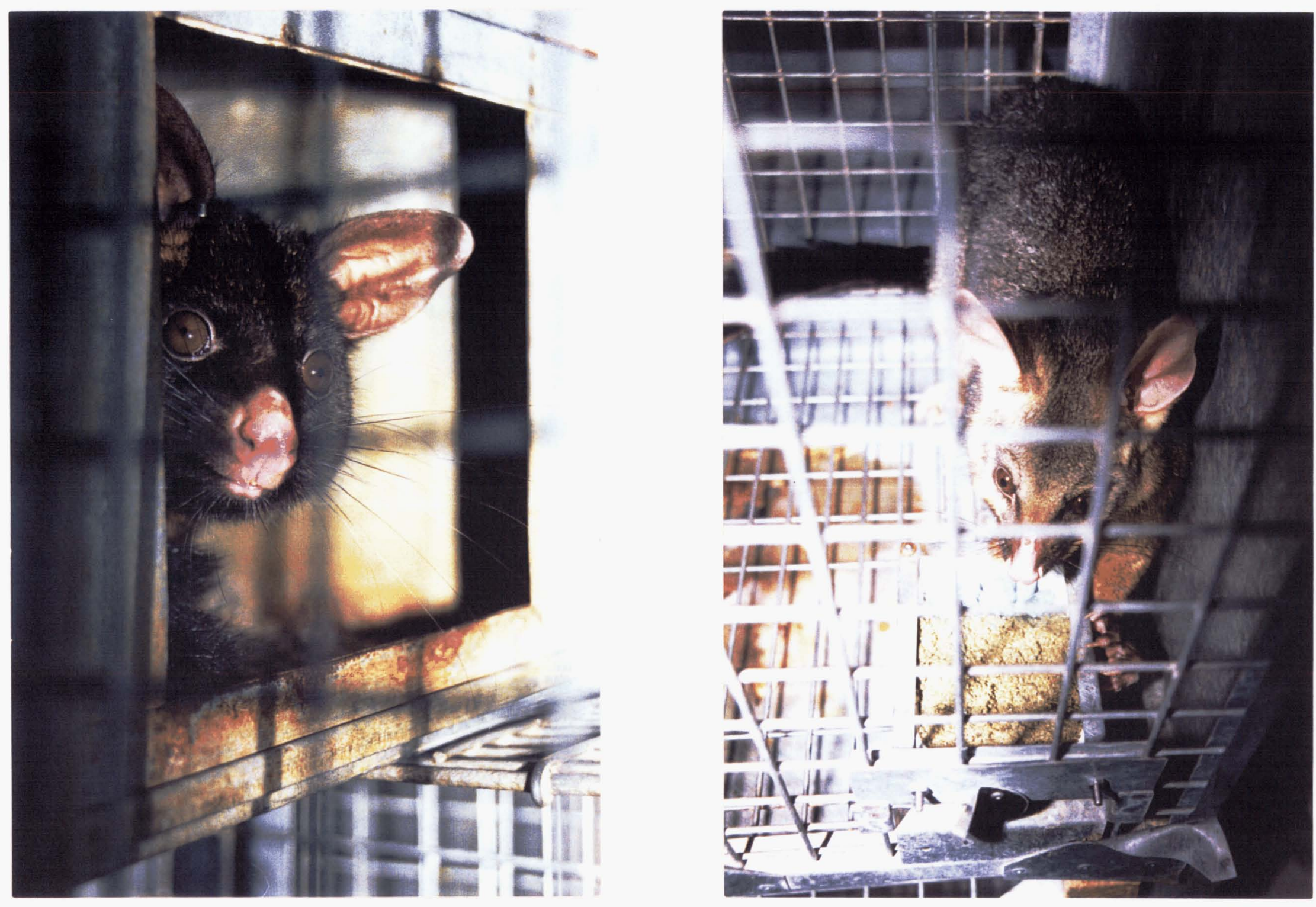


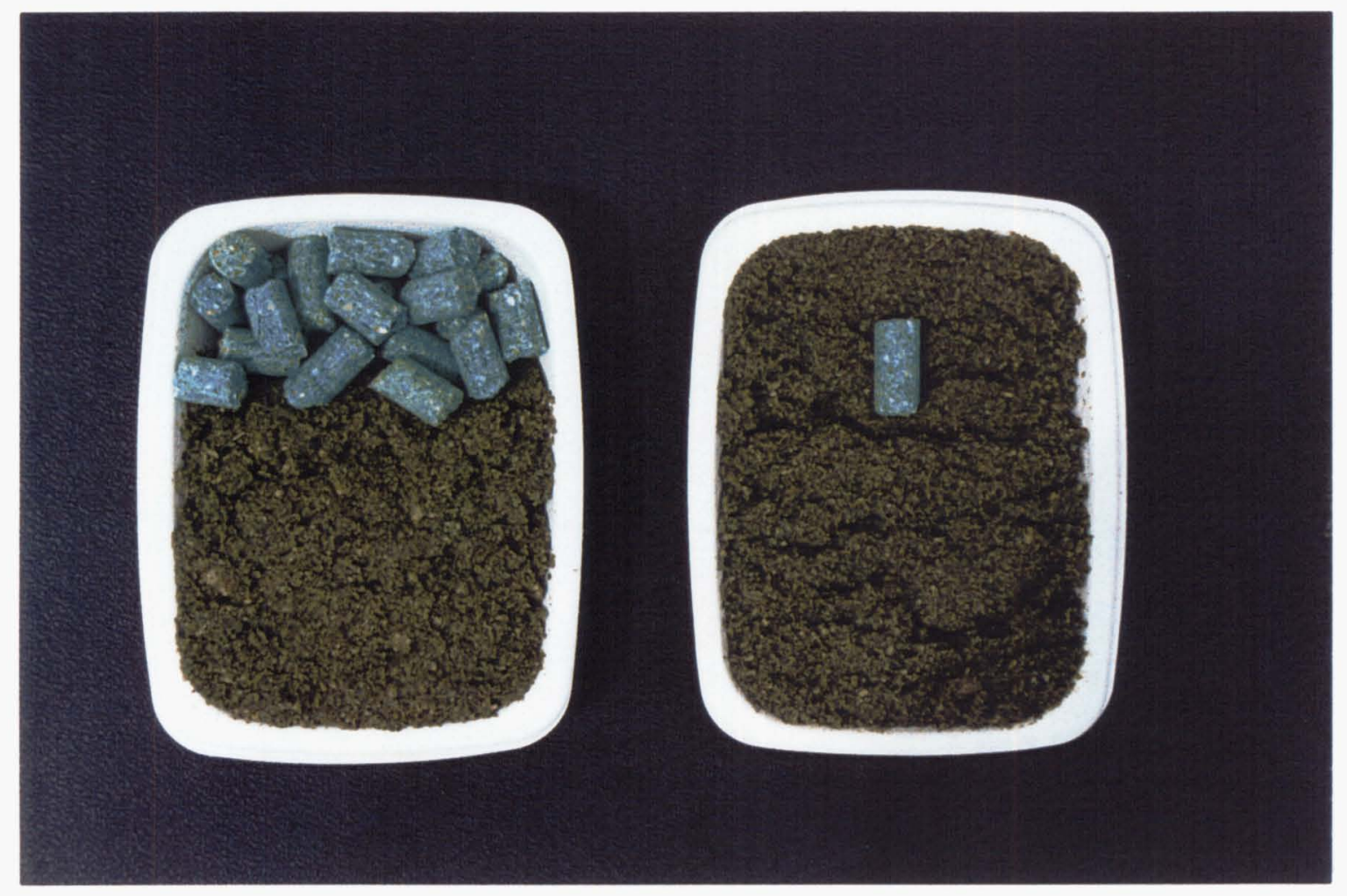

Plate 2.3. Presentation of prefeed, in mash tray (on left; $2.3 \mathrm{a}$ ), and a test bait (on right; $2.3 \mathrm{~b}$ ).

Treatment Group

prefeed

A none

B
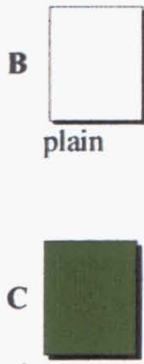

cinnamon.

\begin{tabular}{c|ccc|}
\multicolumn{3}{c}{ Aversion Testing } \\
\cline { 2 - 4 } & $\begin{array}{c}\text { test } 1 \\
\text { sub-lethal dose }\end{array}$ & test 2 & test 3 \\
prefeed & brodifacoum
\end{tabular}
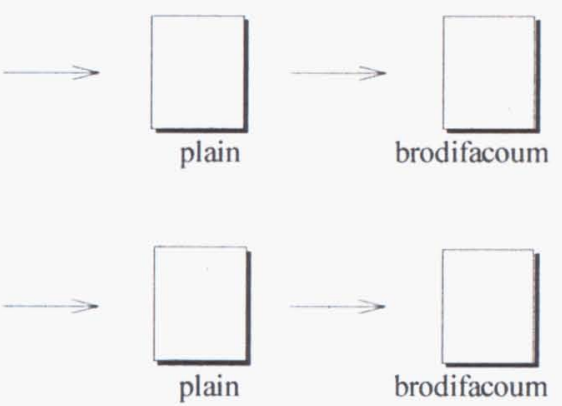

cinn.\& 1080

brodifacoum
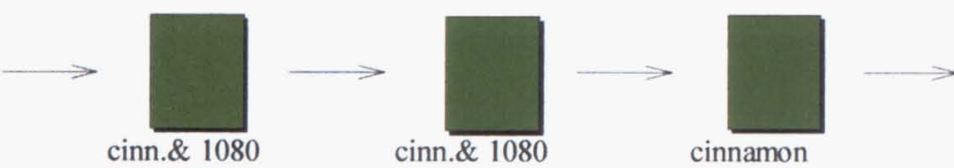

cinn. \& brodi.

Figure 2.1. Prefeeding and testing protocol. Shading denotes the presence of dye. 
After 7 days animals that were averse to the standard RS5 bait, with which they had been sub-lethally poisoned, entered test two. Animals from group A (non-prefed), and group B (plain prefeed), were presented with a plain RS5 pellet (group B's prefeed bait) and group $\mathrm{C}$ with one of their prefeed baits (dyed and lured ) (Fig. 2.1).

After an additional 7 days, animals from groups $A$ and $B$ were presented with a plain RS5 bait containing $0.002 \% \mathrm{wt} / \mathrm{wt}$ brodifacoum (a slow-acting anticoagulant toxin; Eason and Spurr 1995). Those from group C were presented with a cinnamon-lured $(0.1 \%)$, green-dyed $(0.01 \%)$, RS5 bait containing $0.002 \%$ brodifacoum.

In all tests the individual baits were weighed pre- and post-feeding. All test animals consuming less than $0.5 \mathrm{~g}$ of a bait were classed as averse to that bait.

To test for difference in consumption of prefed on the first day, versus the following six day average, a paired-t test was used (Sokal and Rohlf, 1981). Differences in prefeed consumption between treatment groups and days was tested for using repeated measures analysis of variance (ANOVA; Sokal and Rohlf, 1981). An independent t-test was used to compare prefeed consumption of animals that avoided initial sub-lethal poisoning with those that consumed the bait (Sokal and Rohlf, 1981).

For aversion tests $G$-statistics (Sokal and Rohlf, 1981) were calculated to test the goodness of fit of our observed frequency distribution of aversion to the expected frequency distribution representing no difference between treatments. Williams' correction was used to adjust for small sample sizes (Sokal and Rohlf, 1981). To test that the development of aversion for possums averse on their first re-exposure and those averse on their second, was consistent between treatments, the Mantel-Haenszel test was used (Sokal and Rohlf, 1981). 


\subsection{Results}

Consumption of prefeed was significantly lower on the first day it was available compared to the following 6-day average ( $\mathrm{p}<0.001 ;$ Fig. 2.2). However, there was no significant difference in consumption between the two types of prefeed on the first day $(\mathrm{p}=0.43, \mathrm{df}=1)$.

Many possums consumed relatively little prefeed on their first exposure, increasing consumption over the next few days (e.g. C3 \& E9, Table 2.1). Conversely, several possums appeared to find the prefeed relatively unpalatable; initially consuming a relatively large amount and subsequently reducing their consumption (e.g. G2 \& D8, Table 2.1). Whilst consumption of plain prefeed appeared consistently lower than that of dyed/lured prefeed, overall consumption was not significantly different $(p=0.32$, $\mathrm{df}=1$; Fig. 2.2).

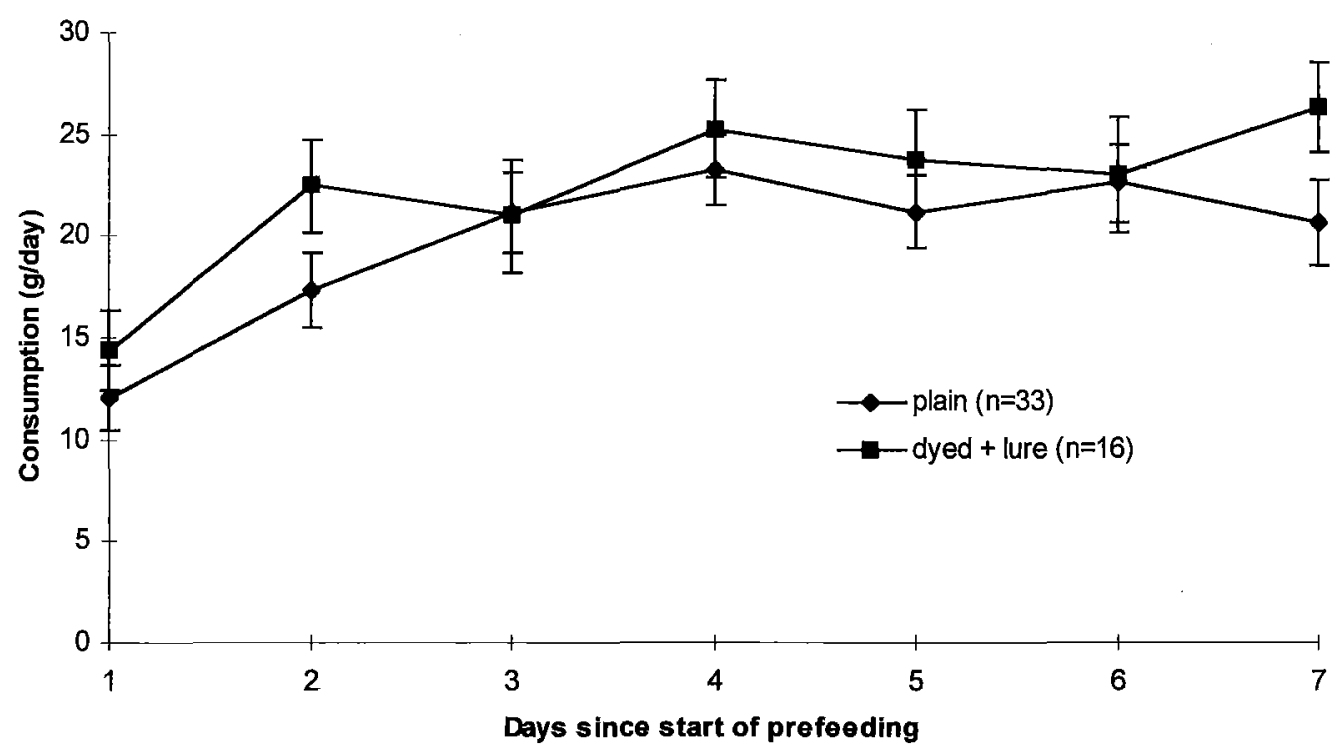

Figure 22. Mean ( \pm S.E.M.) consumption of the two types of prefeed over the seven days that it was provided to groups $B$ and $C$. Each possum received $30 \mathrm{~g} /$ day of prefeed in addition to their mash.

Possums displayed markedly different individual preferences to prefeed, with some individuals consuming all that was provided from first exposure and throughout (e.g D4 \& F6, Table 2.1), and others consuming very little (e.g. B7 \& C8, Table 2.1). Quartiles reflect this; the upper quartiles of dyed/lured and plain prefeed consumption were 30.5 and $30.6 \mathrm{~g} /$ day respectively, whilst lower quartiles were 14.6 and $9.2 \mathrm{~g} /$ day (for data refer Appendix 2.1). 
Table 2.1. Examples of prefeed consumption by individual possums over the seven days that it was provided. Animals shown were selected to highlight the different patterns of consumption. For full data set refer Appendix 2.1.

\begin{tabular}{|c|ccccccc|c|}
\hline \multicolumn{10}{|c|}{ Prefeed consumption (g/day) on nth day of prefeeding } \\
\hline Possum \# & 1st & 2nd & 3rd & 4th & 5th & 6th & 7th & average \\
\hline C3 & 1.6 & 11.6 & 21.3 & 31.3 & 30.6 & 31.8 & 31.0 & 22.7 \\
E9 & 1.7 & 16.0 & 30.4 & 28.2 & 22.2 & 29.3 & 31.7 & 22.8 \\
\hline D4 & 30.2 & 30.1 & 31.5 & 30.2 & 30.2 & 31.1 & 31.7 & 30.7 \\
F6 & 30.3 & 30.9 & 30.8 & 31.0 & 20.2 & 28.6 & 30.9 & 29.0 \\
\hline G2 & 18.5 & 0.0 & 0.0 & 0.0 & 4.6 & 0.0 & 0.0 & 3.3 \\
D8 & 16.8 & 0.0 & 0.0 & 11.7 & 16.2 & 1.8 & 0.7 & 6.7 \\
\hline B7 & 3.8 & 0.0 & 0.0 & 0.0 & 2.9 & 2.8 & 6.9 & 2.3 \\
C8 & 8.6 & 7.5 & 7.5 & 3.7 & 1.4 & 0.0 & 0.4 & 4.2 \\
\hline
\end{tabular}

When 'sub-lethal' baits were first presented five possums did not consume the bait, either as a result of accidentally dropping the bait through the cage floor grating or due to direct rejection. When baits were re-presented to these individuals three continued to avoid the baits, and did so for the duration of the trial (therefore their data was excluded). Two of these three possums had received plain prefeed, and their consumption was significantly lower than the group average $(\mathrm{p}=0.01 ; \mathrm{G} 2$ and D8 respectively; Table 2.1 ).

After prefeeding, all possums were provided a 'sub-lethal' dose of toxic bait. Behavioural symptoms of poisoning related illness were first observed within two hours of poison ingestion as some possums became lethargic and lay on the floor of their cages. In total 9 possums vomited, three of whom later died. Several other possums salivated heavily but survived. Possums that died generally became more lethargic, eventually becoming unconscious until breathing ceased. One individual was observed with upper body convulsions that lasted for several minutes just prior to death. In total 13 of 79 possums $(16.5 \%)$ that consumed the bait provided died.

Testing the first exposure subsequent to the sub-lethal ingestion revealed that $66 \%$ of nonprefed possums were averse to standard toxic bait, compared with $22 \%$ of possums prefed with plain pellets and $8 \%$ of possums prefed with dyed and lured pellets. This effect of prefeeding on the level of aversion was highly significant ( $G=16.6, \mathrm{df}=2, \mathrm{p}<0.001$ ). 
Re-testing those possums not initially averse revealed that $87 \%$ of non-prefed possums were averse on re-exposure, compared with $37 \%$ of possums prefed with plain pellets and $0 \%$ of possums prefed with dyed and lured pellets. Once again the effect of prefeeding on the level of aversion to standard toxic bait was highly significant $(G=18.0$, df $=2$, $\mathrm{p}<0.001)$.

The effect of a repeated re-exposure was consistent between treatments (Mantel-Haenszel test, $p=0.822$ ), so data from the first and second re-exposure were pooled. This made the effect of prefeeding even more pronounced (Fig. 2.3; $G=29.7$, df $=2, \mathrm{p}<0.001$ ).

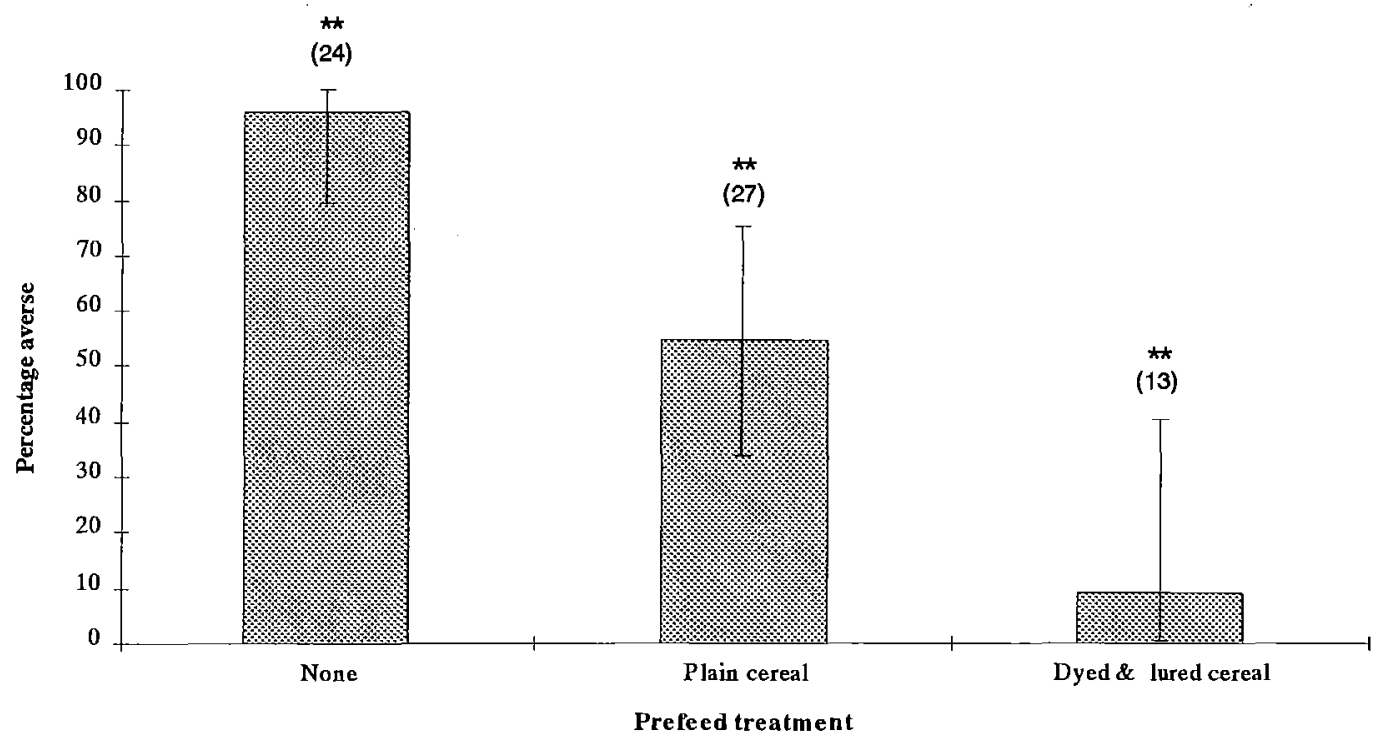

Figure 2.3. The effect of prefeeding on the percentage of possums developing aversions towards toxic cereal bait, containing $0.08 \% 1080$, with which possums had been sublethally poisoned. Possums had been subject to at least one re-exposure to toxic bait. Error bars represent $95 \%$ binomial confidence limits; asterisk represent highly significant differences between treatments $(\mathrm{p}<0.01)$; sample sizes in parenthesis.

Prefeed type had a significant influence on the proportion of possums that developed aversion towards toxic RS5 bait $(G=6.9, \mathrm{df}=1, \mathrm{p}<0.01)$. Of possums prefed with plain pellets, $55 \%$ became averse compared to only $9 \%$ of possums prefed with dyed and lured pellets. 
In test two, prefeeding had a highly significant effect on the subsequent acceptance of non-toxic baits $(G=24.3, \mathrm{df}=1, \mathrm{p}<0.001)$. Of the non-prefed animals $90 \%$ subsequently avoided a plain prefeed bait. In contrast, only $8 \%$ of prefed possums were averse to such baits (Fig. 2.4). The type of prefeed did not cause a statistically significant difference in the proportion of possums that developed aversions towards standard RS5 baits $(8.5 \%$ of 12 possums prefed with plain pellets versus $0 \%$ of 1 possum prefed with dyed and lured pellets; $G=0.2$, df $=1, p>0.05$; although because of the low proportion of prefed animals averse in test one sample sizes were small for this comparison).

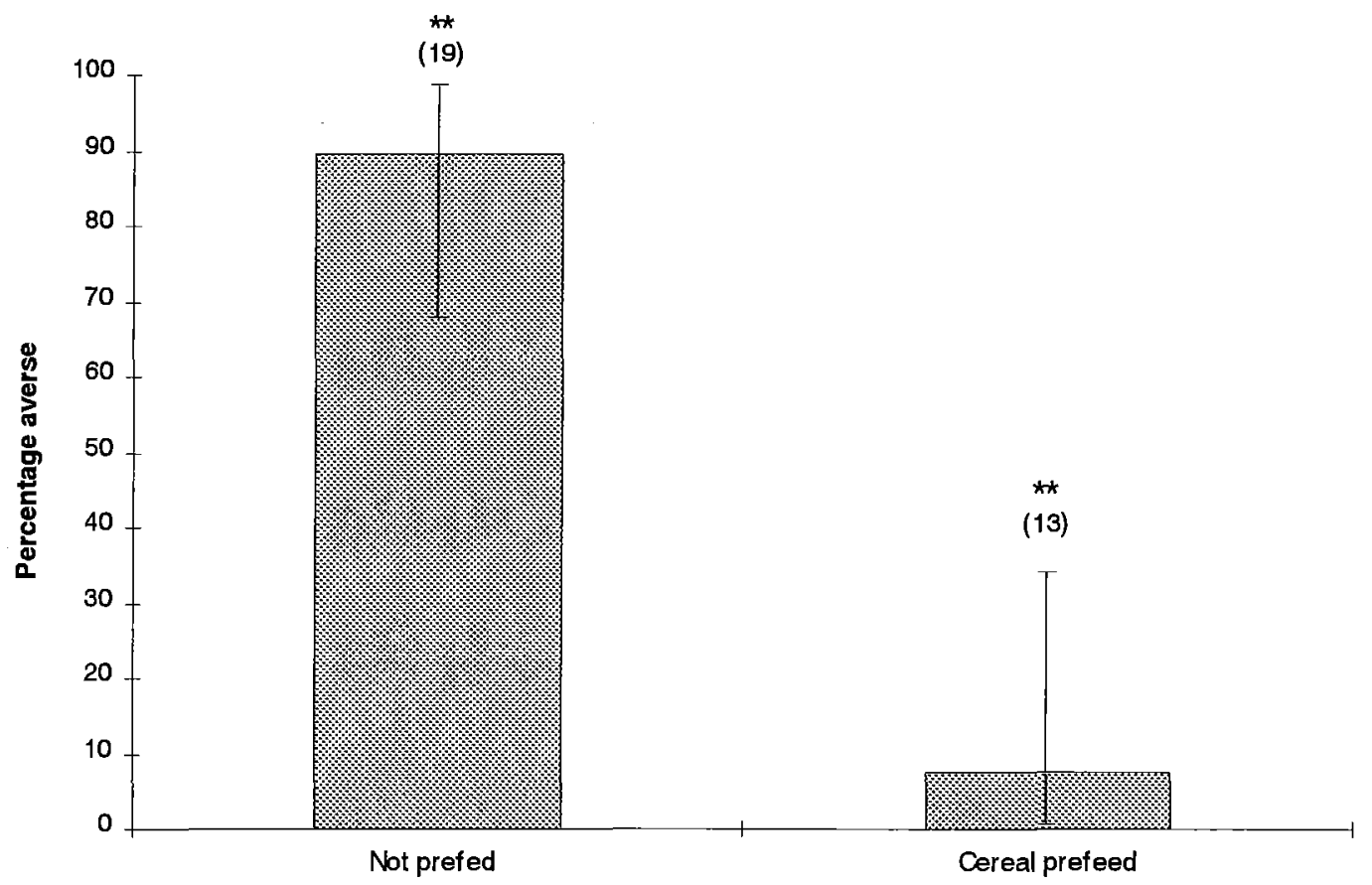

Figure 2.4. The effect of prefeeding on the percentage of possums developing a generalized aversion towards non-toxic cereal bait. Error bars represent 95\% binomial confidence limits; asterisk represent highly significant differences between treatments $(\mathrm{p}<0.01)$; sample sizes in parenthesis.

Pre-feeding also had a highly significant effect in test three on the acceptance of RS5 bait containing brodifacoum (Fig. $2.5, G=11.3$, df $=1$, p $<0.001$ ). Of the non-prefed animals, $92 \%$ avoided the brodifacoum bait compared with $14 \%$ of the prefed animals. The type of prefeed did not cause a significant difference in the proportion of possums that developed an aversion towards the brodifacoum bait $(17 \%$ of 6 possums prefed with plain pellets versus $0 \%$ of the 1 possum prefed with dyed and lured pellets; $G=0.3$, df $=1, p>0.05$; although sample sizes were small for this comparison). 


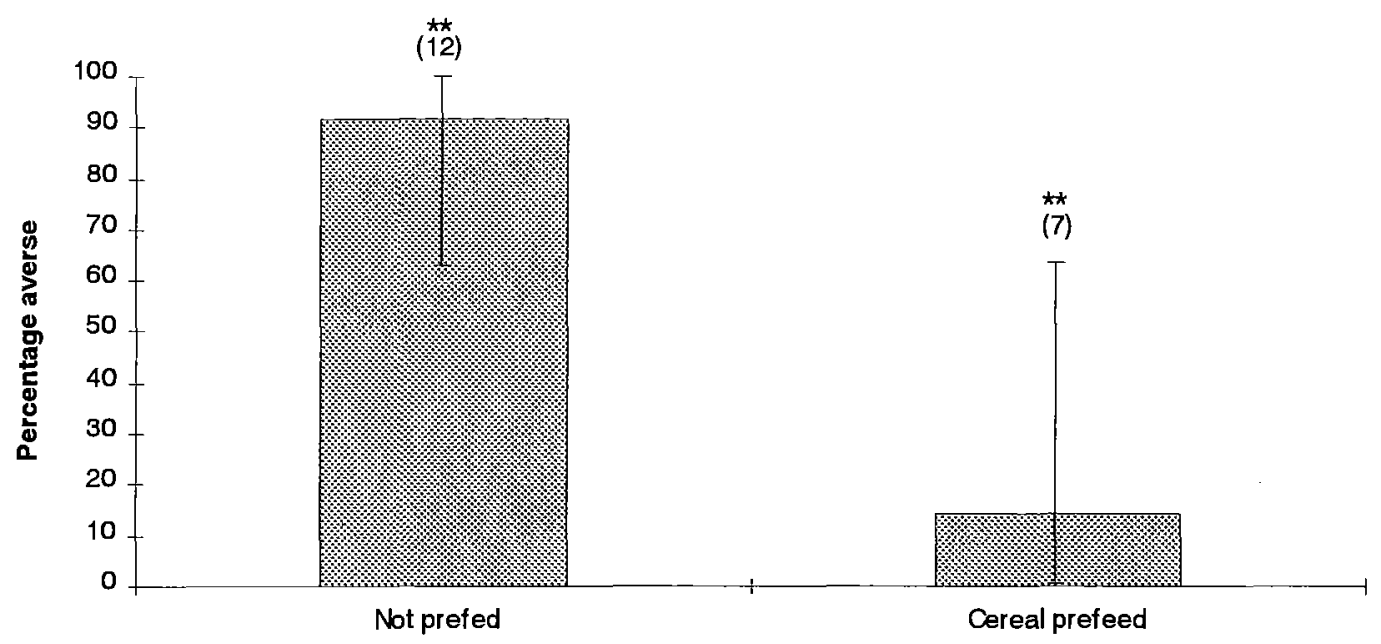

Figure 2.5. The effect of prefeeding on the percentage of possums developing a generalized aversion towards plain cereal bait containing $0.002 \%$ brodifacoum. Error bars represent $95 \%$ binomial confidence limits; asterisk represent highly significant differences between treatments $(\mathrm{p}<0.01)$; sample sizes in parenthesis.

\subsection{Discussion}

This trial has identified mechanisms in the development of aversions in possums similar to those in rodents. As in rodents, familiarization of possums to a bait prior to poisoning inhibits the formation of a learned taste aversion and decreases the generality of shyness (cf. Bhardwaj and Prakash, 1982; Klein et al. 1976).

The significantly lower consumption of both types of prefeed on the first day that it was offered, compared to the seven day average, can be explained as a result of neophobic behaviour. This behaviour is apparent in some individuals that consumed very little when they first encountered (presumably novel) prefeed and then increased their consumption over subsequent exposures (e.g. C3 \& E9, Table 2.1). Such behaviour is consistent with 'neophobic' behaviour in rats (Cowan, 1977), which typically involves 'sampling' novel foods and then increasing consumption on subsequent encounters if post-ingestive are positive. Nevertheless, several possums appeared to find the prefeed relatively unpalatable; initially consuming a relatively large amount and subsequently reducing their consumption (e.g. G2 \& D8, Table 2.1). 
Although neophobic behaviour is not thought to be evident in possums (Hickling, 1994; c.f. rats, e.g. Robbins, 1980a), the data support evidence of O'Connor and Matthews (1996), that possums may display neophobic behaviour. From a pest control perspective, 20 of 49 possums consumed an amount of bait that would have represented less than an $\mathrm{LD}_{95}\left(2.5 \mathrm{mg} 1080 \mathrm{~kg}^{-1}\right.$ bodyweight; Batchelor, 1982) had the bait contained $0.08 \% 1080$, and 9 had the bait contained $0.15 \% 1080$ (Appendix 2.1).

Garcia (1989) contends that for an agent to induce a CFA it must stimulate gastrointestinal malaise and nausea; affecting the emetic system of the brainstem. The behavioural symptoms observed suggest that 1080 has such an affect, with nine possums vomiting and others salivating copiously. We can therefore expect 1080 to induce aversions in possums as readily as in other species (c.f. rats; Nachman and Hartley, 1975).

Although possums were provided with baits containing a dose of only $0.4 \mathrm{mg} 1080 / \mathrm{kg}$ bodyweight, half the $\mathrm{LD}_{50}$ estimated by Bell (1972), 13 of the 79 possums that consumed a bait died (16.5\%). The susceptibility of individual possums to 1080 appears to be variable (McIlroy, 1983), and whilst 16.5\% died, many others did not display any overt symptoms of poisoning and scemed unaffected. Differences in susceptibility are further highlighted by data of Morgan et al. (1996) who provided 40 South Island possums with the same mean dose of $1080(0.4 \mathrm{mg} / \mathrm{kg})$ and observed no mortality.

Other studies of CFAs in possums report a dose-dependent effect, with levels of aversion acquired proportional to the dose of toxin administered (O'Connor and Matthews, 1995; Morgan et al. 1996). However, Morgan et al. (1996) reported only $43 \%$ aversion (compared to $67 \%$ in this study) using the same $0.4 \mathrm{mg} / \mathrm{kg}$ dose of 1080. This is perhaps further indication of the variability in possum's tolerance of 1080. If Morgan et al. (1996) population had a higher tolerance they would presumably experience less severe nausea and therefore a lesser stimulus to form an aversion. 
Previous studies have established that after a single sub-lethal ingestion of 1080 , possums become averse to the bait with which they were poisoned and avoid not only that particular bait, but also specific components such as lure and bait base (O'Connor and Matthews, 1996). In the current trial, possums that were not exposed to non-toxic prefeed baits before sub-lethal poisoning developed an aversion to the toxic bait and also generalized the aversion to the non-toxic cereal bait matrix. This is in agreement with results of O'Connor and Matthews (1996), who concluded that it was extremely unlikely that a non-prefed possum would accept a cereal bait following a sub-lethal poisoning with such a bait.

In contrast, most of the possums that were prefed did not become averse to the toxic bait. It appears that prefed possums often failed to distinguish between the toxic bait and prefeed after being sub-lethally poisoned. Without this distinction they were unable to associate the physiological discomfort they experienced with the toxic bait ingested, because it is not perceived as novel. Furthermore, as predicted by Hickling (1994), most of those that did become averse to the 1080 bait did not generalize this aversion to the prefeed bait. That they did not demonstrates that they were perceiving factors in the toxic bait as different to their prefeed bait, and were using these factors as 'cues' to avoid the toxic bait.

The difference in the development of aversions between the prefeed treatments is further indication of the ability of some possums to recognize factors which differ between the prefeed and toxic baits. Those prefed with plain baits had three factors which differed between the prefeed and toxic baits (dye, lure and 1080). This enabled many of them to distinguish between prefeed and toxic baits and therefore avoid the toxic bait. In contrast, possums that were prefed with dyed and lured baits had only 1080 as a cue for their aversion. Of these possums (13) only one became averse, with the remainder failing to detect the 1080 .

It may be that a greater proportion of possums detect 1080 when baits of high concentration are used (eg. $0.15 \% 1080$, rather than the $0.08 \%$ used here). If this is the case, and such individuals become poison shy rather than bait shy, prefeeding may 
have an additional advantage. Very few prefed animals will become averse to the bait base, so use of an alternative toxin such as brodifacoum in the original bait base may still be successful. This was demonstrated by treatment $\mathrm{C}$, where the only animal that detected 1080 (and therefore rejected the bait) accepted brodifacoum in the same bait base.

The more bait components that a possum is exposed to prior to a sub-lethal ingestion of poison, the harder it becomes for it to subsequently distinguish between a toxic and non-toxic bait. For this reason it would be advantageous to use prefeed of the same bait base, lure and dye concentration as the toxic baits. Pest baits containing toxin are required to be dyed green, in part because such baits are thought to repel birds (Caithness and Williams, 1971). Dye also allows field staff to easily distinguish between toxic and non-toxic baits; use of dyed and lured prefeed would consequently require greater caution by field staff when handling baits of any kind.

Previous studies of non-prefed possums concluded that a change in bait base is necessary to overcome bait shyness (eg., Morgan et al. 1996). However, results from this trial indicate that prefeeding may be a successful alternative technique. This has important implications for managers, particularly if alternative bait bases are more costly, or less palatable to possums.

Results from the present trial indicate that prefeeding possums with a dyed and lured bait has the potential to inhibit the formation of an aversion following a sub-lethal poisoning. In bait station control operations, where prefeeding is commonly used to attract possums to a station, use of dyed and lured prefeed may provide the additional benefit of rendering 'bait-shyness' insignificant. In areas where frequent aerial control operations are conducted there is potential for aversions to render future control operations virtually ineffective within a decade (Hickling, 1995). However, the correct use of appropriate prefeed may sufficiently limit aversions to prevent this occurrence. 
The design of this experiment did not allow distinction between the individual effect of the dye or the cinnamon lure as cues. However, in combination they had a significant effect which indicates one or both are distinctive and act as a cue. Additional research needs to focus on the 'strength' of individual bait components as possums' cues for avoidance. For example, lures that are highly distinctive may be particularly successful in inhibiting the development of aversions when used in both the prefeed and toxic baits; this hypothesis is addressed in Chapter 3. 


\section{Chapter 3}

\section{Influence of bait components and prefeeding duration on}

\section{bait aversion in brushtail possums*}

\subsection{Introduction}

The previous trial (Chapter 2) identified mechanisms in the development of aversions in possums similar to those described in rodents. It established that the relative novelty of a foodstuff has a primary influence on possums' ability to develop CFAs. It also highlighted possums' ability to detect individual bait components and use these factors as 'cues' to either induce or inhibit aversion, depending on their relative novelty. However, the design of the experiment did not allow differentiation between the individual effects of dye and cinnamon lure as cues. Therefore, the second trial was designed to address the influence of cues on the association of toxicosis with foodstuffs and to further elucidate the effect of novelty on the subsequent development of aversions.

Research in other species, particularly rats, has established that they preferentially associate certain cues with poisoning; principally those of taste (e.g. Garcia and Koelling, 1967). I hypothesised that the converse may also occur; i.e. after pre-exposure an animal may preferentially recognise and associate some cues with 'safe' food. Such cues may, or may not, be more distinctive than others and would have a greater influence on the extent to which possums associate the toxic bait with the 'safe' pre-exposed bait. If this reduced their ability to associate the malaise they experienced with the toxic bait, it should reduce their likelihood of developing a CFA.

If a possum is familiar with a non-toxic bait that has strong flavour, then this familiarity reduces the probability of the possum subsequently developing an aversion

\footnotetext{
* Prepared for submission to New Zealand Journal of Zoology
} 
to a toxic version of that bait (Chapter 2). I speculated that the stronger the taste and olfactory cues shared between non-toxic and toxic baits, the less exposures to nontoxic bait would be required before it becomes 'familiar'. Once a non-toxic bait becomes familiar the possum may 'perceive' the toxic bait to be 'safe' non-toxic bait and thus fail to develop a CFA.

The baits commonly used for possum control are carrot or cereal-based. They are required by law to be dyed green, in part because the dye is thought to repel birds (Caithness and Williams, 1971) and also because it allows people to easily distinguish between toxic and non-toxic baits. Lure is also added; most commonly cinnamon oil because it increases the palatability of the baits through masking the 1080 (Morgan, 1990) and has a repellant effect on birds (e.g. Hickling, 1997). Because cinnamon is frequently incorporated in prefeed, and both cinnamon and dye in toxic baits, I chose to examine the relative influence of these two cues on possums' development of aversion.

The aim of the study was to establish whether possums prefed with cinnamon baits, which I perceived to provide stronger taste and olfactory cues than dye, were subsequently less likely to develop an aversion to a toxic bait (which contained both cinnamon and dye), than did those possums prefed with baits containing dye alone. If cinnamon baits provide stronger flavour cues than dye, then I predicted that fewer exposures to the non-toxic baits would be required before the possum perceives the toxic bait to be a non-toxic bait, and thus fails to develop a CFA.

\subsection{Methods}

In October 1996 wild possums were captured using cage traps baited with apple. Trapping was conducted in a forest near Taupo that had no previous history of 1080 poisoning. In total, 89 possums of mixed age and sex were caught and transported to Ruakura, Hamilton, where they were quarantined in cages for six weeks to allow acclimatization to captivity, during which time health checks were conducted. The 
experiment was approved by an Independent Animal Ethics Committee, which regulates the use of animals in experiments under New Zealand legislation.

After acclimatization possums were individually housed in cages, maintained on a reverse 12:12 hour light/dark cycle and trained to a 30 minute feeding period at the start of the dark period (1000 hours). A wet mash diet consisting of cereal-based possum pellets (NRM New Zealand Ltd) mixed with water at a ratio of 1:1.5 (wt/wt) was fed daily. The mash was presented in $85 \times 115 \times 30 \mathrm{~mm}$ plastic containers fitted inside galvanised steel trays attached to the front wall of each cage (Chapter 2, Plate 2.2). Possums were offered $200 \mathrm{~g}$ of mash and a fresh apple daily throughout the trial. Each possum had continuous access to water via a nipple dispenser.

Possums were divided into three main treatment groups, and six sub-treatment groups, balanced for age, sex and bodyweight. Treatment groups A1 and A7 received cinnamonlured RS5 cereal pellets ( $0.1 \%$ cinnamon oil; Animal Control Products, Waimate). Groups B1 and B7 received green-dyed RS5 cereal pellets $(0.01 \%$ Special Green V200A, Bayer NZ Ltd, Auckland) and groups C1 and C7 received green-dyed and cinnamon-lured RS5 cereal pellets (Fig. 3.1). Possums in sub-group 1 received only one prefeed (on the day prior to sub-lethal poisoning) whereas possums in sub-group 7 received prefeed for 7 consecutive days prior to sub-lethal poisoning. Individuals received $30 \mathrm{~g} /$ day of the appropriate cereal pellets, in addition to their apple and a reduced $180 \mathrm{~g} /$ day of mash. Pellets were presented in the front half of the mash trays (Chapter 2; Plates 2.2 and 2.3a). Individual consumption of both the prefeed and mash was recorded daily. 
Treatment Group

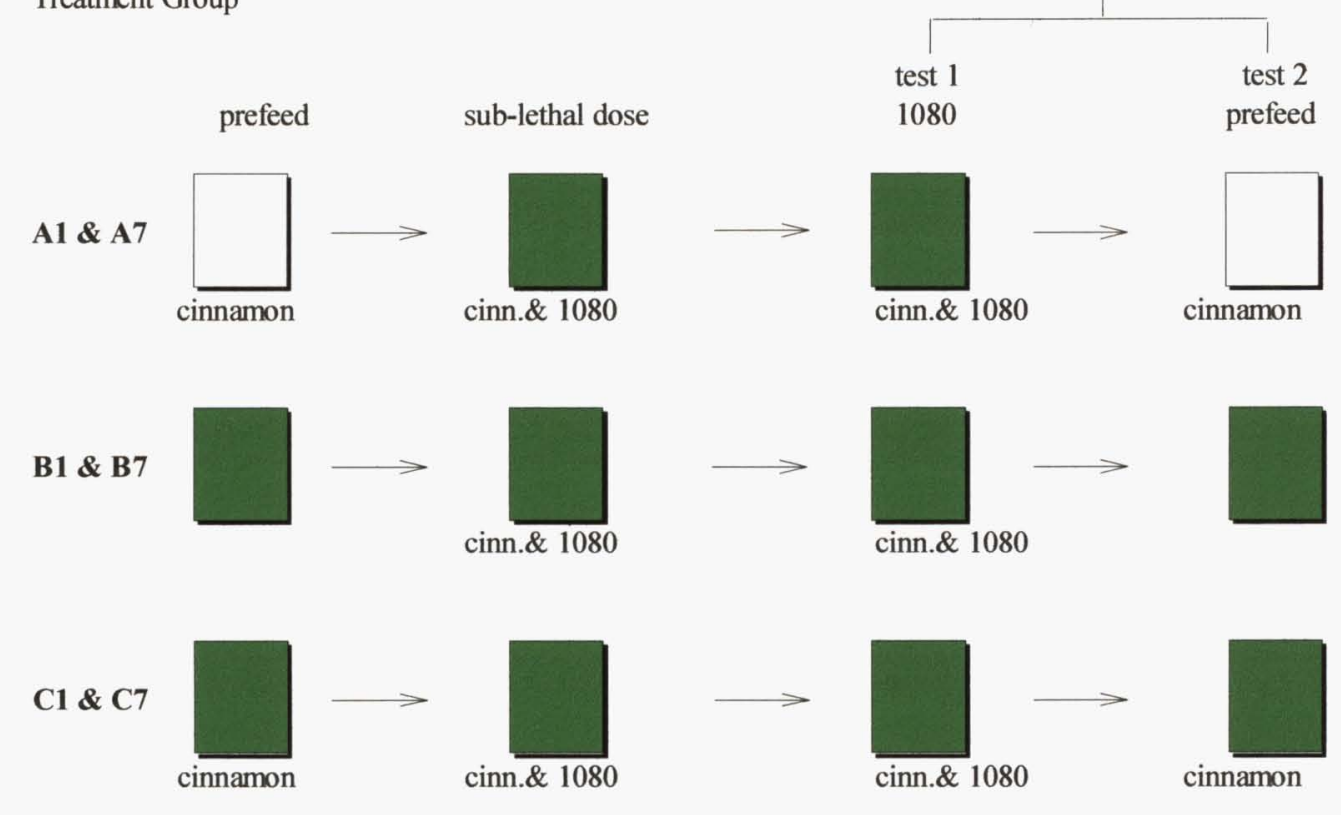

Figure 3.1. Prefeeding and testing protocol. Shading denotes the presence of dye.

On completion of prefeeding, testing was initiated (Fig. 3.1). On test days possums were given $200 \mathrm{~g}$ of mash on which the test bait was placed, centred $2 \mathrm{~cm}$ from the front of the tray (Plate 2.3b). Initially all possums were presented with a standard commercial RS5 toxic bait containing $0.08 \% 1080,0.1 \%$ cinnamon lure, and $0.01 \%$ Special Green V200A

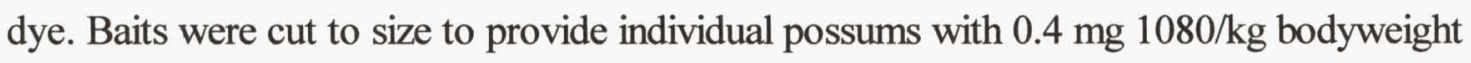
(half the $\mathrm{LD}_{50}$ estimated by Bell, 1972).

Behavioural observations were conducted every hour for the first 6 hours after possums' sub-lethal ingestion and again the following morning. Symptoms of illness were recorded, such as salivation, lethargy, and vomiting.

Following a 7 day recovery period, by which time the surviving individual's consumption had returned to pre-poison levels, each possum was presented with a standard (mean $1.7 \mathrm{~g}$ $\pm 0.05 \mathrm{~g}$ ) toxic bait, such as they had been poisoned with. Those eating less than $0.5 \mathrm{~g}$ were classed as averse (Chapter 2). Animals that were not initially averse were re-tested after another 7 days; averse individuals from either test then entered test two (Fig. 3.1). In this test animals were presented with the same pellet as they had received as prefeed. 
To test for difference in consumption of prefed on the first day, versus the following six day average, a paired-t test was used (Sokal and Rohlf, 1981). Differences in prefeed consumption between treatment groups and days were tested using repeated measures analysis of variance (ANOVA; Sokal and Rohlf, 1981). An independent t-test was used to compare prefeed consumption of animals that avoided initial sub-lethal poisoning with those that consumed the bait (Sokal and Rohlf, 1981).

For each test, Pearson's chi-square $\left(\chi^{2}\right)$ statistics (Sokal and Rohlf 1981) were calculated to test the goodness of fit of our observed frequency distribution of aversion to the expected frequency distribution representing no difference between treatments. To test that the development of aversion for possums averse on their first re-exposure and those averse on their second, was consistent between treatments, the Mantel-Haenszel test was used (Sokal and Rohlf 1981). 


\subsection{Results}

There was no significant difference between the consumption of the different types of prefeed over the 7 days it was provided $(\mathrm{p}=0.46, \mathrm{df}=2)$, although non-dyed/lured tended to be more palatable (Fig. 3.2). Similarly, consumption of prefeed on the first day it was provided was not significantly different from the average over the remaining 6 days ( $\mathrm{p}=0.81$; Fig. 3.2).

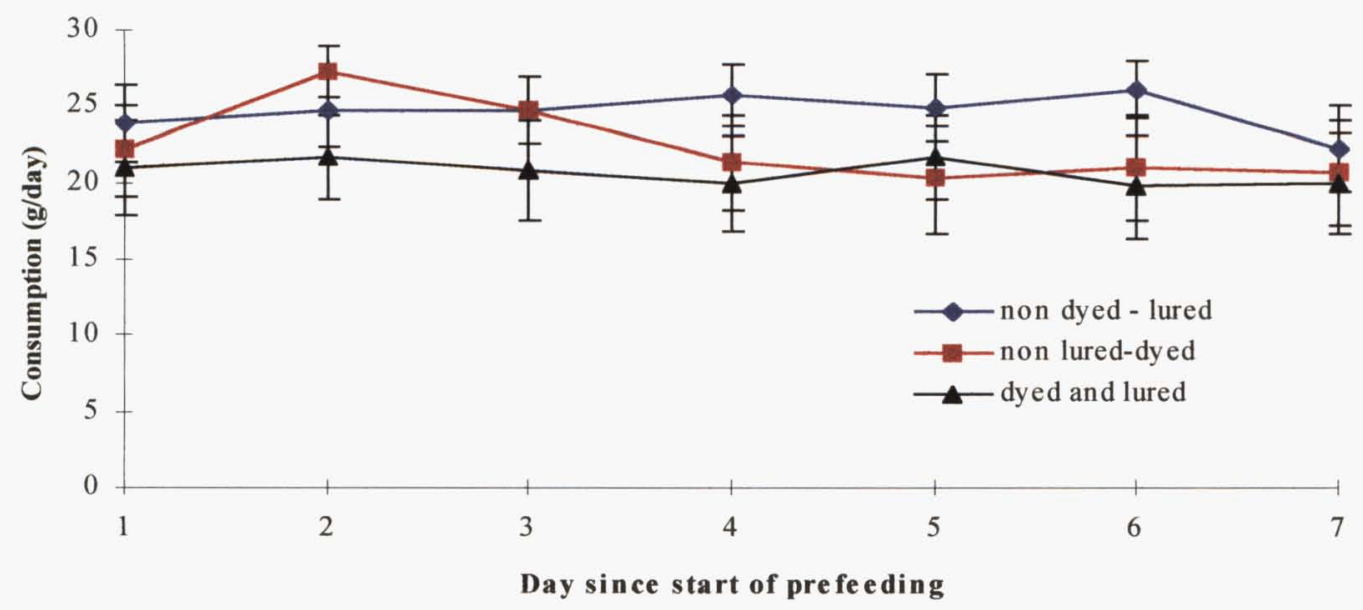

Figure 3.2. Mean ( \pm S.E.M.) daily consumption of prefeed over the seven days that it was provided. Possums received $30 \mathrm{~g} /$ day in addition to their mash.

Once again possums displayed markedly different individual preferences to prefeed (e.g. Table 3.1; for full data refer Appendix 3.1).

When sub-lethal baits were first presented 15 of the 88 possums did not consume the bait, either as a result of accidentally dropping the bait through the cage floor grating or due to direct rejection. When baits were re-presented 10 individuals continued to avoid the baits, and did so for the duration of the trial (therefore their data were excluded). This proportion avoiding consumption of the sub-lethal bait (11\%) was higher than the first trial (4\%), although the difference was not statistically significant $\left(\chi^{2}=2.83, p=0.09\right)$. A greater proportion of possums prefed for seven days ( 8 of 45$)$ avoided the sub-lethal bait than those that received a single days' prefeed (2 of 43); although the difference was non-significant $\left(\chi^{2}=3.76, \mathrm{p}=0.05\right)$. Most of the possums that avoided the sub-lethal bait had gradually reduced their consumption of prefed over the seven days, and as a group their prefeed consumption was significantly lower than the average $(\mathrm{p}<0.001$; Table 3.1$)$. 
Table 3.1. Consumption of prefeed by the 10 possums that subsequently avoided ingestion of a sub-lethal bait.

\begin{tabular}{|c|c|ccccccc|c|c|}
\hline \multicolumn{10}{|c|}{ Prefeed consumption (g/day) on nth day of prefeeding } \\
\hline possum & tmt. & 1st & 2nd & 3rd & 4th & 5th & 6th & 7th & avge. & tmt avg \\
\hline C2 & dye & 27.8 & 30.3 & 30.6 & 14.5 & 2.0 & 2.4 & 0.0 & 15.4 & \\
C6 & dye & 3.1 & 17.3 & 5.5 & 2.3 & 4.0 & 10.8 & 13.4 & 8.1 & 22.0 \\
D6 & dye & 12.0 & 20.3 & 16.8 & 14.4 & 1.9 & 1.2 & 0.0 & 9.5 & \\
\hline C8 & c\&d & 14.1 & 0.0 & 0.6 & 2.6 & 2.3 & 0.6 & 0.0 & 2.9 & \\
D3 & c\&d & 30.5 & 28.1 & 2.7 & 3.3 & 5.7 & 1.7 & 0.0 & 10.3 & \\
D7 & c\&d & 30.1 & 28.7 & 25.7 & 4.4 & 13.2 & 2.1 & 1.5 & 15.1 & 21.3 \\
D8 & c\&d & 0.0 & 0.0 & 0.0 & 4.3 & 30.2 & 0.0 & 30.2 & 9.2 & \\
F7 & c\&d & 15.5 & 19.6 & 11.8 & 10.9 & 6.1 & 11.8 & 3.1 & 11.3 & \\
\hline C3 & dye & 0.0 & 10.8 & & & & & & 0.0 & 20.6 \\
H3 & dye & 7.4 & 10.4 & & & \\
\hline
\end{tabular}

Behavioural symptoms of poisoning related illness were first observed within two hours of poison ingestion as some possums became lethargic and lay on the floor of their cages. Generally symptoms were not widespread or severe, however one possum (which later died) was observed to have vomited and two others salivated excessively. The two possums that died became gradually more lethargic, eventually becoming unconscious until breathing ceased. There were significantly fewer deaths $(2.6 \%)$ than in the first trial $\left(16.5 \% ; \chi^{2}=8.76, \mathrm{df}=1, \mathrm{p}=0.003\right)$, even though 1080 doses were the same.

Testing the first exposure to a toxic bait subsequent to the sub-lethal ingestion (test one) revealed that $11 \%$ of possums had developed an aversion to that bait. When those possums not averse in test one were re-tested a week later a further $23 \%$ had developed an aversion, giving a total of $34 \%$ of possums averse after two exposures. This level of aversion is significantly lower $\left(\chi^{2}=32.7 \mathrm{df}=1, \mathrm{p}<0.0001\right)$ than for the non-prefed possums in the previous trial (66\%; Chapter 2) and that reported by O'Connor and Matthews (1996).

The type of prefeed that possums received had no significant effect on the subsequent aversion expressed towards toxic bait $\left(\chi^{2}=2.13, \mathrm{df}=2, \mathrm{p}=0.34\right)$, although inspection of the data suggested a trend for aversion to be slightly more common when only dye was added to prefeed than when both cinnamon and dye were added (Fig. 3.3). 


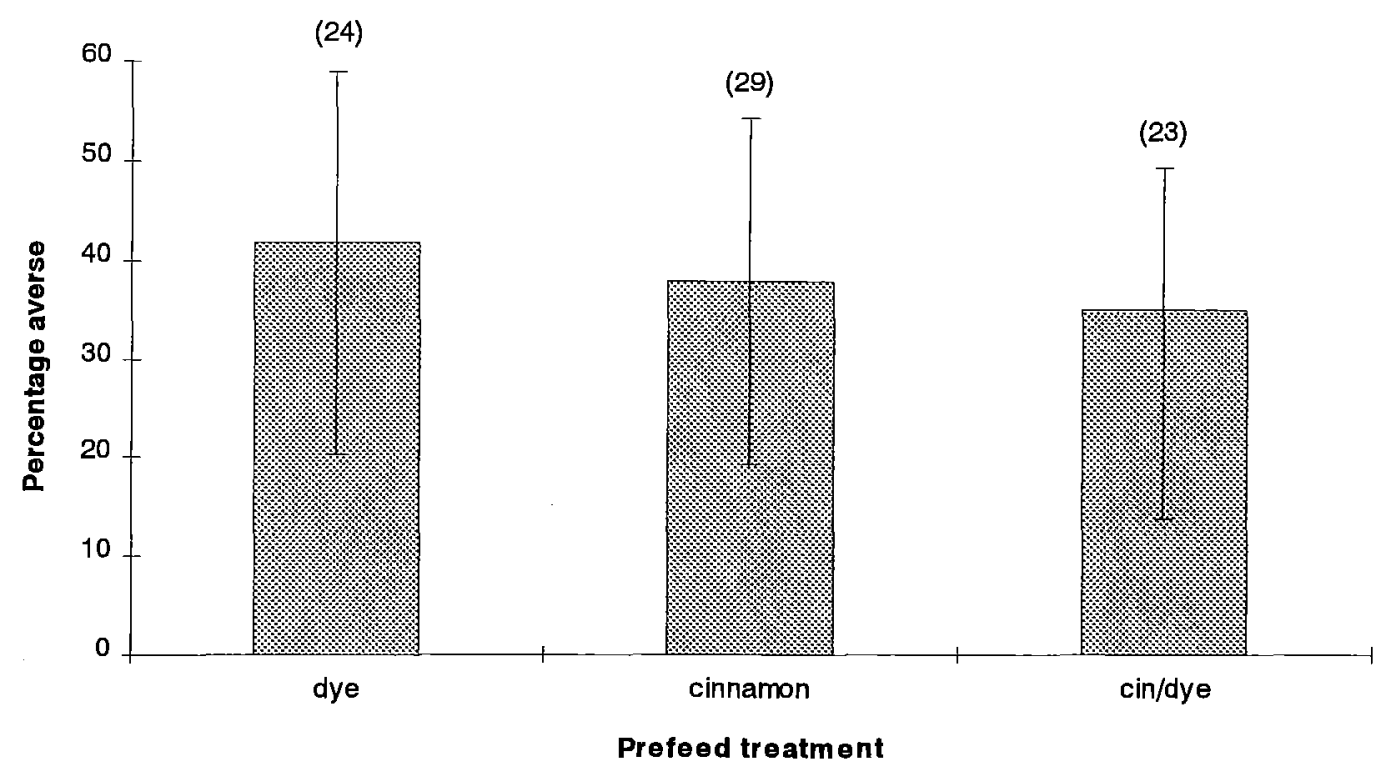

Figure 3.3. The effect of three cereal prefeed treatments on the percentage of possums developing aversions towards toxic cereal bait (containing dye, cinnamon and $0.08 \%$ 1080) with which possums had been previously sublethally poisoned. Error bars represent $95 \%$ binomial confidence limits; sample sizes in parentheses.

The duration of prefeeding that possums received had no overall significant effect on the subsequent development of aversion expressed towards toxic bait $\left(\chi^{2}=3.03\right.$, df $=1$, $\mathrm{p}=0.082$ ). However, there was some indication of a difference in levels of aversion between possums that received dyed pellets for a single day and those that received dyed pellets for seven consecutive days (Fig. 3.4). 


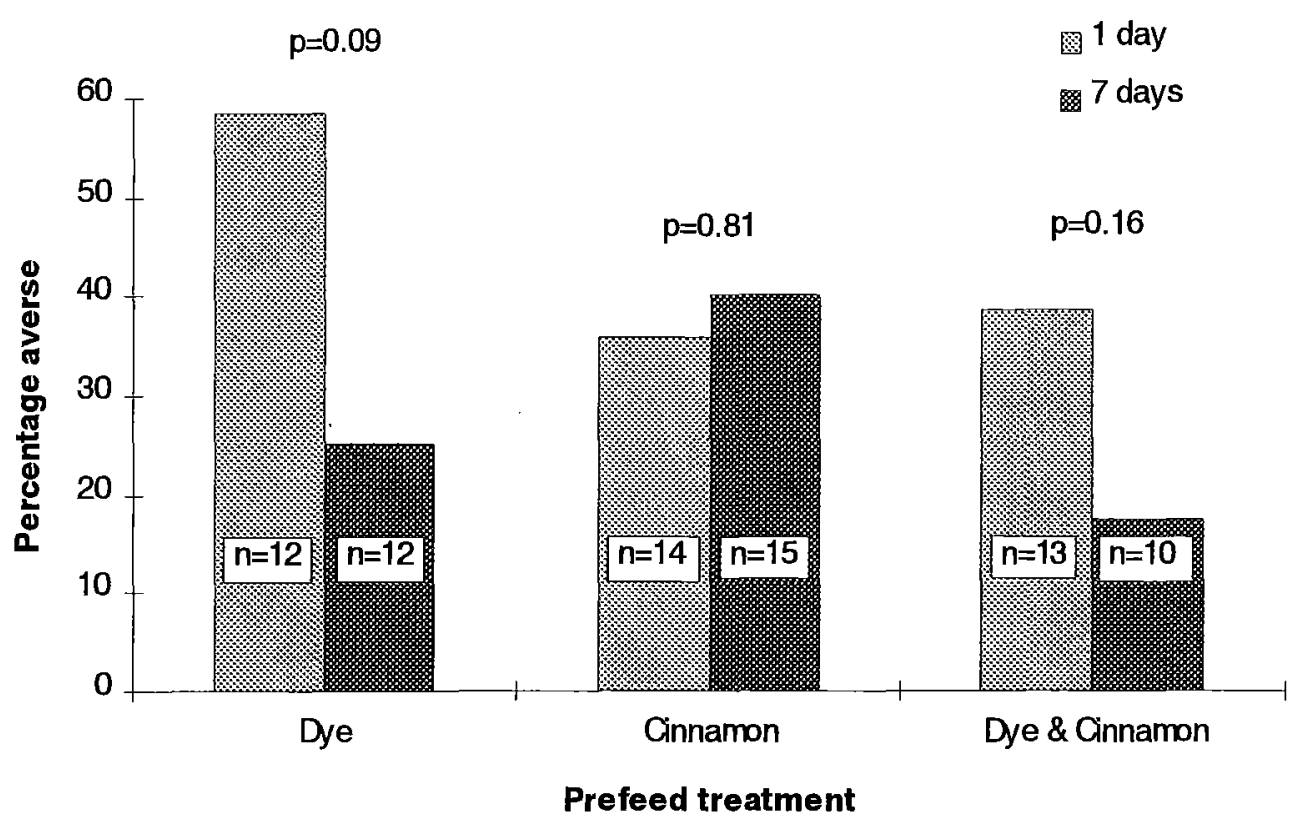

Figure 3.4. The effect of presenting possums with three prefeed treatments for one versus seven days on the development of aversion towards toxic cereal bait (containing dye, cinnamon and $0.08 \% 1080$ ) with which possums had been previously sublethally poisoned. P-values indicate outcomes of $\chi^{2}$ tests for goodness of fit.

Only one of seven possums prefed with dyed and lured baits, that became averse to the toxic bait, generalised this aversion to the non-toxic bait. On average $37 \%$ of possums averse to toxic bait generalised this aversion to the non-toxic bait. The type of prefeed that possums received did not significantly affect this proportion $\left(\chi^{2}=2.85 \mathrm{df}=2, \mathrm{p}=0.24\right)$, nor did the duration of prefeeding that possums had received $\left(\chi^{2}=0.05 \mathrm{df}=1, \mathrm{p}=0.82\right)$. 


\subsection{Discussion}

Although neophobic behaviour expressed towards prefeed was apparent in some individuals in this trial, neophobia was not as pronounced as in the first trial. However, possums again displayed marked differences in their perception of the palatability of the prefeed, with some individuals consuming all that was offered and others preferring the plain lucerne-based mash that they were provided. Once again several possums appeared to find the prefeed relatively unpalatable; initially consuming a relatively large amount and subsequently reducing their consumption (c.g. C8 \& D3, Table 3.1). Many of these animals subsequently avoided ingestion of the sub-lethal bait. The RS5 pellets that were used are considered more palatable than the "Wanganui \#7" cereal bait alternative (Ross et al. 1987; R. Henderson, pers. comm. 1996), so such behaviour may be even more prevalent when " $\# 7$ " baits are used. If animals displayed similar behaviour in the field, perhaps with prefeeding at a bait station, such animals may avoid subsequent consumption of toxic bait.

Behavioural symptoms of poisoning became apparent after a similar delay to that of the first trial. However, symptoms were not as widespread nor as severe as those observed in the previous trial. Despite possums being provided baits containing the

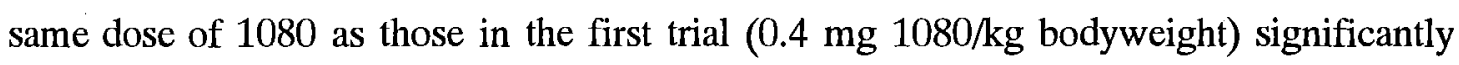
fewer died. The reason for this difference is unknown, but the result provides further evidence (in addition to Chapter 2, and Mcllroy, 1983) of the variability in the susceptibility of possums to 1080 .

In previous research, following an ingested sub-lethal dose of 1080 , over 60 percent of non-prefed possums subsequently expressed an aversion to the toxic bait (O'Connor and Matthews, 1996; Chapter 2). In contrast less than 35\% of prefed possums in this study developed an aversion to the toxic bait. This is in agreement with the results obtained for prefed possums in the first trial (Chapter 2) and is further indication of the importance of novelty in the development of an aversion. 
When a possum ingests a novel bait and suffers no ill effects it presumably learns that the bait (and associated cues) is safe (Kälat \& Rozin, 1973; section 1.4.5). Such learning apparently inhibits subsequent learning when the bait is paired with illness (e.g. sub-lethal 1080 poisoning). The more similar the pre-exposed bait is to the poisoned bait (i.e. the closer the cues) the less likelihood possums will develop an aversion (Chapter 2). Although anthropocentric, I perceived cinnamon lured baits to possess both a more distinctive taste and odour than the unlured dyed baits. Therefore, I predicted that possums prefed with cinnamon lured baits would have stronger taste and olfactory cues linking prefeed and toxic bait which would reduce their ability to associate malaise with the toxic bait. The results suggest that cinnamon does provide possums stronger cues than dye, with less exposures required before aversion development is inhibited (Fig. 3.4). This suggests that not only do taste and olfactory senses provide the strongest cues triggering aversion (e.g. rats; Rusiniak et al. 1982), but in possums they provide the strongest associative cues, linking prefeed and toxic baits. Whilst the dyed baits have a much greater visual similarity to the toxic bait, this cue does not appear to be as significant as the taste and olfactory cues provided by the cinnamon baits. However, dyed prefeed did reduce the apparent novelty of the toxic baits; perhaps through a combination of familiarization of the weaker taste and olfactory cues of the dye and bait base and the visual cues provided by the dye. None of these effects were strong however, so their relevance in the field remains uncertain.

Research on other species has shown that repeated exposures are required before animals are able to form CFAs to visual cues (e.g. Brett et al. 1976). However, if taste cues and visual cues are contiguously presented, taste may potentiate the visual cues to such an extent that animals subsequently avoid baits based on visual cues (e.g. Brett et al. 1976). Results in this trial suggest that the visual, olfactory and taste cues, provided by the green dye, are relatively weak associative cues for possums, compared to the cues provided by cinnamon. For this reason the relative benefits of incorporating the apparently weak taste, olfactory and visual cues provided by dye, in prefeed baits, may be outweighed by economic and practical difficulties provided the relatively strong associative cues of cinnamon are incorporated. 
Previous studies in other species have established that the more familiar a flavour or bait is the harder it will be to induce an aversion to it (Kalat \& Rozin, 1973; Mikulka and Klein, 1975). With some flavours or compounds a single pre-exposure results in the retardation of aversion development (e.g. coffee or vinegar; Siegel 1974), whereas with others several exposures may be necessary before it becomes familiar and subsequent aversion development is inhibited (e.g. sucrose; Fenwick et al. 1975). That a single pre-exposure to a bait containing cinnamon was sufficient to inhibit aversion development, and that a further six days of exposure did not enhance this inhibition, suggests that cinnamon provides strong cues that allows possums to readily associate 'safe' non-toxic and toxic baits (Fig. 3.4). Conversely, the apparent difference in the development of aversion with one and seven days pre-exposure suggests that dye does not provide as stronger cues as cinnamon, so that more experience of the non-toxic bait is required before it becomes familiar. However, this difference was again not statistically significant, perhaps due to sample sizes being inadequate.

Studies that have reported a decrease in aversion with increase in pre-exposure have seldom administered the conditioning compound in the flavour per se, usually choosing to pair the flavour with an intraperitoneal injection (e.g. Nachman \& Ashe, 1973). However, to make my results more applicable to the field situation I chose to provide sub-lethal doses in the baits themselves. Unfortunately this provides a difference between prefeed and toxic baits (i.e. the toxin) that may be perceptible for possums. Research suggests that cinnamon effectively ' masks' the presence of 1080, making it non-repellent to non-prefed possums (Morgan, 1990). However, if 'masked' 1080 remains perceptible, extended exposure to prefeed baits may enable possums to distinguish between prefeed and toxic baits. Such distinction would enable possums that consume a sub-lethal quantity of toxic bait to develop an aversion to the only novel factor in the toxic bait, the poison itself. This appeared to be the case as six of seven possums that received both cinnamon and dye in prefeed, and then exhibited aversion to the toxic bait, subsequently consumed non-toxic prefeed bait that differed from the toxic bait only in the 1080 that the latter contained. 
The study established trends in the role of cues in the limitation of possums' development of aversion that, whilst not statistically significant, are nonetheless encouraging. It appears that possums may only require a single exposure to prefeed with strong cues for subsequent development of aversion to be inhibited. Future research is needed to confirm this speculation, perhaps comparing one versus seven days of prefeeding with orange oil (a highly preferred flavour by possums; Morgan, 1990) and cinnamon, subsequently testing the acceptance of the alternative flavour by averse animals (c.f. Morgan et al. 1996, O'Connor and Matthews, 1996).

The importance of determining whether a single pre-exposure can be sufficient to inhibit aversion development is that a single prefeed application before dropping poison may increase the efficacy of aerial poisoning operations. Such prefeeding may decrease the development of aversions in two ways. Firstly, it may increase the consumption of toxic bait through reduced neophobia (Fraser and Knightbridge, 1995). Secondly, those possums that do ingest a sub-lethal quantity of poison will be less likely to relate the malaise they experience with the toxic bait, and thus more likely to remain 'at risk' when next exposed to poison.

There has been some doubt expressed about cage trials' applicability to the field (pers. obs.). Therefore, research was needed to validate results obtained in the cage trials, in a field situation; this research is addressed in Chapter 4. 


\section{Chapter 4}

\section{Influence of prefeeding at bait stations on the development of}

\section{bait aversions in free-ranging brushtail possums ${ }^{*}$}

\subsection{Introduction}

The previous trials (Chapters $2 \& 3$ ) showed that novelty and bait 'cues' both had a significant influence on possums' development of aversions. Non-prefed possums tend to develop generalised aversions and avoid both toxic and non-toxic bait. In contrast, prefeeding familiarizes possums with the bait base, enabling them to identify individual components when subsequently exposed to other types of bait. If they associate bait components with 'safe' prefeed they will accept the bait, whereas if they associate components with poisoning they will reject it. Bait components can therefore act either as 'familiar' (and therefore safe) cues or as 'aversive' cues.

In the following experiment $\mathrm{I}$ aimed to validate results obtained in the cage trials (Chapters 2 \& 3) in a field situation, showing that non-prefed possums develop generalised aversions, whereas prefed possums' aversions are more specific. In addition, I aimed to further examine whether prefed or non-prefed possums preferentially associate certain cues with poisoning, and use these cues to maintain their aversions. Results of the second trial suggested that prefed possums are able to detect 1080 in a bait, despite the presence of cinnamon. Previously the use of cinnamon as a 'mask' has been interpreted as making 1080 undetectable (cf. Morgan, 1990), therefore clarification of this point will establish possums' ability to develop poison aversion per se. If poison detection is identified future research may need to develop alternative 'masking' agents.

The second cage trial also suggested that taste and/or olfactory senses provide possums with distinctive 'associative' cues, linking prefeed and toxic baits. Baits that I judged to possess strong taste and olfactory cues required fewer exposures before becoming 
familiar than baits that possessed less strong taste and olfactory cues, but strong visual cues. Research in rats indicates that they most easily associate taste cues with malaise, and have difficulty forming aversions to either olfactory or visual cues, if they alone are paired with malaise (Garcia, 1989). However, if taste cues are paired with olfactory and/or visual cues at aversion induction, either cue will subsequently maintain aversion when tested separately, an effect termed 'taste potentiation' (Garcia, 1989). Research is needed to verify the relative strength as 'aversive' cues of gustatory (taste), olfactory and visual senses in possums.

Prefeeding may influence the potentiation of olfactory and visual cues, because possums become familiar with those cues of the non-toxic bait. For example, familiarity of cinnamon, which seems a salient olfactory cue (Chapter 3), may inhibit development of aversion to a subtly different ' complex' olfactory cue (e.g. cinnamon, dye and 1080), or weaker individual olfactory cue (e.g. dye or 1080). If this is the case then prefed possums may have to rely on taste cues to maintain aversions (i.e. they will 'sample' baits before rejection). In contrast, cinnamon in the sub-lethal toxic bait presumably provides olfactory cues for non-prefed possums that are both salient and novel. When the bait is tasted, gustatory, olfactory and visual cues are linked, which may cause potentiation of cinnamon's salient olfactory cues to an extent that subsequently allows maintenance of aversion when a cinnamon lured bait is next encountered. The same potentiation process may also occur with a baits' visual cues; perhaps allowing non-prefed possums, for whom a baits' visual cues are novel and therefore salient (Kalat, 1974), to make the decision to avoid a bait based solely on its appearance.

With this in mind, the field trial was designed to verify the results of the previous cage trials in a field situation and also to address the influence of cues on the association of toxicosis. With two treatment groups, prefed and non-prefed, and concurrent presentation of 4 different bait types I aimed to establish which cues prefed possums recognise as familiar and which cues both prefed and non-prefed possums associate with poisoning. I also aimed to clarify possums' ability to detect 1080 in a bait, despite the presence of a cinnamon 'mask'. 


\subsection{Methods}

The field trial was undertaken at Waiake forest, a 300 ha pine (Pinus radiata), plantation located near Gebbies Pass, Banks Peninsula, Canterbury. The plantation consists of 75\% 12-year-old pines and 25\% 2-year-old pines and has never been subjected to 1080 or cyanide poisoning (R. Miller, pers. comm. 1997). Possums at this site denned in piles of pruned branches under the older trees and foraged on adjacent pasture and grasses under the younger pines (pers. obs.).

In early June, 1997 ten 'Coontrol' bait stations (Possum Control Products, Christchurch) were located along one edge of the plantation, at intervals of greater than $200 \mathrm{~m}$ to minimise the number of possums that would move between them. Each station was filled with approximately $1 \mathrm{~kg}$ of non-toxic ' RS5' cereal baits (Animal Control Products, Waimate) containing $0.1 \%$ cinnamon oil as a lure. After 10 days prefeeding, the station receiving most use was selected for further study and the other stations were removed. A board that had eight $10 \mathrm{~mm}$ holes drilled along the top edge, at $120 \mathrm{~mm}$ spacing, was attached under the remaining bait station, approximately $30 \mathrm{~cm}$ above the ground (Plate 4.1). Additional prefeed baits were inserted in the holes and apples were placed on the ground at the base of the station.

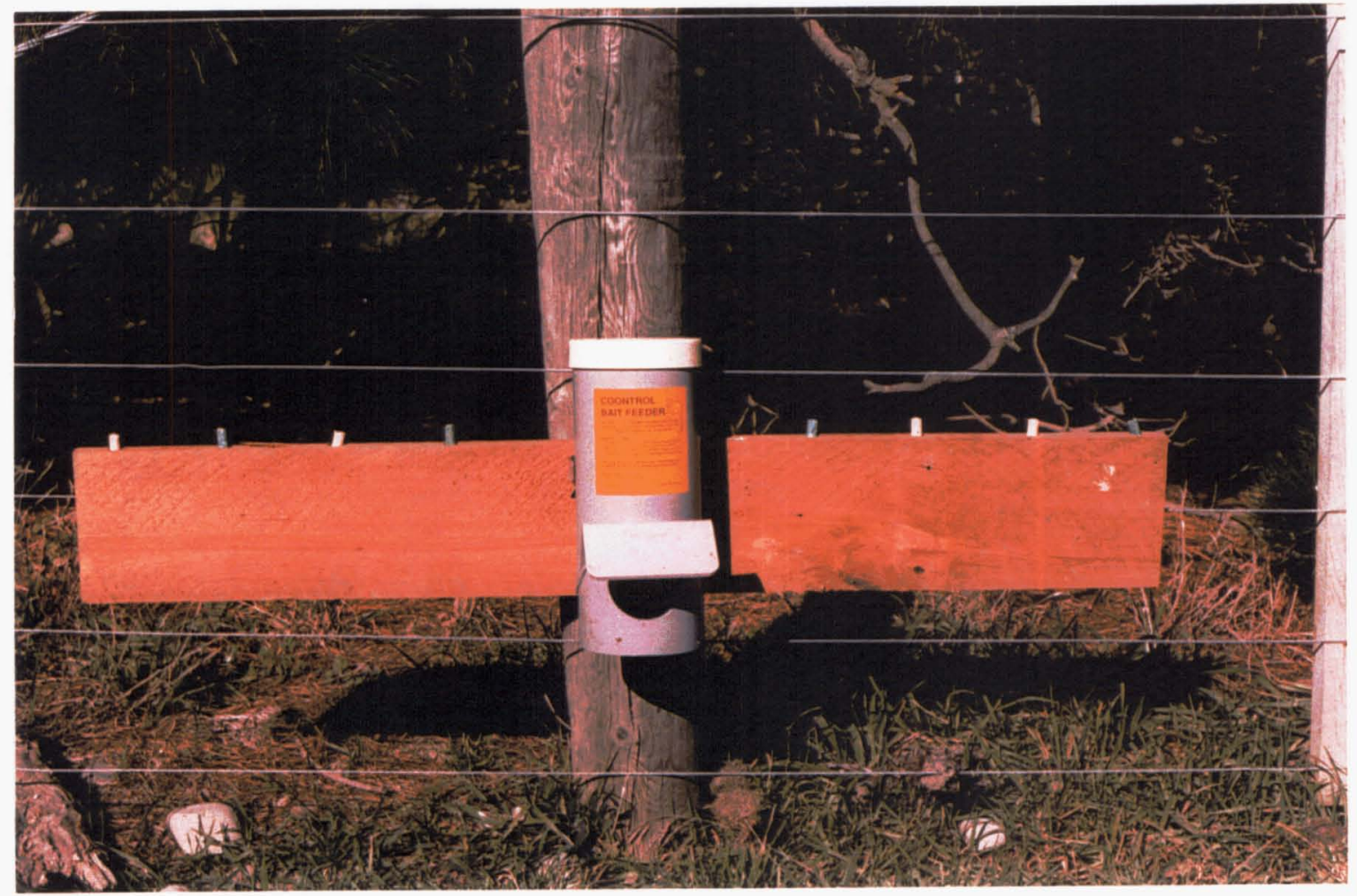

Plate 4.1 Location of bait station and presentation of test baits. 
Prefeeding with cereal bait ceased after three weeks; I then continued to feed apples nearby to ensure possums continued to frequent the bait station. Possums were livetrapped using cage-traps (Grieve Wireworks, Christchurch). Traps were lured with a portion of apple attached to the triggering mechanism. To avoid inducing 'place aversion' (Garcia and Koelling, 1967) cages were located at least 50m from bait stations.

On each night that cage-traps were set, a single standard toxic ' RS5' bait containing $0.1 \%$ cinnamon oil, green dye and $1080(0.08 \%)$ was placed inside an open plastic container (these were used to discourage possums from entering, consuming the bait, and then exiting without triggering the trap; Plate 4.2). Average possum bodyweight was predicted to be approximately $2.5-3.0 \mathrm{~kg}$, therefore baits of $2.5 \mathrm{~g}$ were used to supply each possum with a 1080 dose of approximately $0.8 \mathrm{mg} \mathrm{kg}^{-1}$ (cf. Morgan et al. 1996). A tray was placed in the back half of the cage to prevent possums dropping pellets through the grate. Pellets and pellet fragments remaining after capture and release were weighed to calculate the individual dose of toxin consumed.

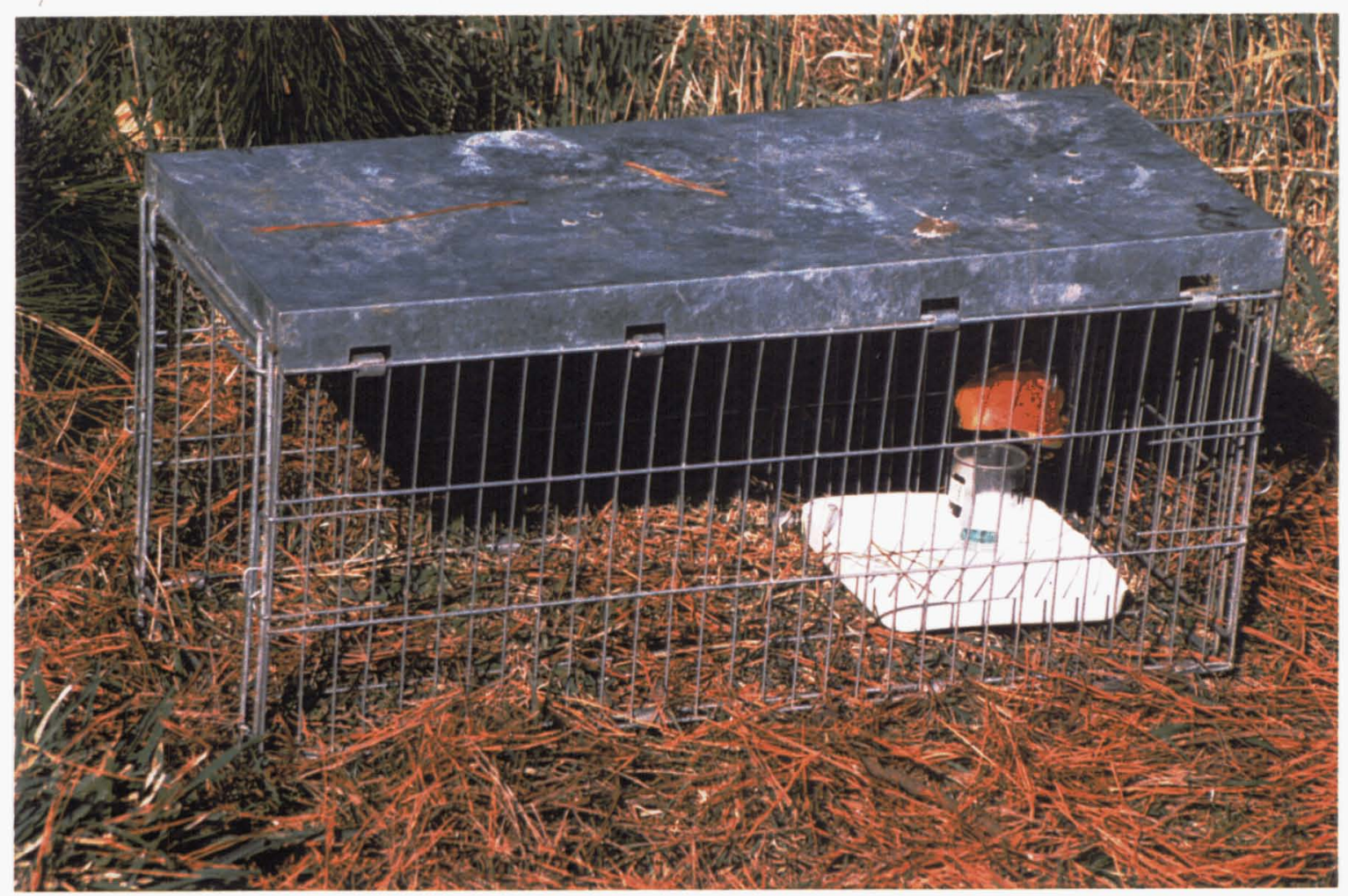

Plate 4.2 Baited cage-trap showing presentation of 'sub-lethal' bait.

Captured possums were weighed, sexed and classified as mature or immature (based on visual inspection of pouch or testes). Possums were then ear tagged using either white or blue 3-cm 'Allflex ${ }^{\mathrm{R}}$ ' ear tags (Allflex New Zealand Ltd., Palmerston North), 
cut into different shapes so that each possum had a unique shape/colour/ear combination that allowed visual differentiation through low-light video and night vision equipment (Plate 4.3; Appendix 4.1).

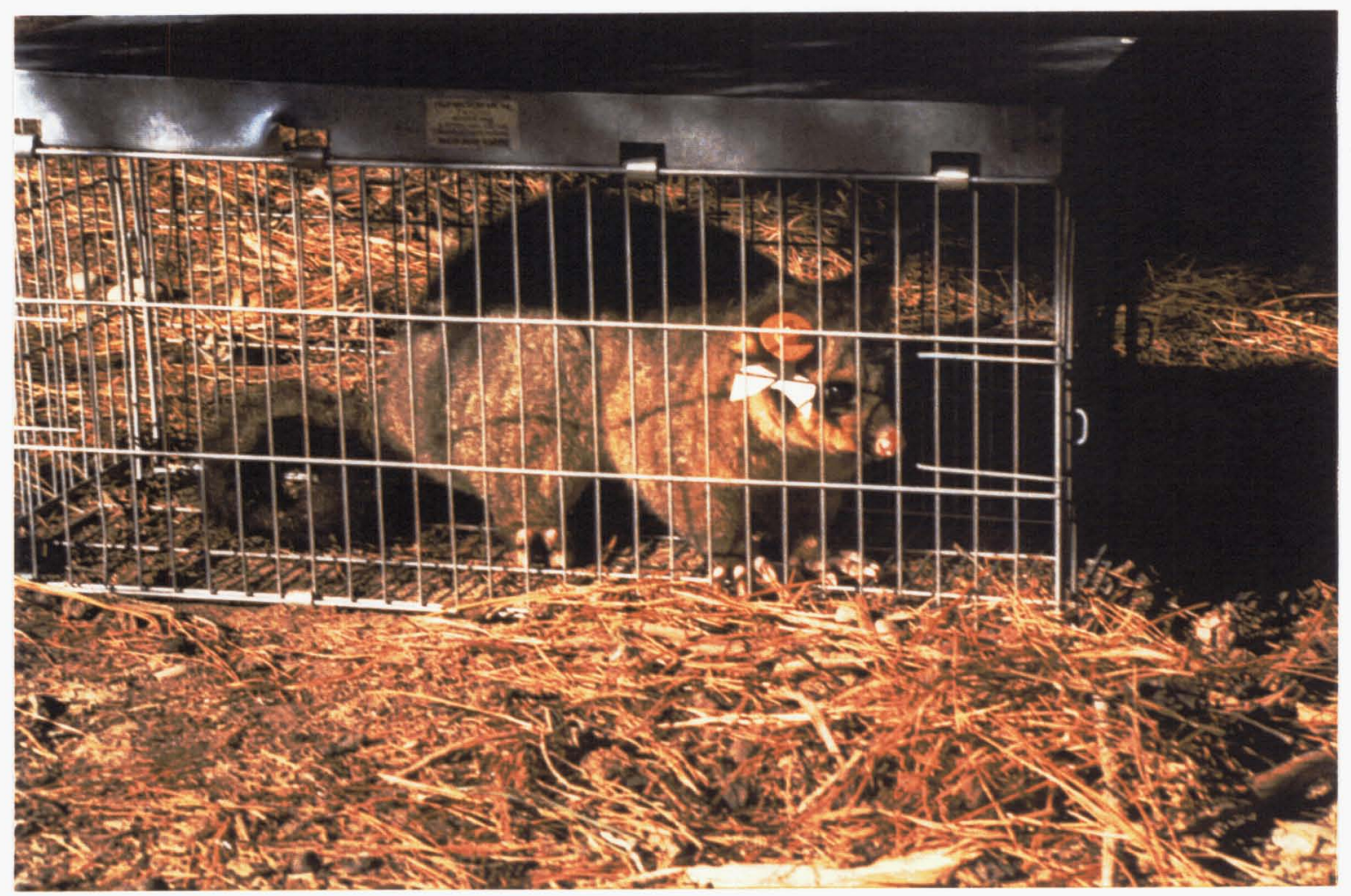

Plate 4.3 Possum displaying tag that enabled individual identification.

After three consecutive evenings of trapping, two non-toxic non-dyed prefeed baits, two non-toxic green-dyed baits, two toxic non-dyed baits, and two toxic green-dyed baits were presented simultaneously on the board attached to the bait station (Fig. 4.1). All baits contained $0.1 \%$ cinnamon oil and were placed in holes drilled in the board (Plate 4.1). One bait of each type was presented either side of the station, with the order of baits randomised (Plate 4.1).

Possums were observed at bait stations using night vision ('Moonlight') and low light video equipment (Bische). Possums' consumption of different baits was recorded, and if possums rejected a bait (i.e. ate less than $1 \mathrm{~g}$ ) the method (i.e. visual/olfactory vs. gustutory) by which it was rejected was also recorded (it was not possible to distinguish between possums' visual and olfactory assessment of baits). The time that possums spent assessing baits was also recorded.

A second treatment procedure was conducted, on the other side of the plantation (over a kilometre away). There, possums were attracted to apples rather than bait stations, 
and were therefore considered 'non-prefed' (Fig. 4.1). Six different locations were initially selected, although after 10 days only the site with greatest use was retained. Approximately 40 apples were placed at the site, with additional apples added when necessary to ensure a continuous supply. A board that had holes drilled along its' top edge in the same manner as that of the bait station (Plate 4.1) was attached at the 'apple station'. Portions of apples were placed in the holes to ensure possums became familiar with the subsequent testing procedure.

Treatment Group

Prefeed

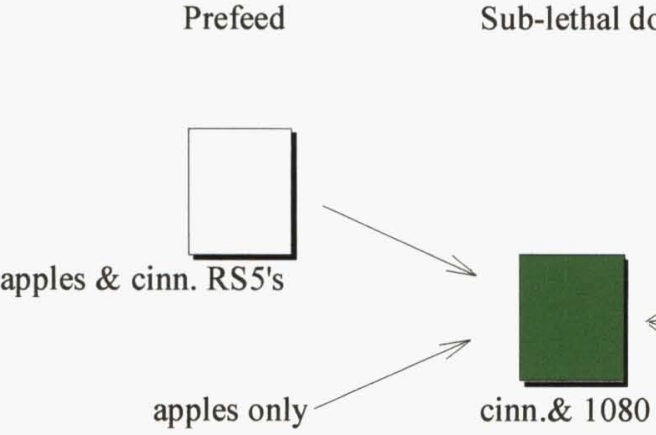

Aversion Testing
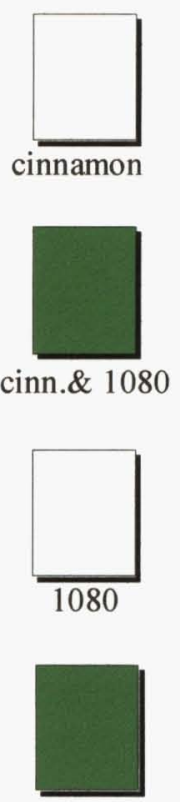

Figure 4.1 Experimental design for the field trial. Shading denotes the presence of dye.

As with the bait station group, after three weeks possums were live-trapped, weighed, sexed and classified as mature or immature. Baits were presented and observations recorded as for the other group (Appendix 4.1).

Two-tailed, homoscedastic, students' t-tests were used to compare mean group bodyweight and sub-lethal dose and the time before 'sampling' a bait for naive versus prefed inidividuals. Pearson's chi-square $\left(\chi^{2}\right)$ statistics (Sokal and Rohlf, 1981) were calculated to test the goodness of fit of the observed frequency distribution of aversion to the expected frequency distribution representing no difference between treatments. 


\subsection{Results}

There was no significant difference in average body-weight of the two treatment groups, (prefed $3.06 \mathrm{~kg}$, non-prefed $3.15 \mathrm{~kg}$; p=0.74). Similarly, there was no significant difference between the average dose of 1080 ingested (prefed $0.73 \mathrm{mg}$ $1080 \mathrm{~kg}^{-1}$, non-prefed $0.69 \mathrm{mg} 1080 \mathrm{~kg}^{-1} ; \mathrm{p}=0.64$ ) during sub-lethal dosing. Of the 30 possums that consumed a 'sub-lethal' dose of 1080 , two were known to have died after ingesting doses of between 0.7 and $0.8 \mathrm{mg} 1080 \mathrm{~kg}^{-1}$. In contrast, three animals were known to have survived doses greater than $1.25 \mathrm{mg} 1080 \mathrm{~kg}^{-1}$. Due to the design of the trial, overall mortality rates could not be determined.

Aversion development was significantly different between prefed and non-prefed treatments, with a greater proportion of non-prefed possums than prefed possums exhibiting aversion to plain baits $\left(\mathrm{p}<0.001 ; \chi^{2}=11.82, \mathrm{df}=1\right.$; Fig. 4.2.). This difference arose because prefed possums were able to distinguish between baits containing dye and/or 1080 from plain bait; and were significantly more likely to be averse to the former $\left(85 \% ; \mathrm{p}=0.0001, \chi^{2}=15.4, \mathrm{df}=1\right)$ than to the latter $(11 \%)$. In contrast, nonprefed possums did not distinguish between the baits, with no difference in aversion levels between plain $(90 \%)$ and the other bait types $\left(85 \% ; \mathrm{p}=0.68, \chi^{2}=0.17, \mathrm{df}=1\right)$. Both prefed and non-prefed possums expressed aversion towards dyed 1080 bait that was not significantly different from that expressed towards either dyed bait $(\mathrm{p}=1.0$, $\chi^{2}=0.00, \mathrm{df}=1 ; \mathrm{p}=0.6, \chi^{2}=0.24, \mathrm{df}=1$; respectively) or non-dyed 1080 bait $(\mathrm{p}=0.60$, $\chi^{2}=0.28, \mathrm{df}=1 ; \mathrm{p}=0.65, \chi^{2}=0.21, \mathrm{df}=1$, respectively). 


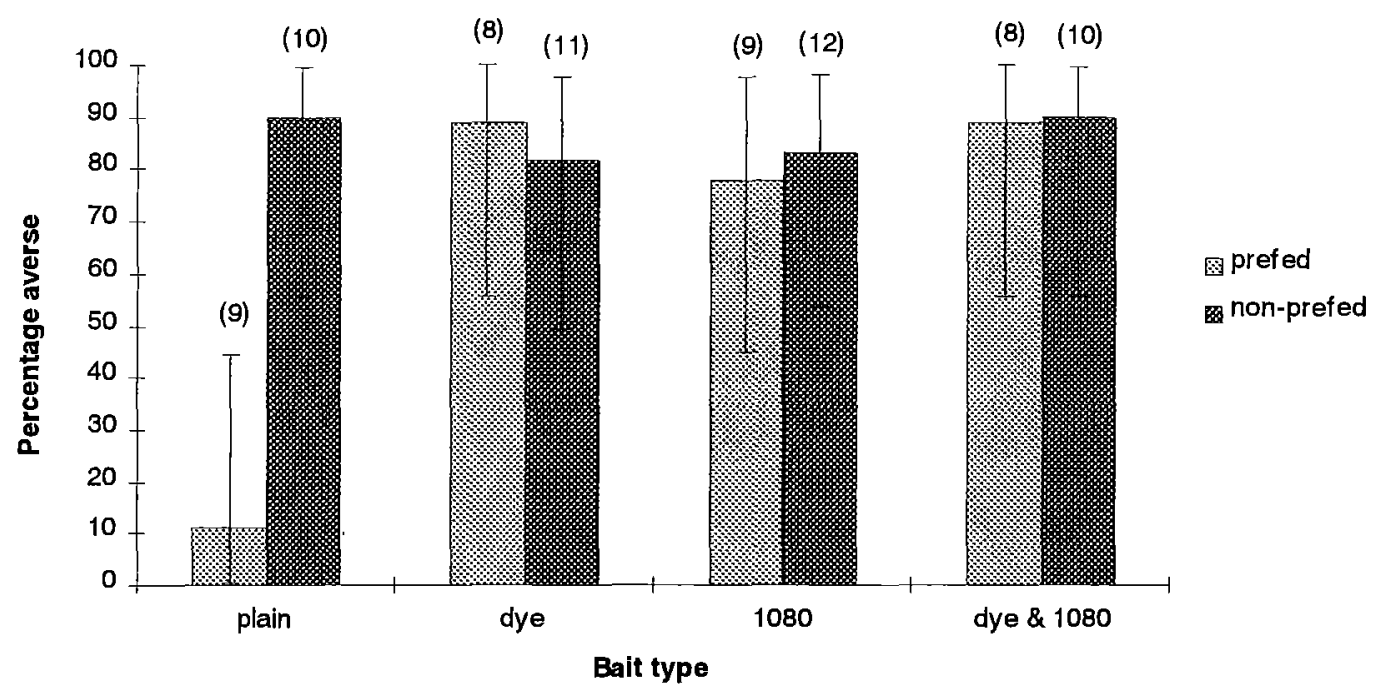

Figure 4.2. The effect of prefeeding on aversion specificity. All baits contained $0.1 \%$ cinnamon wt/wt Error bars represent $95 \%$ binomial confidence limits; sample sizes in parenthesis.

The proportion of baits rejected with different senses appeared to vary between treatments. Of the 38 baits rejected by non-prefed possums, only two (5\%) were tasted, whereas $19 \%$ of the 21 baits rejected by prefed possums were tasted. The difference was non-significant $(\mathrm{p}=0.06)$, with small sample sizes.

Five non sub-lethally poisoned possums were also observed, which consumed all baits encountered, with the exception of one that 'tasted' (ate $<1 \mathrm{~g}$ ) a dyed toxic bait and then dropped it; indicating that the baits presented were generally palatable.

\subsection{Discussion}

The susceptibility of individual possums to 1080 is clearly highly variable (Mcllroy, 1983; Chapters $2 \& 3$ ). The present trial involved relatively few possums (30), but the results provide further indication of this variability in tolerance; three animals survived doses of over $1.25 \mathrm{mg} 1080 \mathrm{~kg}^{-1}$, whilst the two known to have died each consumed less than $0.8 \mathrm{mg} \mathrm{kg}^{-1}$.

Previous trials have established that after a single sub-lethal ingestion of 1080, naive possums become averse to the bait with which they were poisoned and not only avoid 
that particular bait, but also specific components such as lure and bait base (e.g. O'Connor and Matthews, 1996; Chapter 2). This is confirmed in the field by the current trial, in which non-prefed possums developed an aversion to the toxic bait and also generalized the aversion to the non-toxic cereal bait matrix, so that they avoided all cereal baits encountered.

In contrast, most of the possums that were prefed cinnamon lured pellets became averse to the toxic bait but did not generalise their aversion to include the cereal bait matrix; these possums continued to consume prefed pellets. However, prefed possums exhibited the same level of aversion to cinnamon lured baits containing dye and/or 1080 (as did non-prefed possums). This demonstrates that prefed possums are able to detect both dye and 1080 in a cinnamon lured bait, and use this detection to maintain their aversion (Fig. 4.2). Such discernment in aversion is further evidence of the importance of a cue's novelty (cf. Chapters 2 \& 3). Both dye and 1080 were novel when encountered in the bait with which possums were sub-lethally poisoned. As with rats (Kalat \& Rozin, 1973), it is clear that possums associate any novel factor that they can distinguish in the toxic bait with poisoning, and so subsequently avoid any bait in which they recognise such factors.

Previously the addition of $0.1 \%$ cinnamon $w t / w t$ in baits has been interpreted as making 1080 ' undetectable'. This is clearly not the case and detection of 1080 by prefed possums may enable them to develop poison aversion per se, perhaps avoiding any 1080 poisoned bait, irrespective of bait base or lure used (cf. Morgan et al. 1996). However, future research is needed to examine this effect; perhaps also addressing alternative ' masking' agents.

One unanticipated result was the level of aversion expressed by prefed possums towards baits other than those they had been prefed with. In the first trial (Chapter 2) only $21 \%$ of possums that had been prefed with non lured RS5's exhibited aversion to dyed and lured toxic baits on first re-exposure. In contrast, in the current trial over $80 \%$ of prefed possums exhibited aversion to dyed and lured toxic baits, which is a significantly higher proportion $\left(\chi^{2}=11.7, \mathrm{p}<0.001\right.$, df $\left.=1\right)$. This difference is even 
more surprising given the prefeed baits of the current trial had the additional cue of cinnamon in common with the other baits, which should have decreased the proportion of possums able to distinguish between baits when sub-lethally poisoned (cf. Chapters $2 \& 3$ ). One possible explanation for this behaviour is the length of time possums were exposed to the non-toxic baits. Possums of the cage trials had a maximum of seven half-hour periods of access to $30 \mathrm{~g}$ of bait, whereas those of the field trial had three weeks of ad libitum access. Greater exposure may have increased familiarity to an extent where a greater number of possums were able to identify novel factors in the toxic bait when sub-lethally poisoned. Additional research is needed to investigate the relationship between similarity of prefeed and toxic baits, and the optimal duration of prefeed exposure to inhibit aversion development (cf. Chapters 3 \& 5).

Another factor that may have contributed to the apparent difference in behaviour is the dose of 1080 with which aversions were induced. Other studies of CFAs in possums report a dose-dependent effect, with levels of aversion acquired proportional to the dose of toxin administered (O'Connor and Matthews, 1995; Morgan et al. 1996). Prefed possums of the current trial received an average dose of $0.73 \mathrm{mg} 1080$ $\mathrm{kg}^{-1}$, which was nearly twice the $0.4 \mathrm{mg} 1080 \mathrm{~kg}^{-1}$ dose used in the cage trials. A high dose may provide greater 'incentive' for possums to develop an aversion, perhaps increasing its generality (cf. O'Connor and Matthews, 1995). In combination, both greater familiarity and greater 'incentive' may have resulted in prefed possums of the current trial developing a higher level of aversion.

When planning the trial I predicted that the proportion of possums using taste as the basis of their aversion would be higher from prefed than non-prefed possums. I reasoned that the RS5 baits' general appearance (visual cues; except dye), and cinnamon (a salient olfactory cue; Chapter 3) would be familiar and perceived as 'safe' by prefed possums. Therefore, if visual cues are to maintain their aversions, prefed possums would have to distinguish the colour of dye, from the familiar general appearance of the bait. In contrast, non-prefed would find the entire bait novel and could therefore use the baits' general appearance to maintain their aversion. Similarly, if olfactory cues are to maintain their aversions, prefed possums would have to distinguish either the individual smell of dye, or 
1080, from the complex and salient odours of the familiar cinnamon lured bait base. In contrast, non-prefed possums can use the entire baits' complex odour as an olfactory cue.

There was a trend for a greater proportion of prefed than non-prefed possums, to use taste as the basis of their aversion; however, the sample sizes were small and the difference was not statistically significant. Only $5 \%$ of baits that were rejected by nonprefed possums were tasted. This indicates that, as in rats (e.g. Garcia, 1989), when visual and olfactory cues are paired taste, before the onset of malaise, they can subsequently be used to maintain aversion. Similarly, less than $20 \%$ of baits rejected by prefed possums were tasted, despite their familiarity with the prefed baits' visual and olfactory cues, which is further indication that both dye and 1080 provide relatively salient visual and/or olfactory cues.

It appears that both dye and 1080 individually provide strong 'aversive' cues, compared to the relative strength of dye as a 'familiar' cue (Chapter 3 ). However, the current trial did not enable distinction between the strength of visual and olfactory cues provided by individual bait components. Whilst in combination they appear strong, singularly some cues may have a greater influence on possums' aversion and therefore have greater potential for manipulation. Research is needed that addresses the strength of aversions developed to individual bait components. For example, if prefed possums become averse to the dye component of a toxic bait (as well as the 1080) they may subsequently avoid other dyed baits, irrespective of bait base or lure used (cf. Morgan et al. 1996).

Research is also needed to further elucidate the influence of prefeeding on potentiation of non-taste cues. For example, appropriate prefeeding may necessitate a possum tasting a bait before rejection. Such tasting may facilitate aversion extinction when it is not paired with malaise (cf. O'Connor and Matthews, 1997). This may be advantageous when chronic toxins such as brodifacoum are used for 'follow-up' control (Henderson et al. 1997), with animals gradually increasing consumption until a lethal dose is consumed. 


\section{Chapter 5}

\section{General Discussion}

Conditioned food aversions have been extensively studied in rodents; particularly laboratory rats (see Prakash, 1988 for a review). In contrast, there have been less than a dozen studies describing the behaviour in brushtail possums; a behaviour that manifests itself as 'bait shyness' induced through consumption of a sub-lethal quantity of toxic bait encountered during pest control operations. The relatively limited previous research on CFAs in possums is perhaps not surprising as New Zealand is the only country in which possums are considered a major pest species and therefore the only country in which bait shyness has become evident. However, bait shyness is now one of the principal threats to sustained vertebrate pest management in New Zealand (Hickling, 1995).

One of the most salient aspects of CFA research is its similarity across a diverse range of species. When research of this thesis was initiated I hypothesised that 'bait shyness' behaviour in possums would conform to behavioural characteristics described in CFA's of other species. Results obtained for the behavioural parameters that were tested generally supported this prediction; as shown by the influence of novelty and familiarity (Chapters $2,3 \& 4$ ) and distinction and influence of 'cues' (Chapters $3 \& 4$ ) on aversion development.

\subsection{Possums' resistance to poisoning}

The following section outlines characteristics of possums' behaviour identified in my research that influence their susceptibility to poisoning. It also highlights areas where future research may provide additional insights into possums' behaviour that could be utilised in their management. 


\subsubsection{Physiological resistance}

Physiological resistance refers to poisoning-induced metabolic strategies that enable animals to tolerate or detoxify toxins that they have consumed (Chapter 1). Estimates of New Zealand possum populations' tolerance of fluoroacetate have been quite variable (e.g. McIlroy, 1983), although intrinsic variability may have been overstated through comparison of tolerance estimates obtained with varying experimental procedures (McIlroy, 1994).

Results of my research provide further evidence for the occurrence of variability in 1080 tolerance within New Zealand possum populations. The same experimental protocol was used when 'sub-lethally' dosing possums in the first and second cage trials; including 1080 dose $\left(0.4 \mathrm{mg} \mathrm{kg}^{-1}\right)$, time of day (10:00 am), and temperature $\left(20^{\circ} \pm 5^{\circ} \mathrm{C}\right)$. However, there was significantly higher mortality of possums in the first trial $(16.5 \%)$, compared to the second $(2.6 \%)$. Whilst these mortality figures are within the variable findings reported using different experimental protocol (Bell, 1972); considered comparatively they indicate significant population variability.

Although the field trial involved relatively few possums, those results were also indicative of variability in tolerance. Three animals survived doses of over $1.25 \mathrm{mg} \mathrm{kg}^{-1}$, whilst two others died consuming less than $0.8 \mathrm{mg} \mathrm{kg}^{-1}$ (Chapter 4).

\subsubsection{Non-learned behavioural resistance}

Non-learned behavioural resistance describes behavioural traits that are genetically determined (O'Connor and Matthews, 1996) that can reduce an animal's tendency to consume a lethal dose of toxic bait (Brunton et al. 1993).

\section{Neophobia}

Possums are not thought to be a very neophobic species (e.g. Morgan, 1990); indeed some display rather inquisitive behaviour towards novel objects (pers. obs.). However, in contrast to their inquisitive investigatory behaviour, feeding behaviour does indicate some neophobic influence (O'Connor and Matthews, 1996). Prefeeding 
data from the cage trials support this conclusion. In the cage trials, many possums had low consumption of prefeed pellets when they first encountered them. This indicates that they were tentative when confronted with the novel food (i.e. neophobic).

\section{Innate poison avoidance}

Morgan (1990) established that possums are able to detect 1080 in both carrot and cereal baits at concentrations $>0.13 \% \mathrm{wt} / \mathrm{wt}$. However, Morgan also found that by adding $0.1 \% \mathrm{wt} / \mathrm{wt}$ cinnamon possums consumed the same amount of toxic and nontoxic baits and so concluded that cinnamon 'masked' the presence of 1080 , making it 'non-aversive' to possums.

My results differ, with some prefed possums in the cage trials, and many in the field trial, being able to detect 1080 despite the 'masking' effect of $0.1 \% \mathrm{wt} / \mathrm{wt}$ cinnamon. This difference in result may be a consequence of Morgan testing palatability rather than perception per se. Morgan's naive (non-prefed) animals would have found all baits to possess salient flavours, however one that contained a chemical that smelt slightly bitter (as 1080 is thought to; Rammell \& Fleming, 1978), may have been somewhat aversive. If that bitter smell was attenuated by a more palatable flavour (addition of cinnamon to plain barley increased consumption; Morgan, same trial) the chemical may be no longer aversive; but that is not to say it is no longer detectable.

The important distinction between the trials is that I was testing for the maintenance of an aversion (evolved to prevent potentially lethal consumption). Possums in my trials had a strong incentive to detect the toxin and thereby avoid the bait. In contrast, Morgan's animals did not associate the perception of toxin with malaise; their bait avoidance was based on a palatability perception, a much lower incentive.

If, as it seems, possums can detect 1080, research is needed to establish whether they use this detection as the basis of aversion to alternative baits (cf. Morgan et al. 1996; O'Connor and Matthews, 1996). This research could be achieved by sub-lethally poisoning prefed and non-prefed possums with a cereal pellet, verifying that they are averse to that pellet, and then testing their acceptance of toxic and non-toxic carrot baits. 
Cinnamon lure is currently added at $0.1 \% \mathrm{wt} / \mathrm{wt}$ because of its perceived masking effect and because it is thought to repel birds (Udy \& Pracy, 1981). However, recent trials have generated some doubt as to the effectiveness of $0.1 \%$ cinnamon as a bird repellent (Spurr, 1993; Hickling, 1997). Bait palatability trials by Ross et al. (1987) suggested that there was no difference in palatability of baits that contained $0.1 \%$, $0.3 \%$, or $1.0 \%$ cinnamon wt/wt, but similar trials by Henderson (unpublished data) found that palatability decreased at cinnamon concentrations above $0.5 \% \mathrm{wt} / \mathrm{wt}$. Additional research is needed to clarify cinnamon's influence on bait palatability. Such research could also address the 1080 'masking' effect of cinnamon at different concentrations, and cinnamon's effectiveness as a bird deterrent at higher concentrations. If prefed possums can detect 1080 'masked' with $0.1 \% \mathrm{wt} / \mathrm{wt}$ cinnamon (Chapters $3 \& 4$ ), and that concentration is only partially effective repelling birds (Spurr, 1993; Hickling, 1997) an increased cinnamon concentration might prove more effective as both a mask and bird repellent as long as it had no major affect on bait palatability for possums.

\section{Innate bait avoidance}

Possums may reject bait for reasons other than detection of 1080. Bait palatability has been shown to be influenced by moisture and age (Henderson, 1996) with damp and/or old baits being less palatable. However, in the cage trials, despite use of fresh baits in good condition, many possums chose not to consume them, and instead preferred their basal diet of lucerne-based mash. This indicates a difference in perception of palatability between possums; a perception that several possums extended to the toxic bait, subsequently avoiding ingestion of the sub-lethal bait.

Research on cereal bait palatability has established that the 'RS5' baits used in these trials (Animal Control Products, Waimate) are the most palatable currently available (Ross et al. 1987; R. Henderson, unpublished data). If less palatable cereal alternatives had been used the proportion of possums exhibiting such behaviour presumably would have been higher, resulting in a greater number avoiding ingestion of toxic bait. To minimise this behaviour in the field baits must be in good condition (Henderson, 1996), and control should not coincide with seasonally available alternative food that may be preferable. 
In itself, non-learned behavioural resistance may not appear to be of practical significance in possum control operations. However, the combination of the 'cautious feeding' strategy that some possums exhibit and poison and/or bait avoidance apparent in others, may all contribute to a proportion of possums either completely avoiding toxic baits, or only consuming a sub-lethal quantity (Hickling, 1994). These behaviours may become more prevalent when baits are less palatable, such as if they become damp (Henderson, 1996) and in such circumstances may significantly influence the efficacy of the operation; and subsequent operations through induction of learned aversions (section 5.1.3).

The most effective way to limit the development of bait aversion in possums is to minimise the number that ingest a sub-lethal quantity of bait; or maximise the number consuming a lethal dose, the actual objective of the operation (Morgan et al. 1986).

The most important factor governing the proportion of possums that consume a lethal dose is likely to be the palatability of bait they encounter, relative to other food available. 'RS5' baits were originally developed as a wallaby bait, and whilst field tests were conducted confirming their palatability for wallaby, they were found to also be palatable for possums (Peter Thompson, pers. comm. 1997). It is therefore questionable whether the most palatable bait has in fact been generated. Indeed, a significant number of possums in the cage trials seemingly preferred non-flavoured lucerne-based mash to the 'RS5' baits provided. Additional research that addresses bait formulation may therefore be beneficial. Development of a more palatable bait would ensure that a greater proportion of possums encountering baits ingest a lethal quantity.

Development of a bait that is markedly different from others available would have additional benefits of providing another alternative bait base that could be utilised for subsequent operations (cf. Morgan et al. 1996; O'Connor and Matthews, 1996). Research in rats established that textural changes to a foodstuff are sufficient to overcome aversion of rats that avoid one textural form of a food (Bhardwaj \& Khan, 1979). It may therefore be possible to develop a bait using the same ingredients but manufactured in a different formulation that will be accepted by possums that are averse to the other bait formulation. 
Morgan (1990) identified over a dozen flavours that tended to increase mean consumption of barley; however, only addition of orange flavour increased barley consumption significantly in that trial. Whilst flavours added to barley may not improve its palatability, the same flavour may have a different effect when incorporated in a bait matrix. Indeed, research on possums' flavour preferences indicates that addition of flavours has the potential to increase the palatability of a bait (C. O'Connor unpublished data). Additional research is needed that addresses the incorporation of strong flavours in a bait base to improve palatability, and increase baits' salience (see 'strength of cues' below).

\subsubsection{Learned behavioural resistance}

There are two general behavioural mechanisms that result from experience and are therefore classed as 'learned'; enhanced neophobia and conditioned food aversions. Unfortunately trial design did not allow me to examine generation of enhanced neophobia. The following section summarises results relating to conditioned food aversions, and compares behavioural characteristics the research identified in possums' development of aversions, with those described for other species.

\section{The salient influence of novelty}

Perhaps the most notable characteristic of CFAs is the influence of a foodstuff's novelty. Novelty is the primary factor influencing the ease with which an animal develops an aversion to a food, and the strength (and hence duration before extinction) of the aversion. Despite elucidation of this influence in rats, prior to my research, only Hickling (1994) had described the effect in possums.

Results of my trials indicate that, as in other species (e.g. rats, Fenwick et al. 1975), novelty is one of the most influential factors in possums' formation of an aversion. Both of the cage trials indicated that as the prefeed and toxic bait became more similar (and the toxic bait thus seemed more 'familiar') the lower the proportion of possums that subsequently developed an aversion. Presumably prefed possums that do not become averse fail to distinguish between the toxic bait and prefeed bait when sub-lethally poisoned. Without this distinction they are unable to associate the 
physiological discomfort they experience with the toxic bait ingested, assuming that the toxic bait is in fact a 'safe' prefeed bait.

Most prefed possums that became averse to the 1080 bait did not generalize this aversion to the prefeed bait. That they did not demonstrates that they identify novel factors in the toxic bait. Because these factors are novel possums associate them with the malaise they experience after sub-lethal ingestion, and become specifically averse to these factors, or 'cues', continuing to consume prefeed baits.

Detection of individual cues was further emphasised with the field trial. Most prefed possums were able to detect individual bait components in the toxic bait that differed from the prefeed bait (i.e. dye and 1080). In contrast, in both the first cage trial and the field trial, most non-prefed possums (for whom all bait components are novel) exhibited a generalized aversion, avoiding all cereal baits presented.

\section{Strength of ' cues'}

A foodstuff provides a possum various detectable factors that impinge on a combination of gustatory (taste), olfactory, or visual senses. When subsequently encountered the possum may use any of these factors as a cue upon which to base its behaviour. If the possum associates the cue/s with positive ingestion it will accept the foodstuff, whereas if it associates the cue/s with aversive ingestion, it will avoid the food. A food's cues can therefore act as positive 'associative' cues or negative 'aversive' cues.

Results of the second cage trial suggest that of the cues tested (cinnamon and dye) cinnamon lured baits provide stronger associative cues, linking prefeed and toxic baits. This suggests that not only do taste and olfactory senses provide the strongest cues for maintenance of aversion (e.g. rats; Rusiniak et al. 1982), but in possums they provide the strongest associative cues.

The field trial allowed me to observe whether possums' aversions were typically maintained by taste, olfactory and/or visual cues. The majority of baits that were rejected 
were not tasted, and rejection appeared to have been based on olfactory cues; however, a visual influence could not be discounted. This is consistent with findings in other species, where weak cues for maintaining CFAs, such as odour and vision, when paired with taste prior to nausea, become strongly aversive when subsequently tested alone (Garcia, 1989).

\section{Future research; utilising behavioural characteristics}

To my knowledge, there has been no study conducted on the 'strength' of associative cues that link non-toxic and toxic baits. Whilst the second cage trial addressed the influence of cinnamon versus dye as associative cues, the practical limitations of research utilising high possum numbers made clear elucidation of an effect difficult. Future research should ensure that high possums numbers are used when treatments may produce a relatively small effect.

Use of more concentrated lures, and therefore more salient cues (Kalat, 1974; Naheed \& Khan, 1989) in both non-toxic and toxic baits may provide stronger cues for association of baits and therefore reduce the number of exposures required before aversion is inhibited. With sufficiently strong cues linking prefeed and toxic baits, a single exposure to prefeed may be sufficient to inhibit the subsequent development of aversion (Chapter 3).

There may be an additional advantage of using stronger lures; any non-prefed possums developing aversions may associate the lure (as the most salient bait component; Kalat, 1974) with malaise, rather than the toxin or bait base. Indeed, Naheed and Khan (1989) found that if rats were sub-lethally poisoned with a bait that had a distinctive taste cue, such as chocolate or groundnut oil, they would subsequently accept the same bait base if these salient tastes were absent. If the same behaviour occurs in possums, as research needs to verify, non-prefed possums poisoned in a bait with a salient taste, or characteristic, may be successfully repoisoned in the same bait base if this cue is absent. 


\subsection{Management implications}

Behavioural characteristics identified in my research highlight potential management applications. However, the practical limitations of research utilising high possum numbers means that preliminary results should be extrapolated with caution.

\section{Approaches to prefeeding;}

From behavioural characteristics identified in my research two different potential approaches to prefeeding seem promising. However, in addition to the research recommended above, research comparing the relative efficacy of each strategy is needed.

Approach i): Prefeed with a plain bait, then poison with a strongly lured, highly palatable toxic bait. This strategy should overcome any potential neophobia, but more importantly ensure that the bait base is perceived as 'safe'. A high proportion of possums should consume a lethal dose, and any that do not should not subsequently become averse to the 'safe' bait base (i.e. their aversion is directed to the lure and/or toxin/lure combination; Naheed \& Khan, 1989). Prefeeding a plain bait should enhance direction of aversion towards the salient taste cues that are novel in the toxic bait (cf. non-prefed rats; Naheed and Khan, 1989; Chapter 4). Subsequent poisoning could therefore use the same bait but a different lure. That lure must either make the toxin undetectable or sufficiently change its perception that possums do not recognise it and therefore avoid the bait. If such a lure is identified it would enable continued use of the same toxin in the same bait base (an approach that O'Connor and Matthews, (1996) and Morgan et al. (1996), both considered unlikely to succeed).

Approach ii): Prefeed with a saliently lured, highly palatable bait. Poison with a bait that is as similar as possible, i.e. most shared associative cues. This should overcome potential neophobia, and make the entire bait 'safe'. Providing the bait is of sufficient palatability, high numbers of possums should consume a lethal dose. Any possums that ingest a sub-lethal quantity of bait should not become averse to that bait; provided they did not perceive a difference between the prefeed and toxic baits at the time of sub-lethal consumption (Chapters 2, $3 \& 4$ ). As discussed previously, for this 
approach to be successful additional research is needed to establish the relative 1080masking ability of different lures. Similarly, whilst results of the second trial suggest that dye provides weak associative cues, compared to cinnamon, the field trial indicated that dye provides sufficiently strong aversive cues to maintain aversion. Therefore, research is needed that establishes whether the economic and practical difficulties of encorporating dye in prefeed baits are justified by the relative benefits.

There are, however, potential disadvantages in prefeeding with a bait that possums cannot distinguish from a toxic bait. If a possum finds prefeed bait relatively unpalatable, as did several in both cage trials (Chapters $2 \& 3$ ), they may reduce or stop consumption. When confronted with toxic bait, they may then avoid it also. However, possums in the cage trials had a relatively palatable alternative diet available, whereas those in the field may not have ready access to a highly nutritious alternative and therefore may continue to consume prefeed baits. This assumption requires evaluation in a field trial that is replicated to elucidate the influence of seasonal availability of highly palatable foods.

As outlined above, additional research is needed that examines:

- increasing bait palatability;

- detection and 'masking' of 1080 ;

- use of more salient lures;

- prefeeding techniques that maximise sustainable control efficacy.

That possums develop and exhibit similar CFA behavioural characteristics to those described in other species is further evidence for the omnipresence of this behaviour in vertebrate species. This implies that those involved in pest management should consider the influence current poisoning operations have on any non-target species that may in future become targets for control. For example, in areas that are subject to aerial poisoning operations targeting possums $30-40 \%$ of the sympatric red deer population are generally killed (Fraser et al. 1995). Ruminants have the ability to avoid foods that produce aversive postingestive consequences for at least 1-3 years (Burritt and Provenza, 1991), therefore a high proportion of the surviving 60-70\% of 
deer presumably become bait shy. If these individuals became the target of future control, perhaps due to their conservation impacts (Parkes, 1994) or disease status (Fraser et al. 1995), aerial poisoning may prove less effective than anticipated. This effect was shown by Thomas (1997) who demonstrated that control of rabbits with low-strength 1080 baits made a high proportion of the sympatric possum population bait shy and therefore potentially harder to control.

Pest managers involved in novel poisoning strategies, such as the use of 1080 impregnated eggs for stoat control, should also consider the potential influence of aversion development. Eggs may become less palatable over time, so that stoats may only ingest a sub-lethal quantity of toxin and subsequently exhibit aversion to all chicken eggs they encounter, irrespective of the toxin used.

All poisoning operations targeting vertebrate pests should acknowledge the potential influence of aversion development on the future efficacy of control and develop strategies that minimises this influence. Appropriate prefeeding has the potential to increase the initial success of control, limit the development of aversion in any residual possums and enable subsequent control utilising the same bait base. 


\section{References}

Andrews, E. A., Braveman, N. S. (1975). The combined effect of dosage level and interstimulus interval on the formation of a one-poison-based taste aversion in rats. Animal Learning and Behaviour 3:287-289.

Animal Health Board (1996). Animal Health Board; report for year ending 30th June, 1996. Animal Health Board, Wellington. 38p.

Batchelor, C. L. (1978). Compound 1080. Its properties, effectiveness, dangers and use. Report to the Minister of Forests and Minister of Agriculture and Fisheries. New Zealand Forest Service, Wellington. 68p.

Batchelor, C. L. (1982). Quantifying 'bait quality' from the number of random encounters required to kill a pest. New Zealand Journal of Ecology 5:129-139.

Batchelor, C. L. (1983). The possum and rata-kamahi dieback in New Zealand: a review. Pacific Science 37:415-426.

Batchelor, C. L. and Cowan, P. E. (1988). Review of the status of the possum (Trichosurus vulpecula) in New Zealand. Contract Report for the Technical Advisory Committee (Animal Pests), Ministry of Agriculture and Fisheries, Wellington. 129p.

Bell, J. (1972). The acute toxicity of four common poisons to the opossum, Trichosurus vulpecula. New Zealand Veterinary Journal 20:212-214.

Berenbaum, M. R. and Miliczy, E. (1983). Mantids and milkweed bugs: Efficacy of aposematic coloration against invertebrate predators. American Naturalist 111: $64-68$.

Bhardwaj, D. and Khan, J. A. (1979). Effect of texture of food on bait-shy behaviour in wild rats (Rattus rattus) I. Applied Animal Ethology 5:361-367.

Bhardwaj, D. and Prakash, I. (1982). Poison aversion in Rattus rattus through acclimatization. Indian Journal of Experimental Biology 20:396-399.

Brett, L. P., Hankins, W. G. and Garcia, J. (1976). Prey-lithium aversions. III. Buteo hawks. Behavioural Biology 17:87-98.

Brockie, R. E. (1982). Effects of commercial hunters on the number of possums, Trichosurus vulpecula, in the Orongorongo Valley, Wellington. New Zealand Journal of Ecology 5:21-28. 
Brown, K., Innes, J. and Shorten, R. (1993). Evidence that possums prey on and scavenge birds' eggs, birds and mammals. Notornis 40:169-177.

Brunton, C. F. A., Macdonald, D. W. and Buckle, A. P. (1993). Behavioural resistance towards poison baits in brown rats, Rattus norvegicus. Applied Animal Behaviour Science 38:159-174.

Burritt, E. A. and Provenza, F. D. (1990). Food aversion learning in sheep: Persistence of conditioned taste aversions to palatable shrubs (Cercocarpus montanus and Amelanchier alnifolia). Journal of Animal Science 68:10031007.

Burritt, E. A. and Provenza, F. D. (1991). Ability of lambs to learn with delay between food ingestion and consequences given meals containing novel and familiar foods. Applied Animal Behaviour Science 32:179-189.

Campbell, D. J. (1990). Changes in the structure and composition of a New Zealand lowland forest induced by brushtail possums. Pacific Science 44:277-296.

Caithness, T. A., and Williams, G. R. (1971). Protecting birds from poisoned baits. New Zealand Journal of Agriculture 12:38-46.

Coleman, J. D., Gillman, A. and Green, W. Q. (1980). Forest patterns and possum densities within podocarp/mixed hardwood forests in Mt Brian O'Lynn, Westland, New Zealand. New Zealand Journal Ecology 3:69-84.

Cowan, P. E. (1977). Neophobia and neophilia: new-object and new-place reactions of three Rattus species. Journal of Comparative and Physiological Psychology 91:63-71.

Cowan, P. E., (1990). Brushtail Possum. In C. M. King, (Ed.). The Handbook of New Zealand Mammals. Oxford University Press, Auckland, New Zealand. p68-98.

Cowan, P. E. and Moeed, A. (1987). Invertebrates in the diet of brushtail possums, Trichosurus vulpecula, in lowland podocarp/broadleaf forest, Orongorongo Valley, Wellington, New Zealand. New Zealand Journal of Zoology 14:163177.

Department of Conservation, (1994). National possum control plan: A strategy for the sustained protection of native plant and animal communities 1993-2002. Wellington, Department of Conservation. 86p. 
Du Toit, J. T., Provenza, F. D., and Nastis, A. (1991). Conditioned taste aversions: how sick must a ruminant get before it learns about toxicity in foods? Applied Animal Behaviour Science 30:35-46.

Eason, C. T., and Spurr, E. B. (1995). Review of the toxicity and impacts of brodifacoum on non-target wildlife in New Zealand. New Zealand Journal of Zoology 22:371-9.

Elkins, R. L. (1973). Attenuation of drug-induced bait-shyness to a palatable solution as an increased function of its availability prior to conditioning. Behavioural Biology 9:221-226.

Fenwick, S., Mikulka, P. J. and Klein, S. B. (1975). The effect of preexposure to sucrose on the aquisition and extinction of a conditioned food aversion. Behavioural Biology 14:231-235.

Fraser, K. W. (1985). Biology of the rabbit (Oryctolagus cuniculus (L) in Central Otago, New Zealand with emphasis on its behaviour and its relevance to poison operations. Ph.D. thesis, University of Canterbury, New Zealand (unpublished).

Fraser, K. W., Coleman, J. D. and Nugent, G. (1995). Optimal buffer widths for control of possums in the Hauhungaroa Range: 1994- initial population reductions and Tb prevalence in possums, deer and pigs. Landcare Research contract report LC9495/119. 24p.

Fraser, K. W. and Knightbridge, P. (1995). The effectiveness of aerial 1080 poisoning for possums with and without prefeeding. Landcare Research Contract Report LC9596/39. 17p.

Freeland, W. J. and Winter, J. W. (1975). Evolutionary consequences of eating: Trichosurus vulpecula and the genus Eucalyptus. Journal of Chemical Ecology 1:439-455

Freeland, W. J. and Janzen, D. H. (1974). Strategies in herbivory by mammals: the role plant secondary compounds. American Naturalist 108:269-289.

Galef, B. G. (1990). A historical perspective on recent studies of social learning about foods by Norway rats. Canadian.Journal of Psychology 44(3):311-329.

Garcia, J. (1989). Food for Tolman: cognition and cathexis in concert. In T. Archer, and L. Nilson, (Eds.) Aversion, Avoidance and Anxiety: Perspectives on 
Aversely Motivated Behaviour. Erlbaum, Hillside, New Jersey, USA. Lawrence Erlbaum Associates. p45-85.

Garcia, J., Kimerdorf, D. J. and Koelling, R. A. (1955). Conditioned aversion to saccharin resulting from exposure to gamma radiation. Science 11:157-158.

Garcia, J. and Koelling, R. A. (1967). A comparison of aversions induced by X-rays, drugs and toxins. Radiation Research Supplement 7:439-450.

Garcia, J., Hankins, W. G., Robinson, J. H. and Vogt, J. L. (1972). Baitshyness: Tests of CS-US mediation. Physiology and Behaviour 3:807-810.

Garcia, J., Lasiter, P. S., Bernudez-Rattoni, F. and Deems, D. A. (1985). A general theory of aversion learning. Annals of New York Academy of Sciences 443:821.

Garcia, J., Brett, L. P. and Rusiniak, K. W. (1989). Limits of darwinian conditioning. In Klein, S. B. and Mowrer, R. R. (Eds.): Contemporary learning theories: instrumental conditioning theory and the impact of biological constraints on learning. Lawrence Erlbaum Associates, Hillsdale, New Jersey. p180-203.

Greaves, J. H., Rennison, B. D. (1973). Population aspects of warfarin resistance in the brown rat Rattus norvegicus. Mammal Review 3:27-29.

Greaves, J. H., Rennison, B. D. and Redfern, R. (1976). Resistance of the ship rat, Rattus rattus, to warfarin. Journal of Stored Product Research 12:65-70.

Green, W. Q. (1984). A review of ecological studies relevant to the management of the common brushtail possum. In A. P. Smith and I. D. Hume. (Eds): Possums and Gliders. Australian Mammal Society. Surrey Beatty and Sons, Chipping Norton, New South Wales. p487-496.

Gustavson, C. R. (1977): Comparative and field aspects of learned food aversions. In L. M. Barker, M. R. Best and M. Domjan, (Eds.) Learning mechanisms in food selection. Baylor University Press. p22-43.

Henderson, R. J. and Morriss, G. A. (1996). Sub-lethal poisoning of possums with acute pesticides used in bait stations. Proceedings 49th New Zealand Plant Protection Conference 137-142. 
Henderson, R. J., and Hickling, G. J. (1997). The use of different types of toxic bait for sustained control of possums. Proceedings 50th New Zealand Plant Protection Conference 382-390.

Henderson, R. J., Morriss, G. A. and Morgan, D. R. (1997). The use of different types of toxic bait for sustained control of possums. Proceedings 50th New Zealand Plant Protection Conference 382-390.

Hickling, G. J. (1991). The ecology of brushtail possum populations infected with bovine tuberculosis. Symposium on Tb, Publication No. 132 of the foundation for continuing education of the New Zealand Veterinary Association. p67-72

Hickling, G. J. (1994): Behavioural resistance by vertebrate pests to 1080 toxin: implications for sustainable pest management in New Zealand. In A. A Seawright and C. T. Eason (Eds.): Proceedings of the science workshop on 1080. The Royal Society of New Zealand, Miscellaneous Series No. 28. p151158.

Hickling, G. J. (1995). Implications of learned and innate behavioural resistance for single-tactic control of vertebrate pests. Proceedings of the Australian Vertebrate Pest Control Conference 10:303-8.

Howard, W. E., Palmateer, S. D. and Nachman, M. (1968). Aversion to strychnine sulphate by Norway rats, roof rats and pocket gophers. Toxicology and Applied Pharmacology 12:229-241.

Howard, W. E., Marsh, R. E. and Palmateer, S. D. (1973). Selective breeding of rats for resistance to sodium monofluoroacetate. Journal of Applied Ecology 10:731-736.

Hughes, H. R. (1994). Possum Management in New Zealand. Report by Parlimentary Commissioner for the Environment, Wellington, New Zealand. 196p.

Innes, J. (1994). The impact of possums on native fauna. In C. F. J O'Donnell, (Ed.) Possums as Conservation Pests. Proceedings of a workshop on possums as conservation pests. Possum and Bovine TB Control NSS Committee, November 1994, Christchurch, New Zealand. p11-16.

Ionescu, E. and Buresova, O. (1977). Failure to elicit conditioned taste aversion by severe poisoning. Pharmacological and Biochemical Behaviour 6:251-254. 
Julian, A. F. (1981). Tuberculosis in the possum Trichosurus vulpecula. In B. D. Bell, (Ed.) Proceedings 1st Symposium of Marsupials in New Zealand. Victoria University, Wellington, Zoology Publication No.74. p163-174.

Kalat, J. W. (1974). Taste salience depends on novelty, not concentration, in tasteaversion learning in the rat. Journal of Comparative Physiological Psychology 86:47-50.

Kalat, J. W. and Rozin, P. (1973). "Learned safety" as a mechanism in long-delay taste- aversion learning in rats. Journal of Comparative and Physiological Psychology 83 (2):198-207.

Kalmbach, E. R. (1945). “Ten eighty” . A war-produced rodenticide. Science 102:232-233.

Kandel, A. and Chenoweth, M. B. (1952). Tolerance to fluoroacetate and fluorobutyrate in rats. Journal of Pharmocology 104:248-252.

Kerle, J. A. (1984a). Habitat preference and diet of the Northern Brushtail Possum (Trichosurus arnhemensis) in the Alligator Rivers Region, N.T. Proceedings of the Ecological Society Symposium on the Wet-dry tropics.

Kerle, J. A. (1984b). Variation in the ecology of Trichosurus: its adaptive significance. In A. P. Smith and I. D. Hume (Eds) Possums and Gliders. p115127. Surrey Beatty and Sons, Chipping Norton, New South Wales.

King, D. R., Oliver, A. J. and Mead, R. J. (1978). The adaptation of some Western Australian mammals to food plants containing fluoroacetate. Australian Journal of Zoology 26:699-712.

Klein, S. B., Mikulka, P. J., Rochelle, F. P. and. Blair, V. (1978). Postconditioning CS-alone exposure as a source of interference in a taste aversion paradigm. Physiological Psychology 6(2):255-260.

Klein, S. B., Mikulka, P .J., and Hamel, K. (1976): Influence of sucrose preexposure on the acquisition of a conditioned aversion. Behavioural Biology 16:99-104.

Lintermans, M., (1979). Diet selectivity of the brushtailed possum (Trichosurus vulpecula). Honours Thesis Department of Zoology, Monash University, Australia (unpublished). 
MaCaughley, B. J. and Fox, L. R. (1980). Variation in total phenols and condensed tannins in Eucalyptus: Leaf phenology and insect grazing. Australian Journal of Ecology 5:31-35.

MacLennan, D. G. (1984). The feeding behaviour and activity patterns of the brushtail possum, Trichosurus vulpecula, in an open Eucalypt woodland in southeast Queensland. In A. P. Smith and I. D. Hume (Eds) Possums and Gliders. p185-191. Surrey Beatty and Sons, Chipping Norton, New South Wales.

MacLennan, D. G., Blume, L. M. and Johnson, D. E. (1983). Induction of phenol detoxifying microsomal enzymes in juvenile brushtail possums, Trichosurus vulpecula (Marsupialia), by phenols transmitted in the maternal milk. Toxicon Suppliment 3:261-264.

McIlroy, J.C. (1982). The sensitivity of Australian animals to 1080 poison. III.

Marsupial and eutherian herbivores. Australian Wildlife Research 9:487-503.

McIlroy, J. C. (1983). The sensitivity of the brushtail possum (Trichosurus vulpecula) to 1080 poison. New Zealand Journal of Ecology 6:125-131.

McIlroy, J. C. (1994). Susceptibility of target and non-target animals to 1080. In A. A Seawright and C. T. Eason (Eds.): Proceedings of the science workshop on 1080. The Royal Society of New Zealand, Miscellaneous Series No. 28. p9096.

Mead, R. J., Oliver, A. J. and King, D. R. (1979). Metabolism and defluorination of fluoroacetate in the brush-tailed possum (Trichosurus vulpecula). Australian Journal of Biological Science 32:15-26.

Mikulka, P .J. and Klein, S. B., (1975): The effect of different levels of pre-exposure to sucrose on the acquisition and extinction of a conditioned aversion. Behavioural Biology 14:231-235.

Mitchell, D. (1985). Phobic responses to novelty. Annals of New York Academy of Sciences 443:119-126.

Morgan, D. R. (1990). Behavioural response of brushtail possums, Trichosurus vulpecula, to baits used in pest control. Australian Wildlife Research 17:601613. 
Morgan, D. R. (1994a). Improving cost-effectiveness and safety of sodium monofluoroacetate (1080) possum control operations. In A. A Seawright and C. T. Eason (Eds.): Proceedings of the science workshop on 1080. p151-158. The Royal Society of New Zealand, Miscellaneous Series No. 28:144-150.

Morgan, D. R. (1994b). Improving the efficiency of aerial sowing of baits for possum control. New Zealand Journal of Agricultural Reasearch 37:199-206.

Morgan, D. R., Batchelor, C. L. and Peters, J. A. (1986). Why do possums survive acrial poisoning operations? In T. P. Salmon, (Ed.). Proceedings of the Twelfth Vertebrate Pest Conference. p210-214.

Morgan, D. R., Morris, G. and Hickling, G. J. (1996). Induced 1080 bait-shyness in captive brushtail possums and implications for management. Wildlife Research 23:207-11.

Morrison, P. F. and Peters, R. A. (1954). Biochemistry of sodium fluoroacetate poisoning: the effect of fluoroacetate on purified aconitase. Biochemical Journal 58:473-479.

Nachman, M. and Ashe, J. H. (1973). Learned taste aversions in rats as a function of dosage, concentration and route of administration of LiCl. Physiology and Behaviour 10:73-78.

Nachman, M. and Hartley, P. L. (1975). Role of illness in producing learned taste aversions in rats: a comparison of several rodenticides. Journal of Comparative and Physiological Psychology 9:1010-1018.

Naheed, G. and Khan, J. A. (1989). "Poison-shyness" and "bait shyness" developed by wild rats (Rattus rattus L.). I. Methods for eliminating "shyness" caused by barium carbonate poisoning. Applied Animal Behaviour Science 24:89-99.

O'Connor, C. E. and Matthews, L. R. (1995). Cyanide induced aversions in the possum (Trichosurus vulpecula): effect of route of administration, dose and formulation. Physiology and Behavior 58:265-271.

O'Connor, C. E. and Matthews, L. R. (1996). Behavioural mechanisms of bait and poison avoidance. Proceedings of NSSC workshop "improving conventional control of possums" . Royal Society of New Zealand miscellaneous series 35:51-53. 
O'Connor, C. E. and Matthews, L. R. (1997). Duration of cyanide-induced conditioned food aversions in possums. Physiology and Behavior. (In Press).

Oliver, A. J., King, D. R. and Mead, R. J. (1979). Fluoroacetate tolerance, a genetic marker in some Australian mammals. Australian Journal of Zoology 27:363372.

Parkes, J. P. (1994). Relative pestiness- species priorities and interactions. Are possums the problem? In C. F. J. O'Donnell, (Ed.) Possums as Conservation Pests. Proceedings of a workshop on possums as conservation pests. Possum and Bovine TB Control NSS Committee, November 1994, Christchurch, New Zealand. p29-36.

Pass, D. M., Foley, W. J., and Bowden, B. F. (1993). Chemical defence of Eucalyptus trees and feeding of the common ringtail possums (Pseuducheirus peregrinus). In M. L. Augee (Ed.) Abstracts of the Sixth International Theriological Congress. University of New South Wales: Sydney. 236p.

Pelchat, M. L. and Rozin, P. (1982). The special role of nausea in the acquisition of food dislikes by humans. Appetite: Journal of Intake Research 3:341-351.

Pelz, H., Hanisch, D. and Lauenstein, G. (1995). Resistance to anticoagulant rodenticides in Germany and future strategies to control Rattus norvegicus. Pesticide Science 43:61-67.

Pracy, L. T. (1974). Introduction and liberation of the oppossum (Trichosurus vulpecula) into New Zealand. New Zealand Forest Service. 28p.

Prakash, I. (1988). Bait shyness and poison aversion. In I. Prakash (Ed.) Rodent pest management. CRC Press, Boca Raton. p322-340.

Provenza, F. D., Englehardt, W., Leonhard, M. S., Breves, G. and Giesecke, D. (1995). Role of learning in food preferences of ruminants: Greenhalgh and Reid revisited. Proceedings of the 8th International Symposium on Ruminant Physiology p233-247.

Rammell, C. G. and Fleming, P. A. (1978). Compound 1080, properties and use of sodium monofluoroacetate in New Zealand. Ministry of Agriculture and Fisheries, Wellington, New Zealand. 112p.

Revusky, S. H. (1968). Aversion to sucrose produced by contingent X radiation; 
Temporal and dosage parameters. Journal of Comparative and Physiological Psychology 65:17-22.

Revusky, S. H. and Bedarf, E. W. (1967). Association of illness with prior ingestion of novel foods. Science 155: 219-220.

Revusky, S. H. and Garcia, J. (1970). Learned associations over long delays. In G. H. Bower, (Ed.) The Psychology of Learning and Motivation: Advances in Research and Theory. Vol. 4. New York: Accademic Press. 428p.

Riley, A. L. \& Tuck, D. L. (1985): Conditioned taste aversions: A behavioural index of toxicity. In N.S. Braveman and P. Bronstein (Eds.) Experimental assessments and clinical applications of conditioned food aversions. New York Academy of Science, New York. p272-291.

Robbins, R. J. (1978). Poison-based taste aversion learning in deer mice (Peromyscus maniculatus bairdi). Journal of Comparative and Physiological Psychology 92 (4):642-650.

Robbins, R. J. (1980a). Taste-aversion learning and its implications for rodent control. In J. P. Clark, (Ed.) Proceedings of the 9th Vertebrate Pest Conference, California. Fresno Publishers, California. p114-121

Robbins, R. J. (1980b). Learning and non-learned neophobia enhancement both contribute to the formation of illness-induced taste aversion by deer mice (Peromyscus maniculatus bairdi). Animal Learning and Behaviour 4:534-542.

Rose, A. B., Pekelharing, C. J., and Platt, K. H. (1992). Magnitude of canopy dieback and implications for conservation of southern rata-kamahi (Metrosideros umbellata-Weinmannia racemosa) forests, central Westland, New Zealand. New Zealand Journal of Ecology 16:23-32.

Ross, W. D., Bell, J. and Robson, D. L. (1987). Preference and acceptability of commercially prepared cereal pellets and the effectiveness of sodium monofluoroacetate (1080) on caged possums. MAF Qual research project (unpublished). 25p.

Ross, W. D., Sullivan, G. and Dalgliesh, P. (1993). Vertebrate pest control using 1080: warnings for the future. Proceedings of the 9 th Australasian Vertebrate Pest Conference. 
Rozin, P. and Fallon, A. E. (1987). A perspective on disgust. Psychological Review 94:23-41.

Rozin, P. and Kalat, J. W. (1971). Specific hungers and poison avoidance as adaptive specializations of learning. Psychological Review 78:459-486.

Rusiniak, K. W., Palmerino, C. C, Rice, A. G., Forthman, D. L. and Garcia, J. (1982). Flavor-illness aversions: Potentiation of odour by taste with toxin but not shock in rats. Journal of Comparative and Physiological Psychology 96:527539.

Schwartz, M. D., Jacobsen, P. B. and Bovbjerg, D. H. (1996). Role of nausea in the development of aversions to a beverage paired with chemotherapy treatment in cancer patients. Physiology and Behaviour 59(4):659-663.

Siegel, S. (1974). Flavor preexposure and "learned safety" . Journal of Comparative and Physiological Psychology 87:1073-1082.

Smith, P., Inglis I. R., Cowan C. P., Kerins, G. M. and Bull, D. S. (1994): Symptom dependent taste aversion induced by an anticoagulant rodenticide in the brown rat (Rattus norvegicus). Journal of Comparative Psychology (vol. 106) 3:282290.

Sokal, R. R. and Rohlf, F. J. (1981). Biometry 2nd ed. Freeman \& Company, New York. 859 p.

Spurr, E. B. (1993). Feeding by captive rare birds on baits used in poisoning operations for control of brushtail possums. New Zealand Journal of Ecology 17:13-18.

Stryer, L. (1988). Biochemistry. Third edition. W.H. Freeman \& Company, New York. 1089p.

Sugihara, R. T., Tobin, M.E. and Koehler, A. E. (1995). Zinc phosphide baits and prebaiting for controlling rats in Hawaiian sugarcane. Journal of Wildlife Management 59:882-889.

Thomas, M. C. C. (1997). Impact of rabbit (Oryctolagus cuniculus) control with 1080 poison on possum (Trichosurus vulpecula) populations at Scargill, North Canterbury. MSc thesis, Lincoln University, Canterbury, New Zealand. (unpublished), 92p. 
Thomas, M. D. (1994). Possum control in native forest using sodium monofluoroacetate (1080) in bait stations. Proceedings of the New Zealand Plant Protection Conference 47:107-111.

Tortora, G. J. and Grabowski, S. J. (1993). Principles of Anatomy and Physiology 7th edition. HarperCollins College Publishers, 10 East 53rd Street, New York. 999 p.

Twigg, L. E. (1994). Occurrence of fluoroacetate in Australian plants and tolerance to 1080 in indigenous Australian animals. In A. A Seawright and C. T. Eason (Eds.): Proceedings of the science workshop on 1080. The Royal Society of New Zealand, Miscellaneous Series No.28. p151-158

Twigg, L. E. and King, D. R. (1991). The impact of fluoroacetate-bearing vegetation on native Australian fauna: a review. Oikos 61:412-430.

Udy, P. B. and Pracy, L. T. (1981). Baits, birds and field operations. Counterpest 6:13-15.

Warburton, B. and Cullen, R. (1993). Cost-effectiveness of different possum control methods. Landcare Research Contract Report LC9293/101 (unpublished). 16p.

Warburton, B. and Drew, K. W. (1994). Extent and nature of cyanide-shyness in some populations of Australian brushtail possums in New Zealand. Wildlife Research 21:599-605.

Wheeler, S. H. and Hart, D. S. (1979). The toxicity of sodium monofluoroacetate to wild rabbits, Oryctolagus cuniculus (L.), from three sites in Western Australian. Australian Wildlife Research 6:57-62.

Worthy, T.H. 1990: An analysis of the distribution and relative abundance of moa species. New Zealand Journal of Zoology 17:213-241. 


\section{Appendix 2.1}

Consumption of prefeed over the seven days that it was provided (First trial; plain (non-dyed non-lured RS5 pellets) versus dyed and cinnamon lured RS5 pellets).

\begin{tabular}{|c|c|c|c|c|c|c|c|c|c|}
\hline \multicolumn{10}{|c|}{ Prefeed consumption ( $g /$ day) on the nth day of prefeeding } \\
\hline possum & $\operatorname{tm} t$ & 1 & 2 & 3 & 4 & 5 & 6 & 7 & average \\
\hline $\mathrm{B} 2$ & Plain & 8.2 & 9.2 & $\overline{19.9}$ & 20.4 & 26.1 & 27.4 & 17.1 & 18.3 \\
\hline B5 & & 3.2 & 3.5 & 6.9 & 19.5 & 22.2 & 21.6 & 19.2 & 13.7 \\
\hline C1 & & 7.3 & 14.9 & 16.0 & 21.9 & 16.8 & 21.2 & 15.2 & 16.2 \\
\hline C3 & & 1.6 & 11.6 & 21.3 & 31.3 & 30.6 & 31.8 & 31.0 & 22.7 \\
\hline D4 & & 30.2 & 30.1 & 31.5 & 30.2 & 30.2 & 31.1 & 31.7 & 30.7 \\
\hline D8 & & 16.8 & 0.0 & 0.0 & 11.7 & 16.2 & 1.8 & 0.7 & 6.7 \\
\hline E1 & & 4.1 & 23.0 & 28.0 & 19.5 & 21.6 & 30.8 & 31.0 & 22.6 \\
\hline E2 & & 4.2 & 17.4 & 19.0 & 27.5 & 25.8 & 19.5 & 20.9 & 19.2 \\
\hline E3 & & 7.6 & 27.1 & 31.0 & 30.8 & 26.3 & 31.0 & 30.1 & 26.3 \\
\hline$F_{1}$ & & 19.6 & 26.7 & 31.1 & 30.0 & 31.4 & 30.7 & 30.4 & 28.6 \\
\hline F6 & & 30.3 & 30.9 & 30.8 & 31.0 & 20.2 & 28.6 & 30.9 & 29.0 \\
\hline F11 & & 9.4 & 31.3 & 30.3 & 31.4 & 31.3 & 30.6 & 31.0 & 27.9 \\
\hline G2 & & 18.5 & 0.0 & 0.0 & 0.0 & 4.6 & 0.0 & 0.0 & 3.3 \\
\hline G6 & & 13.9 & 21.4 & 26.2 & 31.4 & 30.4 & 31.2 & 31.5 & 26.6 \\
\hline G12 & & 5.3 & 31.0 & 32.0 & 30.9 & 30.6 & 30.4 & 31.5 & 27.4 \\
\hline $\mathrm{H} 11$ & & 2.1 & 21.7 & 22.9 & 29.5 & 10.3 & 4.4 & 1.0 & 13.1 \\
\hline A5 & & 7.9 & 15.4 & 20.7 & 20.7 & 17.4 & 16.0 & 16.1 & 16.3 \\
\hline B1 & & 0.0 & 0.0 & 0.0 & 1.7 & 0.0 & 13.8 & 8.5 & 3.4 \\
\hline B7 & & 3.8 & 0.0 & 0.0 & 0.0 & 2.9 & 2.8 & 6.9 & 2.3 \\
\hline B9 & & 6.1 & 17.3 & 30.2 & 30.2 & 31.0 & 31.6 & 31.9 & 25.5 \\
\hline $\mathrm{C}_{2}$ & & 13.1 & 9.5 & 24.0 & 28.1 & 20.8 & 30.8 & 14.5 & 20.1 \\
\hline $\mathrm{C7}$ & & 23.7 & 30.7 & 31.6 & 30.9 & 28.4 & 30.9 & 30.7 & 29.6 \\
\hline $\mathrm{C}_{11}$ & & 11.1 & 7.7 & 2.6 & 4.2 & 0.0 & 31.5 & 6.6 & 9.1 \\
\hline D5 & & 18.4 & 30.2 & 31.3 & 31.4 & 30.3 & 25.4 & 13.3 & 25.8 \\
\hline D6 & & 20.4 & 7.0 & 5.8 & 15.6 & 6.2 & 7.4 & 0.0 & 8.9 \\
\hline D7 & & 24.5 & 30.8 & 31.4 & 31.2 & 28.0 & 31.6 & 31.2 & 29.8 \\
\hline E4 & & 28.8 & 30.5 & 28.2 & 15.4 & 16.5 & 2.1 & 19.7 & 20.2 \\
\hline E8 & & 6.1 & 10.1 & 17.0 & 23.8 & 24.6 & 23.7 & 24.9 & 18.6 \\
\hline E9 & & 1.7 & 16.0 & 30.4 & 28.2 & 22.2 & 29.3 & 31.7 & 22.8 \\
\hline $\mathrm{F} 2$ & & 7.2 & 8.5 & 30.6 & 29.7 & 30.7 & 30.8 & 29.1 & 23.8 \\
\hline $\mathrm{F} 8$ & & 1.8 & 19.5 & 23.2 & 31.3 & 30.1 & 30.9 & 29.9 & 23.8 \\
\hline F12 & & 16.6 & 13.5 & 12.3 & 17.0 & 4.3 & 6.4 & 2.5 & 10.4 \\
\hline $\mathrm{H} 5$ & & 27.7 & 26.4 & 31.4 & 30.2 & 30.9 & 28.9 & 30.9 & 29.5 \\
\hline average & & 12.1 & 17.4 & 21.1 & 23.2 & 21.2 & 22.6 & 20.7 & 19.8 \\
\hline$\overline{A 6}$ & C\&D & 14.7 & 14.2 & 13.6 & 15.4 & 24.8 & 8.7 & 17.1 & 15.5 \\
\hline A9 & & 11.3 & 19.1 & 19.7 & 28.2 & 18.4 & 23.7 & 29.6 & 21.4 \\
\hline A10 & & 0.8 & 26.3 & 1.4 & 30.6 & 0.8 & 31.2 & 29.3 & 17.2 \\
\hline B3 & & 5.4 & 0.0 & 0.0 & 6.6 & 22.0 & 29.7 & 31.3 & 13.6 \\
\hline C6 & & 28.4 & 28.3 & 28.7 & 30.3 & 30.0 & 30.9 & 31.1 & 29.7 \\
\hline $\mathrm{C} 8$ & & 8.6 & 7.5 & 7.5 & 3.7 & 1.4 & 0.0 & 0.4 & 4.2 \\
\hline $\mathrm{C}_{12}$ & & 9.2 & 28.7 & 30.2 & 31.7 & 25.8 & 0.0 & 28.9 & 22.1 \\
\hline D1 & & 9.0 & 28.7 & 26.5 & 30.3 & 27.4 & 31.8 & 29.6 & 26.2 \\
\hline D12 & & 16.1 & 18.6 & 8.9 & 14.3 & 17.7 & 11.7 & 12.7 & 14.3 \\
\hline E5* & & 20.5 & 21.4 & 27.6 & 27.0 & 25.4 & 27.9 & 31.5 & 25.9 \\
\hline E10 & & 9.8 & 27.4 & 31.3 & 30.5 & 31.1 & 30.6 & 31.1 & 27.4 \\
\hline F3 & & 14.3 & 19.4 & 18.3 & 30.2 & 31.4 & 26.1 & 31.8 & 24.5 \\
\hline F5 & & 24.9 & 30.6 & 30.4 & 30.8 & 31.2 & 30.7 & 31.1 & 30.0 \\
\hline G8 & & 15.0 & 30.2 & 30.5 & 31.4 & 30.0 & 31.3 & 31.2 & 28.5 \\
\hline G11 & & 28.0 & 28.3 & 30.8 & 31.1 & 30.2 & 31.2 & 31.0 & 30.1 \\
\hline $\mathrm{H} 7$ & & 12.9 & 30.8 & 30.3 & 31.7 & 31.4 & 22.2 & 24.0 & 26.2 \\
\hline & average & 14.3 & 22.5 & 21.0 & 25.2 & 23.7 & 23.0 & 26.4 & 22.3 \\
\hline
\end{tabular}




\section{Appendix 3.1}

Consumption of prefeed over the seven days that it was provided (Second trial; Cin.= non-dyed cinnamon lured RS5 pellets; Dye =dyed non-lured RS5 pellets; $C \& D=d y e d$ cinnamon lured RS5 pellets ).

\begin{tabular}{|c|c|ccccccc|c|}
\hline \multicolumn{7}{|c|}{ Prefeed consumption (g/day) on the nth day of prefeeding } & \\
\hline possum & tmt. & 1 & 2 & 3 & 4 & 5 & 6 & 7 & average \\
\hline A9 & Cin. & 30.1 & 29.7 & 30.2 & 30.1 & 30.3 & 30.4 & 23.8 & 29.2 \\
B1 & & 1.7 & 0.0 & 2.8 & 9.0 & 18.5 & 21.8 & 15.8 & 9.9 \\
B10 & & 30.3 & 30.6 & 30.0 & 15.9 & 21.6 & 26.4 & 24.2 & 25.6 \\
B3 & & 28.5 & 27.6 & 23.7 & 30.6 & 30.1 & 30.4 & 30.7 & 28.8 \\
B7 & & 22.2 & 24.0 & 22.7 & 28.2 & 30.9 & 30.9 & 30.3 & 27.0 \\
C11 & & 30.9 & 30.4 & 30.9 & 30.2 & 30.8 & 30.9 & 30.4 & 30.6 \\
C5 & & 7.1 & 6.8 & 10.3 & 9.6 & 4.2 & 12.3 & 4.4 & 7.8 \\
D11 & & 30.1 & 30.1 & 30.0 & 29.0 & 18.0 & 13.4 & 0.0 & 21.5 \\
D5 & & 8.2 & 17.1 & 25.9 & 30.4 & 27.8 & 30.5 & 30.9 & 24.4 \\
F3 & & 30.7 & 30.0 & 30.5 & 30.7 & 30.6 & 30.5 & 30.1 & 30.4 \\
F5 & & 30.6 & 30.8 & 30.2 & 30.2 & 30.0 & 30.1 & 30.6 & 30.4 \\
G10 & & 30.2 & 30.6 & 30.5 & 30.8 & 30.3 & 30.4 & 30.7 & 30.5 \\
G3 & & 30.1 & 30.5 & 30.2 & 30.7 & 30.3 & 30.5 & 30.8 & 30.4 \\
G6 & & 27.0 & 25.7 & 27.5 & 30.5 & 30.3 & 30.4 & 30.4 & 28.8 \\
H1 & & 19.8 & 26.4 & 15.4 & 21.2 & 10.4 & 12.6 & 5.6 & 15.9 \\
\hline average & & 23.8 & 24.7 & 24.7 & 25.8 & 24.9 & 26.1 & 23.2 & 24.8 \\
\hline A10 & Dye & 30.5 & 30.3 & 30.8 & 30.4 & 30.7 & 30.5 & 30.6 & 30.5 \\
A2 & & 11.1 & 7.5 & 10.4 & 0.0 & 0.5 & 0.0 & 2.0 & 4.5 \\
A3 & & 2.1 & 30.3 & 28.9 & 23.1 & 24.0 & 24.6 & 25.1 & 22.6 \\
C12 & & 30.4 & 30.8 & 30.4 & 28.5 & 30.0 & 30.6 & 30.7 & 30.2 \\
C2 & & 27.8 & 30.3 & 30.6 & 14.5 & 2.0 & 2.4 & 0.0 & 15.4 \\
C6 & & 3.1 & 17.3 & 5.5 & 2.3 & 4.0 & 10.8 & 13.4 & 8.1 \\
D12 & & 30.3 & 30.2 & 17.5 & 0.0 & 1.1 & 2.2 & 0.0 & 11.6 \\
D6 & & 12.0 & 20.3 & 16.8 & 14.4 & 1.9 & 1.2 & 0.0 & 9.5 \\
E12 & & 30.9 & 30.8 & 30.4 & 30.5 & 30.3 & 30.0 & 30.1 & 30.4 \\
E6 & & 29.3 & 30.5 & 28.6 & 29.8 & 30.6 & 30.0 & 30.2 & 29.9 \\
F12 & & 30.8 & 30.0 & 30.5 & 30.4 & 30.4 & 30.6 & 30.0 & 30.4 \\
F6 & & 25.8 & 30.2 & 18.9 & 26.9 & 30.5 & 30.5 & 30.2 & 27.6 \\
G8 & & 30.5 & 30.2 & 30.2 & 30.4 & 30.5 & 30.5 & 26.4 & 29.8 \\
H2 & & 6.3 & 30.3 & 30.8 & 30.0 & 30.2 & 30.4 & 30.6 & 26.9 \\
H9 & & 30.5 & 30.1 & 30.5 & 29.5 & 27.1 & 30.9 & 30.9 & 29.9 \\
\hline average & & 22.1 & 27.3 & 24.7 & 21.4 & 20.3 & 21.0 & 20.7 & 22.5 \\
\hline
\end{tabular}




\section{Appendix 3.1 (continued)}

\begin{tabular}{|c|c|ccccccc|c|}
\hline A11 & C\&D & 0.0 & 16.6 & 30.3 & 16.4 & 28.0 & 30.1 & 30.8 & 21.7 \\
A6 & & 30.0 & 30.5 & 28.6 & 30.3 & 30.6 & 30.5 & 30.8 & 30.2 \\
B4 & & 17.1 & 21.1 & 30.5 & 14.3 & 22.2 & 30.7 & 23.7 & 22.8 \\
C1 & & 5.3 & 13.7 & 30.0 & 30.9 & 30.2 & 24.2 & 24.9 & 22.7 \\
C7 & & 30.5 & 30.7 & 28.4 & 30.3 & 27.8 & 28.6 & 30.3 & 29.5 \\
C8 & & 14.1 & 0.0 & 0.6 & 2.6 & 2.3 & 0.6 & 0.0 & 2.9 \\
D1 & & 30.5 & 30.6 & 29.1 & 30.7 & 30.7 & 30.4 & 30.2 & 30.3 \\
D3 & & 30.5 & 28.1 & 2.7 & 3.3 & 5.7 & 1.7 & 0.0 & 10.3 \\
D7 & & 30.1 & 28.7 & 25.7 & 4.4 & 13.2 & 2.1 & 1.5 & 15.1 \\
D8 & & 0.0 & 0.0 & 0.0 & 4.3 & 30.2 & 0.0 & 30.2 & 9.2 \\
E1 & & 20.0 & 16.2 & 5.0 & 30.7 & 13.0 & 19.1 & 11.8 & 16.5 \\
E7 & & 30.6 & 30.5 & 27.8 & 29.6 & 27.1 & 24.8 & 20.5 & 27.3 \\
F1 & & 30.3 & 28.3 & 30.7 & 30.1 & 28.3 & 30.5 & 30.2 & 29.8 \\
F7 & & 15.5 & 19.6 & 11.8 & 10.9 & 6.1 & 11.8 & 3.1 & 11.3 \\
H10 & & 30.2 & 30.1 & 30.7 & 30.8 & 30.2 & 30.4 & 30.9 & 30.5 \\
\hline average & & 21.0 & 21.6 & 20.8 & 20.0 & 21.7 & 19.7 & 19.9 & 20.7 \\
\hline
\end{tabular}

\section{Appendix 4.1}

Selected video footage of possums' behaviour towards various baits following sub-lethal poisoning. A copy of this footage will be retained in the Department of Entomology \& Animal Ecology, Lincoln University. 